\title{
Implementações de Tableaux para Raciocínio por Aproximações
}

\author{
WAGNER DiAS
}

Orientador:

Prof. Dr. Marcelo Finger

Dissertação apresentada ao Instituto de Matemática e Estatística da Universidade de São Paulo, como parte dos requisitos para obtenção do título de Mestre em Ciências na área de Computação.

\author{
IME - USP
}


Aos meus pais

Vicentina e Osvaldo e aos meus irmãos Natália e Ricardo 


\section{Agradecimentos}

Meus agradecimentos ao professor Marcelo Finger, pela paciência e disponibilidade durante a orientação.

À professora Renata Wassermann, pela dica dos slides e outros comentários preciosos.

Aos meus pais, Osvaldo e Vicentina, por toda a preocupação, cuidado e amor desde sempre.

Aos meus irmãos, Ricardo e Natália, pela companhia indispensável.

Ao Marcos Haftel, pelas longas conversas que me ajudaram muito.

Aos amigos Phalkon; Shigueo, Alexandre Noma, Telmo, Tadao, Lau, Kubo, Marcelo Vinagreiro; Leo Inoue e Cris Uchida; Janaína; Tati e Fábio Doy; Dani, Pat Oda, Pat Tárcia, Fê Etlinger, Vinho, Sabrina, Well. Pelo incentivo e pelas reuniões na lanchonete, na praça e no banco azul...

Ao Sifu Wagner Irineu e à União Ton Lon, por me aceitarem como filho e irmão.

Ao Yapapá, ao Todos os Cantos e ao Coral da Poli; e ao Luther King, por ter proporcionado momentos únicos de felicidade.

A Lucy, à Sira e ao Martinho Lutero, por terem acreditado em mim e por terem feito de mim uma pessoa muito mais feliz. 


\section{Resumo}

Atualmente não se conhece nenhum método de prova para a lógica proposicional clássica que tenha tempo polinomial. Os métodos de tabela-verdade e o de tableaux analíticos são imediatamente implementáveis em uma máquina, mas já foi provado [D'A90] que nenhum dos dois é mais eficiente que o outro no caso geral. Por outro lado, o sistema de tableaux KE de D'Agostino é essencialmente mais eficiente que ambos. Uma outra abordagem para resolver o problema da validade de fórmulas é o raciocínio por aproximações. Cadoli e Schaerf [SC95] propuseram um método de raciocínio por aproximações com respostas aproximadas que: (a) dão informações semanticamente claras sobre o problema a cada passo de aproximação; (b) cada resposta aproximada é mais fácil de computar que a resposta do problema original; e (c) podem ser melhoradas, e eventualmente convergem para a resposta correta. No entanto este método está restrito ao formato clausal e não fornece uma heurística de aproximação. Finger e Wassermann [FW01] propuseram um método que generaliza o raciocínio por aproximações de Cadoli e Schaerf, eliminando a restrição a cláusulas e introduzindo a heurística de aproximação. Eles estendem a semântica da lógica $S_{3}$ usada no método de Cadoli e Schaerf para toda a lógica proposicional, e propõem o método de tableaux $\mathrm{KE}-S_{3}$ para essa lógica - baseado nos tableaux KE de D'Agostino. O objetivo deste trabalho é implementar o método de Tableaux Analíticos, o método de Tableaux KE de D'Agostino e o Método de Tableaux KE- $S_{3}$ e fazer um teste comparativo dos métodos. 


\section{Abstract}

At the present moment there is no knowledge of a polynomial proof method for classic propositional logic. The truth table and the analytic tableau methods are readily implementable in a machine, but none of these two methods is more efficient than the other, as proved in [D'A90]. On the other hand, D'Agostino's KE tableau is essentially more efficient than both methods. Another approach to solve the problem of determining the validity of formulae is approximate reasoning. Cadoli and Schaerf [SC95] have proposed one such method with approximate answers that: (a) provide semantically clear information at each approximation step; (b) are easier to compute than the answer of the original problem; and (c) can be improved, and eventually converge to the right answer. Finger and Wassermann [FW01] have proposed a method that generalizes Cadoli and Schaerf's approximate reasoning, eliminating the restriction to clauses. They extend the semantic of the logic $S_{3}$ used in Cadoli and Schaerf's method to the propositional logic, and propose the KE- $S_{3}$ tableau for this logic - based in D'Agostino's KE tableau. The goal of this work is to implement the analytic tableau, D'Agostino's KE tableau and Finger and Wassermann's KE- $S_{3}$ tableau, and compare these methods using benchmark formulae. 


\section{Sumário}

Introdução

1 Lógica Proposicional Clássica 4

1.1 Sintaxe . . . . . . . . . . . . . . . . . . . . 4

1.2 Semântica . . . . . . . . . . . . . . . . . 6

2 Métodos de Tableaux 9

2.1 Tableaux Analíticos . . . . . . . . . . . . . . . . . . . . . . 9

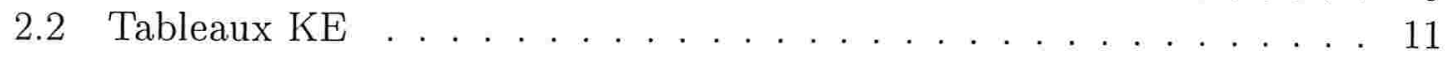

3 Raciocínio por Aproximações $\quad 17$

3.1 O método de raciocínio por aproximações de Cadoli e Schaerf . . . . 17

3.2 Tableaux KE-S $S_{3} \ldots \ldots \ldots$. . . . . . . . . . . . . . . . 20

4 Implementação 23

4.1 Arcabouços orientados a objetos . . . . . . . . . . . . . . . 23

4.2 O arcabouço para métodos de tableaux . . . . . . . . . . . . . . 26

4.3 As implementações . . . . . . . . . . . . . . . . . . . . . . 27

4.3 .1 As heurísticas . . . . . . . . . . . . . . . . . . . . 27

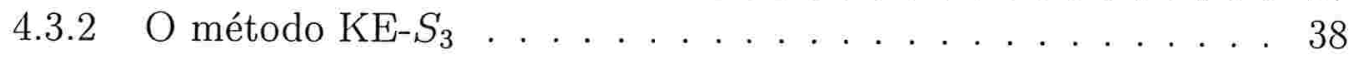

5 Resultados 46

5.1 Os casos de teste . . . . . . . . . . . . . . . . . . 46

5.2 Resultado dos casos de teste . . . . . . . . . . . . . . . . . . . . . . . . . . . . . . . . . . . . 47

5.2 .1 Tableau analítico . . . . . . . . . . . . . . . . . . . . . . . . . . . 48

5.2 .2 Tableau KE . . . . . . . . . . . . . . . . . . . . . . . . . . . . . 49

5.2 .3 Tableau $\mathrm{KE}_{-} S_{3} \ldots \ldots \ldots \ldots \ldots$

6 Conclusão $\quad 55$

A Manual do Usuário do Arcabouço para Métodos de Tableau $\quad 57$

A.1 Classe Formula . . . . . . . . . . . . . . . . . . . . . 57

A.1.1 enum opType . . . . . . . . . . . . . . 57

A.1.2 Construtores e destrutor . . . . . . . . . . . . . . . 60

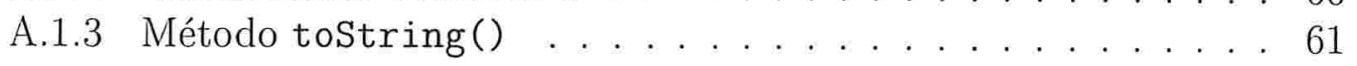


A.1.4 Método value() . . . . . . . . . . . . . . . . . . . . . 61

A.1.5 Método polarity() . . . . . . . . . . . . . . 61

A.1.6 Função parse () . . . . . . . . . . . . . . . . . . . 61

A.2 Classe SignedFormula . . . . . . . . . . . . . . . . . 62

A.2.1 enum Sign . . . . . . . . . . . . . . . . 62

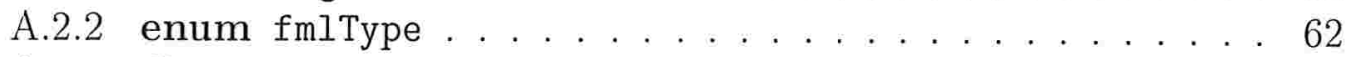

A.2.3 Construtor . . . . . . . . . . . . . . . . . . . . . . . . . 62

A.2.4 Método fmlType ()$\ldots \ldots \ldots \ldots$

A.2.5 Método toString( $) \ldots \ldots \ldots \ldots$. . . . . . . . . 63

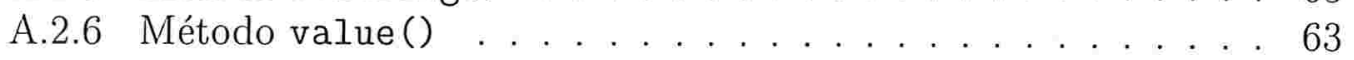

A.2.7 Método polarity ()$\ldots \ldots \ldots \ldots$

A.3 Classe Tableau . . . . . . . . . . . . . . . . . 63

A.3.1 Construtores e destrutor . . . . . . . . . . . . . . . 63

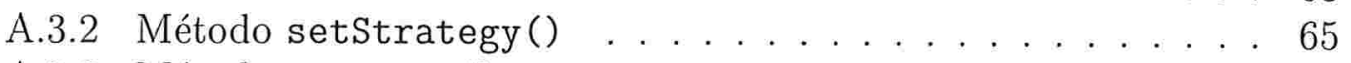

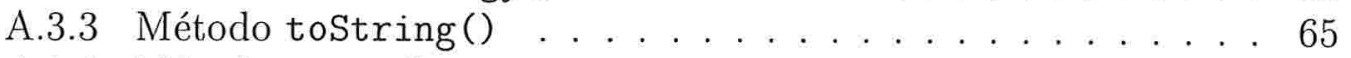

A.3.4 Método close ()$\ldots \ldots \ldots \ldots \ldots \ldots$

A.3.5 Método countNodes() . . . . . . . . . . . . . 66

A.3.6 Método countFormulae () . . . . . . . . . . . 66

A.3.7 Método applyRule() . . . . . . . . . . . . . . 66

A.3.8 Método createChild() . . . . . . . . . . . 67

A.4 Classe TableauStrategy . . . . . . . . . . . . . . . . 67

A.4.1 Método init() . . . . . . . . . . . . . . 67

A.4.2 Método classify() . . . . . . . . . . . . . . . . 69

A.4.3 Método chooseAlpha() . . . . . . . . . . . . . . 69

A.4.4 Método chooseBeta() . . . . . . . . . . . . . 69

A.4.5 Método nextRule( $) \quad \ldots \ldots \ldots \ldots$

$\begin{array}{ll}\text { B Gráficos } & 71\end{array}$

$\begin{array}{ll}\text { Bibliografia } & 84\end{array}$ 


\section{Lista de Figuras}

2.1 Tableau analítico para $\vdash((p \rightarrow q) \wedge(q \rightarrow r)) \rightarrow(p \rightarrow r) . \ldots . . . .12$

2.2 Tableau KE para $\vdash((p \rightarrow q) \wedge(q \rightarrow r)) \rightarrow(p \rightarrow r)$. . . . . . . . 15

2.3 Tableau KE para verificar a inconsistência do conjunto de fórmulas $\{\neg p \rightarrow q, \neg p \rightarrow \neg q, p \rightarrow r, p \rightarrow \neg r\} \ldots \ldots \ldots$

3.1 Tableau KE-S $S_{3}$ para $\neg p \vee q, \neg q \vee r \vdash \neg p \vee r \ldots \ldots . \ldots . \ldots 22$

4.1 Um esquema de um arcabouço. . . . . . . . . . . . . . . . . . . . . . 24

4.2 Implementação de um arcabouço. . . . . . . . . . . . . . . . . . . . 25

4.3 A estrutura básica do projeto. . . . . . . . . . . . . . . . . 28

4.4 Tableau analítico para $a_{1} \vee b_{1}, a_{1} \rightarrow a_{2} \vee b_{2}, b_{1} \rightarrow a_{2} \vee b_{2} \vdash a_{2} \vee b_{2}$. . . 29

4.5 Tableau analítico para $a_{1} \vee b_{1}, a_{1} \rightarrow a_{2} \vee b_{2}, b_{1} \rightarrow a_{2} \vee b_{2} \vdash a_{2} \vee b_{2}$. . . 30

4.6 Tableau KE (incompleto) para $a_{1} \vee b_{1}, \Gamma_{2} \vdash a_{3} \vee b_{3} \ldots \ldots . \ldots . . .33$

4.7 Tableau KE para $a_{1} \vee b_{1}, \Gamma_{2} \vdash a_{3} \vee b_{3}$ usando a heurística da valoração. 35

4.8 Continuação da Figura 4.7. . . . . . . . . . . . . . . . . . . . . 36

4.9 Tableau KE para $a_{1} \vee b_{1}, \Gamma_{2} \vdash a_{3} \vee b_{3}$ usando a heurística da polaridade. 37

4.10 Árvore para o seqüente $A_{1}, A_{2}, \ldots, A_{n} \vdash B_{1}, B_{2}, \ldots, B_{m}$. . . . . . . 38

4.11 Representação em árvore do seqüente $a \vee c, e \rightarrow f, a \rightarrow b, c \rightarrow d \vdash b \vee d .40$

4.12 Tableau para o seqüente $a \vee c, e \rightarrow f, a \rightarrow b, c \rightarrow d \vdash b \vee d$ usando a

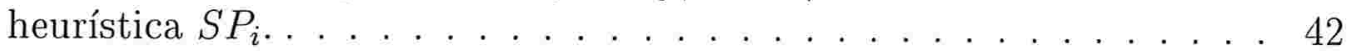

4.13 Representação em árvore do seqüente $a \vee c, \neg e \vee f, \neg a \vee b, \neg c \vee d \vdash b \vee d .42$

4.14 Tableau para o seqüente $a \vee c, \neg e \vee f, \neg a \vee b, \neg c \vee d \vdash b \vee d$ usando a

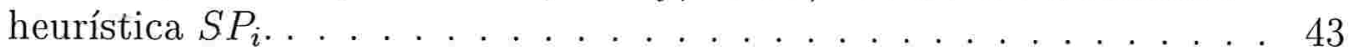

4.15 Tableau para o seqüente $a \vee c, \neg e \vee f, \neg a \vee b, \neg c \vee d \vdash b \vee d$ usando a heurística $P B_{i}$. O tableau fecha com $S=\{a, c\} \ldots \ldots 45$

A.1 Classes componentes do arcabouço para métodos de tableau. . . . . . 58

A.2 Declaração da classe Formula. . . . . . . . . . . . . . . . . . . 59

A.3 Declaração da classe SignedFormula. . . . . . . . . . . . . . . . . 62

A.4 Declaração da classe Tableau. . . . . . . . . . . . . . . . . . . . 64

A.5 Declaração da classe TableauStrategy. . . . . . . . . . . . . . 68 


\section{Lista de Tabelas}

2.1 Regras de expansão de tableaux analíticos . . . . . . . . . . . . . . 10

2.2 Regras de expansão de tableaux KE . . . . . . . . . . . . . . . . . . 13

3.1 Regras de expansão de tableaux $\mathrm{KE}-S_{3} \ldots \ldots$. . . . . . . . . . . . 21

4.1 Número de nós gerados e número de fórmulas geradas na prova do seqüente $a_{1} \vee b_{1}, \Gamma_{n} \vdash a_{n+1} \vee b_{n+1}$ pelo método de tableau analítico usando as regras de preferência $D_{i}$ e $U_{i} \ldots \ldots$. . . . . . . . . . . . 31

4.2 Regras de expansão de tableaux KE com duas premissas anotadas com polaridades. . . . . . . . . . . . . . . . 34

4.3 Tabela de distâncias entre os átomos do seqüente $a \vee c, e \rightarrow f, a \rightarrow$ $b, c \rightarrow d \vdash b \vee d \ldots \ldots \ldots \ldots 1$

4.4 Tabela de distâncias entre os átomos do seqüente $a \vee c, \neg e \vee f, \neg a \vee$ $b, \neg c \vee d \vdash b \vee d \ldots \ldots \ldots 41$

5.1 Teste do método de tableaux analíticos. . . . . . . . . . . . . . . . . 48

5.2 Teste do método de tableaux KE. . . . . . . . . . . . . . . . . . . 49

5.3 Teste do método de tableaux KE com heurística da distância. . . . . . 50

5.4 Teste do método de tableaux KE- $S_{3}$ sem a heurística da distância. . . 52

5.5 Teste do método de tableaux KE- $S_{3}$ com a heurística da distância. . . 53

5.6 Teste do método de tableaux $\mathrm{KE}-S_{3}$ com fórmulas irrelevantes, sem a heurística da distância. . . . . . . . . . . . . . . . . . . . 54

5.7 Teste do método de tableaux KE- $S_{3}$ com fórmulas irrelevantes e com a heurística da distância. . . . . . . . . . . . . . . . . . . 54 


\section{Introdução}

Atualmente, uma das maiores questões no campo da Teoria da Computação é o problema $\mathcal{P}=\mathcal{N} \mathcal{P}$.

$\mathcal{P}$ é uma classe de complexidade definida como o conjunto de problemas de decisão (problemas que admitem resposta do tipo sim ou não) que podem ser resolvidos em tempo polinomial $-O\left(n^{k}\right)$ para alguma constante $k$.

$\mathcal{N} \mathcal{P}$ é a classe de complexidade dos problemas de decisão cuja resposta pode ser verificada em tempo polinomial através de um certificado.

Existe uma classe de problemas -- a classe dos problemas $\mathcal{N P}$-completos -- com a propriedade de que, se qualquer um dos problemas puder ser resolvido em tempo polinomial, então todo problema de $\mathcal{N} \mathcal{P}$ é polinomial, ou seja, $\mathcal{P}=\mathcal{N} \mathcal{P}$.

Mas até hoje nenhum problema $\mathcal{N} \mathcal{P}$-completo tem solução polinomial conhecida, o que leva a maioria dos pesquisadores de Teoria da Computação a crer que $\mathcal{P} \neq \mathcal{N} \mathcal{P}$, ou seja, que há problemas em $\mathcal{N P}$ de natureza inerentemente superpolinomial.

Um resultado conhecido é a prova de que o problema SAT é $\mathcal{N} \mathcal{P}$-completo [Coo71, CLR90], ou seja, o problema de determinar se uma fórmula da lógica proposicional clássica é satisfatível (ou válida) é difícil.

De fato, não se conhece nenhum método de prova para a lógica proposicional clássica que tenha tempo polinomial.

O método da tabela-verdade — atribuído a Wittgenstein por [D'A90] - é imediatamente implementável em uma máquina, mas é exponencial: para uma fórmula com $n$ átomos distintos, a tabela-verdade tem $2^{n}$ linhas.

O método de tableaux analíticos ${ }^{2}$ é uma alternativa também facilmente imple-

\footnotetext{
${ }^{2} \mathrm{O}$ método original é de autoria de Charles Peirce. Outros aperfeiçoaram o método, como Beth e Hintikka. O método consolidou-se a partir da versão de Smullyan, que é a versão implementada neste trabalho.
} 
mentável. Mas há fórmulas (as fórmulas "gordas" — fórmulas que têm tamanho total grande comparado com o número de símbolos proposicionais distintos) cuja prova gera um número grande de ramos no tableau analítico comparado ao número de linhas da tabela-verdade correspondente. Em outras palavras, tableaux analíticos não $p$-simulam ${ }^{3}$ tabelas-verdade.

Por outro lado, as tabelas-verdade não p-simulam os tableaux analíticos, e portanto os dois métodos são incomparáveis - um não é mais eficiente que o outro.

D'Agostino [D'A90] aponta uma razão para esse fenômeno como sendo uma inadequação das regras de ramificação do tableau analítico que afeta a complexidade das provas no caso geral. Ele propõe o sistema de tableaux $\mathrm{KE}$, e mostra que $\mathrm{KE}$ p-simula tableau analítico, mas o inverso não é verdade, ou seja, o sistema KE é essencialmente mais eficiente que o sistema de tableaux analíticos.

Uma outra abordagem para resolver o problema da satisfatibilidade de fórmulas é o raciocínio aproximado.

O raciocínio aproximado apresenta vantagens particularmente quando se está num cenário de recursos limitados: se o tempo é limitado, pode-se usar a informação da resposta até então obtida como uma aproximação da resposta exata do problema original.

Cadoli e Schaerf [SC95] propuseram uma técnica de raciocínio aproximado. Em seu método, eles definem duas famílias de lógicas que servem como um limitante superior (incorreto e completo) e um limitante inferior (correto e incompleto) para a lógica clássica. O método busca respostas aproximadas nessas duas famílias de lógicas que satisfazem as seguintes propriedades: (a) dão informações semanticamente claras sobre o problema a cada passo de aproximação; (b) são mais fáceis de computar que a resposta do problema original; e (c) podem ser melhoradas, e eventualmente convergem para a resposta correta.

O método faz uma restrição à linguagem - fórmulas na forma clausal —, de modo a tornar viável a computação das respostas aproximadas. Além disso, não existe uma heurística que indica qual o próximo passo de aproximação.

\footnotetext{
${ }^{3}$ [D'A90] e [D'A92] descrevem a relação (de ordem parcial) de p-simulação (atribuída a Cook) como um modo de se medir a complexidade relativa de sistemas de prova. Sistemas que se p-simulam mutuamente podem ser considerados essencialmente de mesma complexidade. Um sistema $\mathrm{S}$ que p-simula um sistema $\mathrm{S}^{\prime}$ mas o contrário nāo é verdade, pode ser considerado essencialmente mais eficiente que $\mathrm{S}^{\prime}$.
} 
Finger e Wassermann [FW01] propuseram um método que generaliza o raciocínio aproximado de Cadoli e Schaerf, eliminando a restrição a cláusulas. Eles estendem a semântica da lógica $S_{3}$ usada no método de Cadoli e Schaerf para toda a lógica proposicional, e propõem o método de tableaux $\mathrm{KE}-S_{3}$ para essa lógica - baseado nos tableaux KE de D'Agostino - , e que além disso exibe uma heurística que indica a seqüência de passos de aproximação.

O objetivo deste trabalho é implementar o método de Tableaux Analíticos (versão de Smullyan), o método de Tableaux KE de D'Agostino e o Método de Tableaux $\mathrm{KE}-S_{3}$ e fazer um teste comparativo dos métodos.

No Capítulo 1, são descritos os fundamentos básicos da lógica clássica proposicional em seus aspectos sintáticos e semânticos.

No Capítulo 2, são descritos o método de Tableaux Analíticos de Smullyan e o método de Tableaux KE de D’Agostino, ambos para a lógica proposicional clássica.

No Capítulo 3, são descritos o método de raciocínio aproximado de Cadoli e Schaerf e o método de Tableaux KE- $S_{3}$ de Finger e Wassermann.

No Capítulo 4, é discutida a implementação dos métodos de tableaux.

No Capítulo 5, são apresentados os resultados da comparação entre os métodos de tableaux.

Finalmente, no Capítulo 6 é apresentada a conclusão. 


\section{Capítulo 1}

\section{Lógica Proposicional Clássica}

No decorrer de todo o texto, a não ser que seja explicitamente dito o contrário, usaremos as convenções a seguir.

\subsection{Sintaxe}

Os conectivos lógicos são os quatro símbolos:

1. ᄀ: negação;

2. $\wedge:$ conjunção;

3. $\vee$ : disjunção;

4. $\rightarrow:$ implicação.

O conectivo da negação é chamado de conectivo unário. Os três últimos são chamados de conectivos binários.

As variáveis proposicionais (ou variáveis ou átomos) são os símbolos pertencentes ao conjunto enumerável $\mathcal{P}=\left\{p_{1}, p_{2}, \ldots\right\}$. Usaremos letras minúsculas $(p, q, r, s, \ldots)$ para denotar elementos de $\mathcal{P}$.

Os símbolos ( e ) são chamados de parênteses e são usados para pontuação.

Uma fórmula é um elemento que pode ser definido recursivamente a partir do seguinte conjunto de regras:

$F_{0}$ : Todo elemento $p$ de $\mathcal{P}$ é uma fórmula; 
$F_{1}$ : Se $A$ é uma fórmula, então $\neg A$ é uma fórmula;

$F_{2}$ : Se $A, B$ são fórmulas, então $(A \wedge B)$ é uma fórmula;

$F_{3}$ : Se $A, B$ são fórmulas, então $(A \vee B)$ é uma fórmula;

$F_{4}$ : Se $A, B$ são fórmulas, então $(A \rightarrow B)$ é uma fórmula.

Usaremos letras maiúsculas $(A, B, C, \ldots)$ para denotar fórmulas e letras maiúsculas gregas $(\Gamma, \Delta, \ldots)$ para denotar conjuntos de fórmulas. O conjunto de todas as fórmulas será denotado por $\mathcal{L}$.

Os parênteses poderão ser omitidos quando permitido pelo contexto.

As subfórmulas imediatas de uma fórmula $A$ são dadas pelas regras ( $B$ e $C$ são fórmulas):

$I_{0}:$ Se $A \in \mathcal{P}$, então $A$ não tem subfórmulas imediatas;

$I_{1}$ : Se $A$ é da forma $\neg B$, então $B$ é a única subfórmula imediata de $A$;

$I_{2}$ : Se $A$ é da forma $(B \wedge C)$, então $B$ e $C$ são as únicas subfórmulas imediatas de $A ;$

$I_{3}$ : Se $A$ é da forma $(B \vee C)$, então $B$ e $C$ são as únicas subfórmulas imediatas de $A$;

$I_{4}$ : Se $A$ é da forma $(B \rightarrow C)$, então $B$ e $C$ são as únicas subfórmulas imediatas de $A$.

As subfórmulas de uma fórmula $A$ são dadas pelas regras:

$S_{1}$ : Se $X$ é uma subfórmula imediata de $A$ ou $X=A$, então $X$ é uma subfórmula de $A$;

$S_{2}$ : Se $X$ é uma subfórmula de $Y$ e $Y$ é uma subfórmula de $A$, então $X$ é uma subfórmula de $A$.

Um seqüente é uma expressão da forma

$$
A_{1}, A_{2}, \ldots, A_{n} \vdash B_{1}, B_{2}, \ldots, B_{m}
$$


onde todo $A_{i}$ e todo $B_{j}$ são fórmulas. O seqüente exprime o fato de que, se todas as fórmulas $A_{1}, \ldots, A_{n}$ são verdadeiras, então ao menos uma das fórmulas dentre $B_{1}, \ldots, B_{m}$ é verdadeira.

A lista de fórmulas à esquerda do símbolo $\vdash$ é chamada de antecedente do seqüente, e a lista à direita é chamada de conseqüente do seqüente.

Para a lógica proposicional clássica, podemos considerar que as listas $A_{1}, A_{2}, \ldots, A_{n}$ e $B_{1}, B_{2}, \ldots, B_{m}$ são conjuntos de fórmulas. ${ }^{1}$

Uma fórmula assinalada é uma expressão da forma $T A$ ou $F A$, onde $A \in \mathcal{L}$ e $T$ e $F$ são os sinais possíveis de uma fórmula assinalada, respectivamente verdadeiro e falso.

O conjugado de uma fórmula assinalada é o resultado da operação de inversão do sinal, ou seja, para uma fórmula $A, T A$ é o conjugado de $F A$ e vice-versa.

As subfórmulas de uma fórmula assinalada $S A(S=T, F)$ são todas as fórmulas da forma $T B$ ou $F B$, onde $B$ é subfórmula de $A$.

\subsection{Semântica}

Um valor-verdade é um elemento do conjunto $V=\{0,1\}$. Os elementos 0 e 1 são chamados, respectivamente, de falso e verdadeiro.

Uma valoração é uma função $v: \Gamma \rightarrow V$. Deste modo, dizemos que $A \in \Gamma$ é verdadeira sob $v$ se $v(A)=1$, e falsa sob $v$ caso contrário.

Uma valoração $v: \mathcal{L} \rightarrow V$ é uma valoração booleana se, para toda fórmula $A, B \in \mathcal{L}:$

$B_{1}: v(\neg A)=1$ sse $v(A)=0 ;$

$B_{2}: v(A \wedge B)=1$ sse $v(A)=1$ e $v(B)=1$

$B_{3}: v(A \vee B)=0$ sse $v(A)=0$ e $v(B)=0 ;$

$B_{4}: v(A \rightarrow B)=0$ sse $v(A)=1$ e $v(B)=0$.

\footnotetext{
${ }^{1}$ Isto não é verdade para outras lógicas, como a lógica relevante ou a lógica linear, onde o número de ocorrências das fórmulas deve ser levado em consideração. Nesses casos, as listas de fórmulas podem ser representadas por multi-conjuntos, ou seja, conjuntos onde cada elemento tem uma multiplicidade.
} 
A valoração pode ser estendida para fórmulas assinaladas se acrescentarmos as seguintes condições:

$B_{5}: v(T A)=1$ sse $v(A)=1$;

$B_{6}: v(F A)=1$ sse $v(A)=0$.

Uma fórmula $A$ é uma tautologia (denotamos $\models A$ ) se $A$ é verdadeira sob todas as valorações booleanas.

Uma valoração $v$ satisfaz um conjunto de fórmulas $\Gamma$ se toda fórmula de $\Gamma$ é verdadeira sob $v$.

Um conjunto de fórmulas $\Gamma$ implica logicamente uma fórmula $A$ (denotamos $\Gamma \models$ $A)$ se $A$ é verdadeira sob toda valoração booleana que satisfaça $\Gamma$.

Considere a fórmula $A$. A polaridade de uma subfórmula $B$ de $A$ é uma relação binária Pol : $\mathcal{L} \times \mathcal{L} \rightarrow\{-,+\}$.

Denotamos $\operatorname{Pol}(B, A)=+$ quando a polaridade de $B$ é + em $A$, e dizemos que $B$ tem polaridade positiva em $A$. Denotamos $P o l(B, A)=-:-$ quando a polaridade de $B$ é - em $A$, e dizemos que $B$ tem polaridade negativa em $A^{2}$.

Podemos definir a polaridade de todas as subfórmulas de uma fórmula $A$ indutivamente a partir das seguintes regras $(B, C$ e $D$ são subfórmulas de $A)$ :

$$
\begin{aligned}
& P_{1}: \operatorname{Pol}(A, A)=+; \\
& P_{2 a}: \text { Se } \operatorname{Pol}(B, A)=+ \text { e } B=\neg C \text { então } \operatorname{Pol}(C, A)=-; \\
& P_{2 b}: \text { Se } \operatorname{Pol}(B, A)=- \text { e } B=\neg C \text { então } \operatorname{Pol}(C, A)=+; \\
& P_{3 a}: \text { Se } \operatorname{Pol}(B, A)=+ \text { e } B=C \vee D \text { então } \operatorname{Pol}(C, A)=\operatorname{Pol}(D, A)=+; \\
& P_{3 b}: \text { Se } \operatorname{Pol}(B, A)=- \text { e } B=C \vee D \text { então } \operatorname{Pol}(C, A)=\operatorname{Pol}(D, A)=-; \\
& P_{4 a}: \text { Se } \operatorname{Pol}(B, A)=+ \text { e } B=C \wedge D \text { então } \operatorname{Pol}(C, A)=\operatorname{Pol}(D, A)=+; \\
& P_{4 b}: \text { Se } \operatorname{Pol}(B, A)=- \text { e } B=C \wedge D \text { então } \operatorname{Pol}(C, A)=\operatorname{Pol}(D, A)=-; \\
& P_{5 a}: \text { Se } \operatorname{Pol}(B, A)=+ \text { e } B=C \rightarrow D \text { então } \operatorname{Pol}(C, A)=-\operatorname{e} \operatorname{Pol}(D, A)=+;
\end{aligned}
$$

\footnotetext{
${ }^{2}$ Por simplicidade, se for possível omitir o contexto da fórmula $A$, denotamos simplesmente $B^{+}$quando a polaridade de $B$ é positiva em $A$, e $B^{-}$quando a polaridade de $B$ é negativa em $A$.
} 
$P_{5 b}:$ Se $\operatorname{Pol}(B, A)=-$ e $B=C \rightarrow D$ então $\operatorname{Pol}(C, A)=+\mathrm{e} \operatorname{Pol}(D, A)=-$.

A polaridade pode ser estendida a fórmulas assinaladas, se substituirmos a regra $P_{1}$ acima por:

$P_{1 a}:$ Se $A=T B$, então $\operatorname{Pol}(B, A)=+$;

$P_{1 b}:$ Se $A=F B$, então $\operatorname{Pol}(B, A)=-$. 


\section{Capítulo 2}

\section{Métodos de Tableaux}

Neste capítulo apresentaremos dois métodos de resolução baseados em tableaux: o método de tableaux analíticos de Smullyan, e o método de tableaux KE de D'Agostino.

\subsection{Tableaux Analíticos}

O tableau analítico é um método de prova consolidado por Smullyan [Smu68] baseado em árvores de fórmulas assinaladas. A idéia básica do método é tentar provar o seqüente

$$
A_{1}, A_{2}, \ldots, A_{n} \vdash B_{1}, B_{2}, \ldots, B_{m}
$$

através da expansão da árvore associada.

O método consiste em, dado um tableau inicial para o seqüente, estendê-lo através das regras de expansão, até que se chegue num estado onde se possa decidir a validade do seqüente.

O tableau inicial para o seqüente acima é a árvore de um ramo onde cada nó é uma das fórmulas assinaladas $T A_{1}, T A_{2}, \ldots, T A_{n}, F B_{1}, F B_{2}, \ldots, F B_{m}$.

As regras de expansão do tableau estendem o tableau inicial. As regras de expansão de tableaux analíticos são apresentadas na Tabela 2.1.

Para cada regra de expansão, as fórmulas que aparecem acima da linha horizontal são as premissas da regra. As fórmulas que aparecem abaixo da linha horizontal são as conclusões da regra. 


\begin{tabular}{|ccc|}
\hline$\frac{T \neg A}{F A} \quad(T \neg)$ & $\frac{F \neg A}{T A} \quad(F \neg)$ \\
$\frac{T(A \wedge B)}{T A}(T \wedge)$ & $\frac{F(A \wedge B)}{F A \mid F B} \quad(F \wedge)$ \\
$T B$ & & \\
$\frac{T(A \vee B)}{T A \mid T B}$ & $(T \vee)$ & $\frac{F(A \vee B)}{F A} \quad(F \vee)$ \\
$\frac{T(A \rightarrow B)}{F A \mid T B}$ & $(T \rightarrow)$ & $\frac{F(A \rightarrow B)}{T A} \quad(F \rightarrow)$ \\
& & $F B$
\end{tabular}

Tabela 2.1: Regras de expansão de tableaux analíticos

Sejam $X, Y, Z$ fórmulas assinaladas. As regras da forma

$$
\begin{array}{ll}
\frac{X}{Y} & \frac{X}{Y} \\
Z
\end{array}
$$

são denominadas regras do tipo $\alpha$.

As regras da forma

$$
\frac{X}{Y \mid Z}
$$

são denominadas regras do tipo $\beta$.

Uma regra pode ser aplicada a um ramo do tableau se este ramo contiver a premissa da regra (um ramo do tableau é um caminho da raiz até uma folha).

A aplicação de uma regra do tipo $\alpha$ a um ramo do tableau consiste em adicionar as conclusões da regra a este ramo.

A aplicação de uma regra do tipo $\beta$ a um ramo do tableau consiste em bifurcar o ramo e, a cada ramo resultante, adicionar a conclusão correspondente.

Se um ramo do tableau contiver duas fórmulas conjugadas (ou seja, se contiver $T A$ e $F A$ para alguma fórmula $A$ ), dizemos que o ramo está fechado.

Se todos os ramos do tableau estiverem fechados, dizemos que o tableau está fechado, e neste caso, $A_{1}, A_{2}, \ldots, A_{n} \vdash B$. 
Se, por outro lado, o tableau não estiver fechado (estiver aberto), e não houver nenhuma regra aplicável, então $A_{1}, A_{2}, \ldots, A_{n} \nvdash B$.

Exemplo 2.1 O tableau da Figura 2.1 foi obtido a partir do tableau inicial (composto apenas da fórmula 1) através de aplicações sucessivas das regras de expansão. As fórmulas 2 e 3 foram obtidas de 1 através da regra $(F \rightarrow)$. As fórmulas 4 e 5 foram obtidas de 2 através da regra $(T \wedge)$. As fórmulas 6 e 7 foram obtidas de 3 através da regra $(F \rightarrow)$. As fórmulas 8 e 9 foram obtidas de 4 através da regra $(T \rightarrow)$. As fórmulas 10 e 11 foram obtidas de 5 através da regra $(T \rightarrow)$. O símbolo $\times$ indica que o ramo correspondente do tableau está fechado. Deste modo, o ramo que termina com a fórmula 8 está fechado, porque contém as fórmulas conjugadas 6 e 8. O ramo que termina com a fórmula 10 está fechado, porque contém as fórmulas conjugadas 9 e 10. O ramo que termina com a fórmula 11 está fechado, porque contém as fórmulas conjugadas 7 e 11. Logo, o tableau está fechado, e portanto,

$$
\vdash((p \rightarrow q) \wedge(q \rightarrow r)) \rightarrow(p \rightarrow r)
$$

Em [Smu68], Smullyan provou a correção e a completude do método de tableaux. analíticos, ou seja, se $\vdash$ representa a relação de conseqüência estabelecida pelo método de tableaux analíticos, e $\models$ a relação de consequiência lógica (semântica), então

$$
A_{1}, A_{2}, \ldots, A_{n} \vdash B \text { se e somente se } A_{1}, A_{2}, \ldots, A_{n} \models B
$$

\subsection{Tableaux KE}

D'Agostino propôs em [D'A90] o método de Tableaux KE como uma melhoria do método de tableaux analíticos de Smullyan, no sentido computacional. Tableaux KE p-simulam tableaux analíticos, mas tableaux analíticos não p-simulam tableaux $\mathrm{KE}^{1}$.

Os tableaux KE são semelhantes aos tableaux analíticos, pois também utilizam fórmulas assinaladas, apresentam regras de expansão com premissas e conclusões, e

\footnotetext{
${ }^{1}$ Em outras palavras, para toda prova em tableau analítico de tamanho $n$, existe uma prova em tableau KE com tamanho polinomial em $n$, mas existe pelo menos uma prova em tableau KE de tamanho $n$ cuja prova correspondente em tableau analítico tem tamanho superpolinomial em $n$.
} 


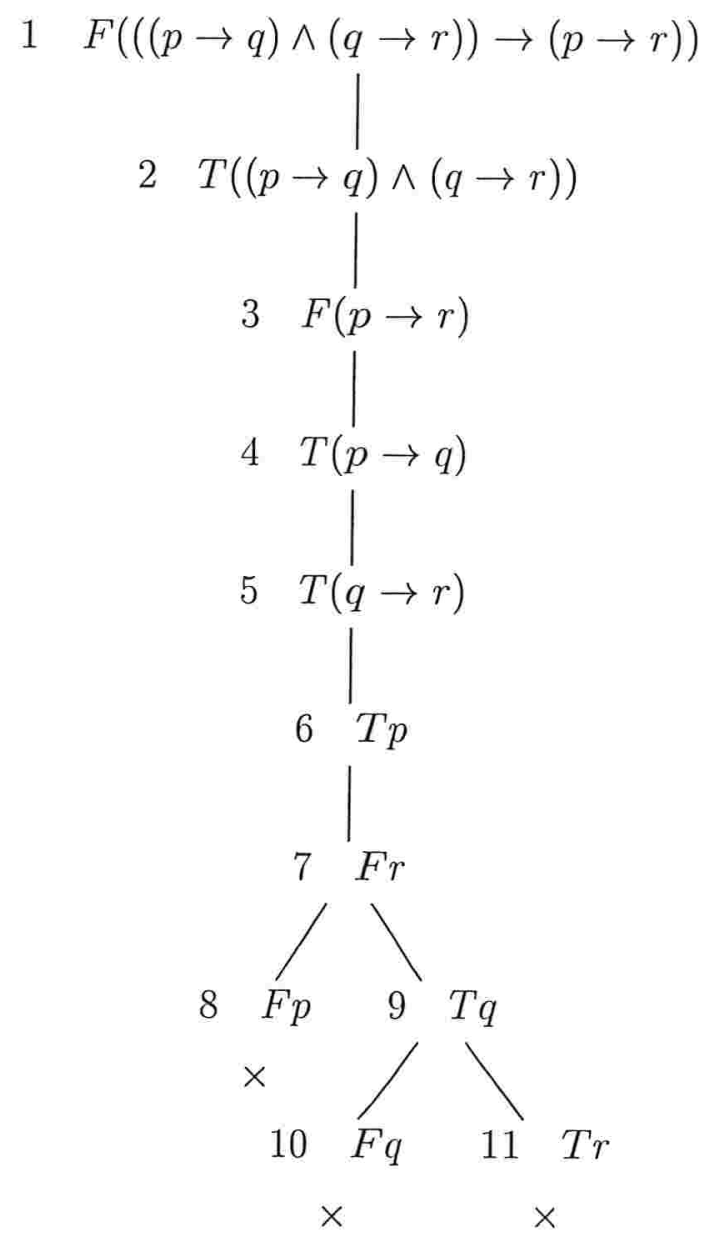

Figura 2.1: Tableau analítico para $\vdash((p \rightarrow q) \wedge(q \rightarrow r)) \rightarrow(p \rightarrow r)$. 
têm as mesmas regras para a construção do tableau inicial e para o fechamento do tableau.

As regras de expansão do tableau KE são apresentadas na Tabela 2.2.

\begin{tabular}{|c|c|c|c|c|c|}
\hline$\frac{T \neg A}{F A}$ & $(T \neg)$ & $\frac{F \neg A}{T A}$ & $(F \neg)$ & & \\
\hline $\begin{array}{c}\frac{T(A \wedge B)}{T A} \\
T B\end{array}$ & $(T \wedge)$ & $\begin{array}{c}F(A \wedge B) \\
\frac{T A}{F B}\end{array}$ & $\left(F \wedge_{1}\right)$ & $\begin{array}{c}F(A \wedge B) \\
\frac{T B}{F A}\end{array}$ & $\left(F \wedge_{2}\right)$ \\
\hline $\begin{array}{c}\frac{F(A \vee B)}{F A} \\
F B\end{array}$ & $(F \vee)$ & $\begin{array}{c}T(A \vee B) \\
\frac{F A}{T B}\end{array}$ & $\left(T \vee_{1}\right)$ & $\begin{array}{c}T(A \vee B) \\
F B \\
T A\end{array}$ & $\left(T \vee_{2}\right)$ \\
\hline$\frac{F(A \rightarrow B)}{T A}$ & $(F \rightarrow)$ & $\begin{array}{c}T(A \rightarrow B) \\
T A \\
T B\end{array}$ & $\left(T \rightarrow_{1}\right)$ & $\begin{array}{c}T(A \rightarrow B) \\
F B \\
F A\end{array}$ & $\left(T \rightarrow_{2}\right)$ \\
\hline$\overline{T A \mid F A}$ & $(P B)$ & & & & \\
\hline
\end{tabular}

Tabela 2.2: Regras de expansão de tableaux KE

Os conectivos lógicos $\wedge, \vee$ e $\rightarrow$ têm três regras de expansão: uma com uma premissa e duas conclusões, e duas com duas premissas e uma conclusão. Nas regras com duas premissas, a primeira premissa é a premissa primária e a segunda é a premissa secundária ${ }^{2}$. O conectivo unário $\neg$ tem duas regras com uma premissa.

A regra $(P B)$ permite que, a qualquer momento, o tableau seja bifurcado em ramos com as duas fórmulas conjugadas $T A$ e $F A$. Isto corresponde ao Princípio da Bivalência, ou seja, o fato de uma fórmula poder assumir apenas um dos valores verdade: $0(\mathrm{~F})$ ou $1(\mathrm{~T})$. Note que esta é a única regra que permite a bifurcação de ramos do tableau.

O uso da regra $(P B)$ no sistema KE deve se restringir a aplicações analíticas, ou seja, a fórmula $A$ sobre a qual a regra se aplica deve servir como premissa secundária de alguma fórmula $\beta$ não analisada. Isto garante a propriedade (também presente no tableau analítico) de que toda regra de expansão adiciona uma subfórmula de

\footnotetext{
${ }^{2}$ Por simplicidade, chamaremos as fórmulas que podem ser premissas de alguma regra com uma premissa de fórmulas $\alpha$, e as fórmulas que podem ser premissas primárias de alguma regra com duas premissas de fórmulas $\beta$.
} 
alguma fórmula mais complexa ocorrente no tableau. ${ }^{3}$

Exemplo 2.2 Vamos refazer o Exemplo 2.1 usando o método de tableaux KE. O tableau-da Figura 2.2 foi-obtido a partir do tableau inicial (composto apenas da fórmula 1) através de aplicações sucessivas das regras de expansão. As fórmulas 2 e 3 foram obtidas de 1 através da regra $(F \rightarrow)$. As fórmulas 4 e 5 foram obtidas de 2 através da regra $(T \wedge)$. As fórmulas 6 e 7 foram obtidas de 3 através da regra $(F \rightarrow)$. A fórmula 8 foi obtida usando-se a regra $\left(T \rightarrow_{1}\right)$ com a fórmula 4 como premissa primária e a fórmula 6 como premissa secundária. A fórmula 9 foi obtida usando-se a regra $\left(T \rightarrow_{1}\right)$ com a fórmula 5 como premissa primária e a fórmula 8 como premissa secundária. Neste ponto, o tableau está fechado, pois seu único ramo contém as fórmulas conjugadas 7 e 9 . Portanto,

$$
\vdash((p \rightarrow q) \wedge(q \rightarrow r)) \rightarrow(p \rightarrow r)
$$

Note que, no Exemplo 2.1, foram geradas 11 fórmulas e houve duas bifurcações. Neste caso, foram geradas 9 fórmulas e o tableau fechou sem bifurcar nenhuma vez.

Exemplo 2.3 Neste exemplo, queremos provar a inconsistência do conjunto $\{\neg p \rightarrow$ $q, \neg p \rightarrow \neg q, p \rightarrow r, p \rightarrow \neg r\}$. Para isso construímos o tableau da Figura 2.3. Note que é impossível fechar o tableau sem o uso da regra $(P B)$, pois a partir do tableau inicial não há nenhuma regra $\alpha$ ou $\beta$ que possa ser utilizada.

[D'A90] apresenta a prova de correção e completude do método de tableaux KE.

\footnotetext{
${ }^{3}$ No sistema KE proposto por D'Agostino esta restrição da aplicação da regra (PB) está presente para garantir a propriedade da subfórmula e manter o caráter analítico do sistema de tableau. Num sistema mais genérico, ao invés de ser uma obrigação, esta restrição pode constituir apenas uma heurística de bifurcação. É correto e possível bifurcar o tableau sobre fórmulas que não geram premissas secundárias.
} 
$1 \quad F(((p \rightarrow q) \wedge(q \rightarrow r)) \rightarrow(p \rightarrow r))$

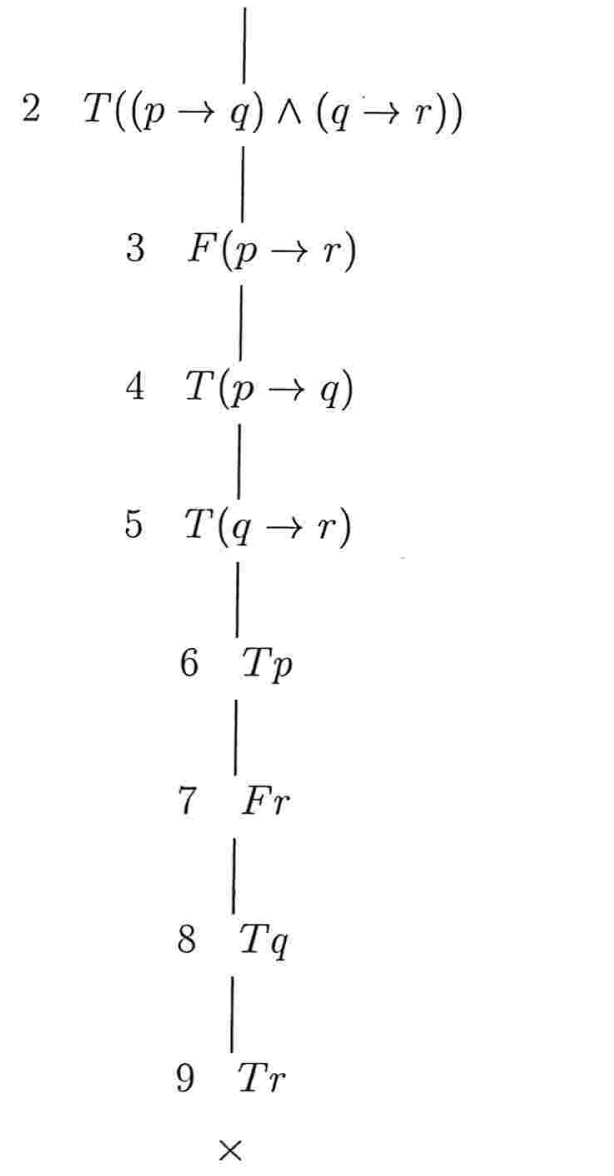

Figura 2.2: Tableau KE para $\vdash((p \rightarrow q) \wedge(q \rightarrow r)) \rightarrow(p \rightarrow r)$. 


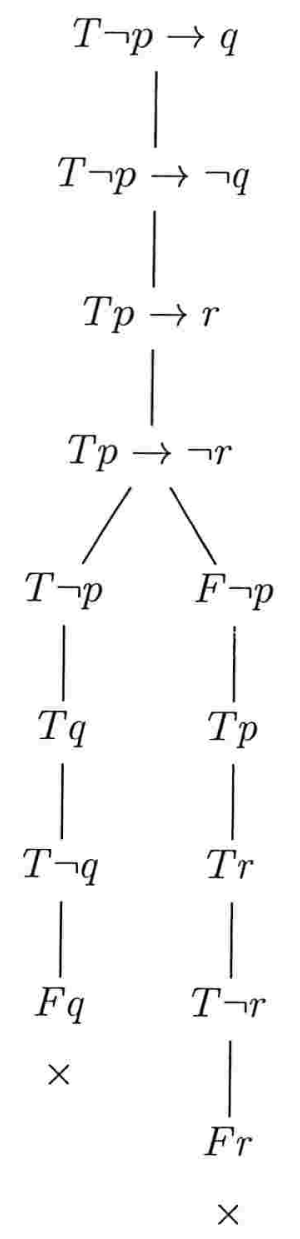

Figura 2.3: Tableau KE para verificar a inconsistência do conjunto de fórmulas $\{\neg p \rightarrow q, \neg p \rightarrow$ $\neg q, p \rightarrow r, p \rightarrow \neg r\}$. 


\section{Capítulo 3}

\section{Raciocínio por Aproximações}

Neste capítulo, apresentaremos o método de raciocínio por aproximações de Cadoli e Schaerf, e o método de tableaux KE para a lógica $S_{3}$ (ou tableaux KE- $S_{3}$ ).

\subsection{O método de raciocínio por aproximações de Cadoli e Schaerf}

Cadoli e Schaerf propuseram em [SC95] um método de raciocínio por aproximações. Esse método aproxima a lógica clássica por duas famílias de lógicas: a família $S_{1}$, que serve como um limitante superior, e a família $S_{3}$, que serve como um limitante inferior da lógica clássica. O método se restringe a fórmulas na forma clausal (ou seja, conjunções de disjunções de literais).

Ambas as famílias de lógicas $S_{1}$ e $S_{3}$ são baseadas em um conjunto-contexto $S$, que é um conjunto de átomos. Os elementos de $S$ são os elementos que se comportam classicamente na lógica. Deste modo, as lógicas $S_{1}$ e $S_{3}$ se aproximam da lógica clássica conforme o conjunto $S$ aumenta.

Uma valoração $v$ em $S_{1}$ é definida como se segue:

- $v(p) \neq v(\neg p)$, se $p \in S$;

- $v(p)=v(\neg p)=0$, se $p \notin S$.

Para um conjunto de fórmulas $\Gamma$ e uma fórmula $A$, dizemos que $\Gamma$ implica logicamente $A$ em $S_{1}$ (e escrevemos $\Gamma \models_{S}^{1} A$ ) se toda valoração em $S_{1}$ que satisfaça $\Gamma$ também satisfaz $A$. 
Pode-se provar que $\models_{S}^{1}$ é completa e incorreta com relação a $\models$. Ou seja, para todo $\Gamma$ e para todo $A$,

$\Gamma \not \models_{S}^{1} A \Rightarrow \Gamma \not \forall A$

Uma valoração $v$ em $S_{3}$ é definida como se segue:

- $v(p) \neq v(\neg p)$, se $p \in S$;

- $v(p) \neq v(\neg p)$ ou $v(p)=v(\neg p)=1$, se $p \notin S$.

Para um conjunto de fórmulas $\Gamma$ e uma fórmula $A$, dizemos que $\Gamma$ implica logicamente $A$ em $S_{3}$ (e escrevemos $\Gamma \models_{S}^{3} A$ ) se toda valoração em $S_{3}$ que satisfaça $\Gamma$ também satisfaz $A$.

Pode-se provar que $\models_{S}^{3}$ é correta e incompleta com relação a $\models$. Ou seja, para todo $\Gamma$ e para todo $A$,

$$
\Gamma \models_{S}^{3} A \Rightarrow \Gamma \models A
$$

Note que, se $S=\mathcal{P}$, então $v(p) \neq v(\neg p)$ para todo $p \in \mathcal{P}$, ou seja, tanto $S_{1}$ como $S_{3}$ coincidem com a lógica clássica.

O raciocínio por aproximações de Cadoli e Schaerf baseia-se em simplificações dos conjuntos de fórmulas, que utilizam as propriedades das lógicas $S_{1}$ e $S_{3}$ descritas acima.

Lema 3.1 (Cadoli \& Schaerf [SC95]) Seja simplifica-1( $\Gamma, S)$ o resultado de apagar todos os literais do conjunto de fórmulas $\Gamma$ que mencionam átomos fora do conjunto $S$. O conjunto $\Gamma$ é $S_{1}$-satisfatível sse simplifica-1( $\left.\Gamma, S\right)$ é classicamente satisfativel.

Teorema 3.2 (Cadoli \& Schaerf [SC95]) Seja $A=A_{S} \vee A_{\bar{S}}$, onde os átomos de $A_{S}$ estão todos em $S$ e nenhum dos átomos de $A_{\bar{S}}$ está em $S$. $O$ conjunto $\Gamma \models_{S}^{1} A$ sse $\Gamma \cup\left\{\neg A_{S}\right\}$ não é $S_{1}$-satisfatível. ${ }^{1}$

\footnotetext{
${ }^{1}$ Isto só pode ser feito porque $A_{S}$ se comporta classicamente, e assim podemos calcular sua negaçāo em forma clausal.
} 
Lema 3.3 (Cadoli \& Schaerf [SC95]) Seja simplifica-3(Г, S) o resultado de apagar todas as cláusulas de $\Gamma$ que contêm pelo menos um átomo fora de $S$. O conjunto $\Gamma$ é $S_{3}$-satisfatível sse simplifica-3 $(\Gamma, S)$ é classicamente satisfatível.

Teorema 3.4 (Cadoli \& Schaerf [SC95]) Seja A tal que os átomos de A estejam todos em $S$. $O$ conjunto $\Gamma \models_{S}^{3} A$ sse $\Gamma \cup\{\neg A\}$ não é $S_{3}$-satisfativel.

Um algoritmo para decidir se $\Gamma \models A$ baseado no raciocínio por aproximações pode ser feito da seguinte maneira: começando com $S$ igual ao conjunto dos átomos de $A$ e passo a passo adicionando átomos a $S$, e efetuando as simplificações simplifica-1 e simplifica-3, parando com o menor $S$ tal que $\Gamma \nvdash_{S}^{1} A$ ou $\Gamma \models_{S}^{3} A$.

Um tal algoritmo apresenta certas desvantagens:

- O método é restrito a fórmulas na forma clausal, devido às simplificações simplifica-1 e simplifica-3;

- Não se tem uma heurística para determinar qual átomo será adicionado ao conjunto $S$ a cada passo.

Exemplo 3.5 Seja $\Gamma=\{\neg p \vee q, \neg q \vee r\}$ e $A=\neg p \vee r$. Queremos decidir se $\Gamma \models A$.

1. Faça $S \leftarrow\{p, r\}$. Temos:

- simplifica-1 $\left(\Gamma \cup \neg A_{S}, S\right)=\{\neg p, r, p, \neg r\}$, e portanto $\Gamma \cup \neg A_{S}$ não é $S_{1^{-}}$ satisfatível, ou seja, $\Gamma \models{ }_{S}^{1} A$.

- simplifica-3( $\Gamma \cup \neg A, S)=\{p, \neg r\}$, e portanto $\Gamma \cup \neg A$ é $S_{3}$-satisfatível, ou seja, $\Gamma \nvdash_{S}^{3} A$.

2. Faça $S \leftarrow S \cup\{q\}$. Temos:

- simplifica- $1\left(\Gamma \cup \neg A_{S}, S\right)=\{\neg p \vee q, \neg q \vee r, p, \neg r\}$, e portanto $\Gamma \cup \neg A_{S}$ não é $S_{1}$-satisfatível, ou seja, $\Gamma \models{ }_{S}^{1} A$.

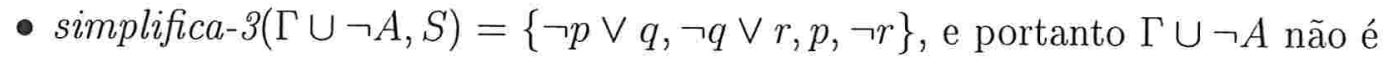
$S_{3}$-satisfatível, ou seja, $\Gamma \models_{S}^{3} A$, donde concluímos que $\Gamma \models A$. 


\subsection{Tableaux $\mathrm{KE}-S_{3}$}

Finger e Wassermann propuseram em [FW01] o método de tableaux KE- $S_{3}$ como uma generalização do método de Cadoli e Schaerf para raciocínio por aproximações.

A fim de eliminar a restrição a cláusulas presente no método de Cadoli e Schaerf, eles apresentam uma semântica $S_{3.2}$ para o fragmento completo de $S_{3}{ }^{2}$

A semântica $S_{3.2}$ se baseia em uma valoração proposicional:

Definição 3.6 (Finger \& Wassermann [FW01]) Uma $S_{3.2}$-valoração $v_{S}^{3.2}$ é uma função $v_{S}^{3.2}: \mathcal{L} \rightarrow\{0,1\}$ que estende uma valoração proposicional $v_{p}$ (ou seja, $v_{S}^{3.2}(p)=v_{p}(p)$ ), satisfazendo as seguintes condições:
(i) $v_{S}^{3.2}(\alpha \wedge \beta)=1$
(ii) $v_{S}^{3.2}(\alpha \vee \beta)=0$
$\Leftrightarrow v_{S}^{3.2}(\alpha)=v_{S}^{3.2}(\beta)=1$
(iii) $v_{S}^{3.2}(\alpha \rightarrow \beta)=0$
$\Leftrightarrow v_{S}^{3.2}(\alpha)=v_{S}^{3.2}(\beta)=0$
(iv) $v_{S}^{3.2}(\neg \alpha)=0$
$\Leftrightarrow v_{S}^{3.2}(\alpha)=1$ e $v_{S}^{3.2}(\beta)=0$
$\Rightarrow v_{S}^{3.2}(\alpha)=1$
(v) $v_{S}^{3.2}(\neg \alpha)=1, \alpha \in S \Rightarrow v_{S}^{3.2}(\alpha)=0$

As condições (iv) e (v) exprimem o fato de que, se $\alpha \in S$, então $\alpha$ deve se comportar classicamente, enquanto que se $\alpha \notin S$, então $\alpha$ pode se comportar classicamente ou paraconsistentemente, ou seja, $\alpha$ e $\neg \alpha$ podem ambos assumir o valor 1 .

As regras de expansão do tableau KE- $S_{3}$ são apresentadas na Tabela 3.1.

Note que a antiga regra $(T \neg)$ foi substituída por:

$$
\frac{T \neg A}{F A} \quad \text { se átomos }(A) \subseteq S
$$

Esta regra só poderá ser aplicada a um ramo se este ramo contiver o antecedente da regra e a condição átomos $(A) \subseteq S$ for satisfeita.

A regra $(T \neg)$ é uma restrição da regra clássica, que torna o sistema $\mathrm{KE}-S_{3}$ subclássico. De fato, todo tableau que fecha em KE-S $S_{3}$ também fecha na lógica clássica.

Observemos agora como uma heurística de aproximação é obtida no método de tableaux KE-S $S_{3}$. O algoritmo é apresentado a seguir:

1. $S \leftarrow \emptyset$.

2. Transformar o seqüente de entrada em um tableau KE- $S_{3}$ inicial.

\footnotetext{
${ }^{2} \mathrm{O}$ nome $S_{3.2}$ se deve ao fato de ser uma semântica de dois valores para $S_{3}$.
} 


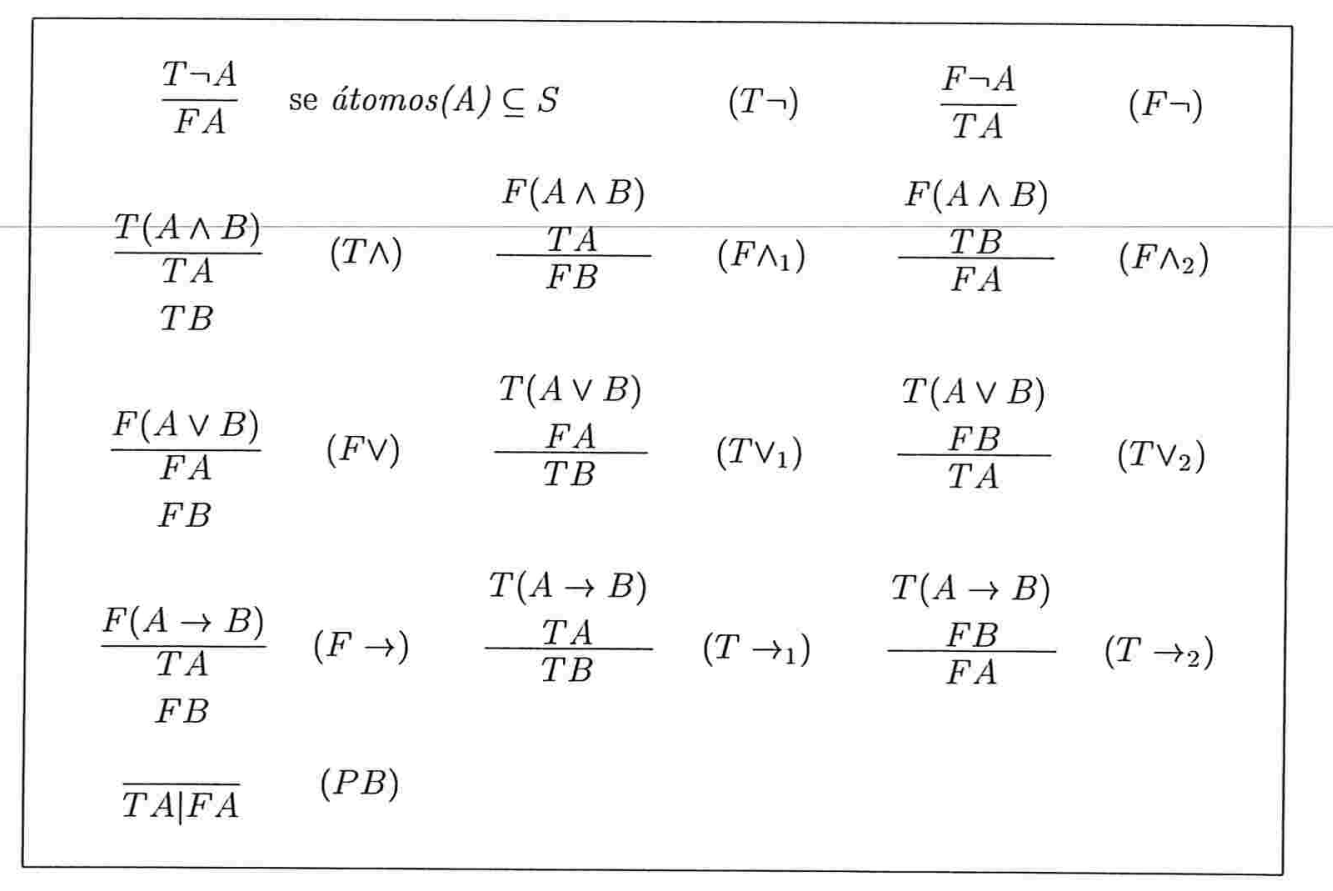

Tabela 3.1: Regras de expansão de tableaux $\mathrm{KE}-S_{3}$

3. Expandir o tableau até que ele feche ou fique bloqueado devido à impossibilidade de aplicação de regras. ${ }^{3}$

4. Se o tableau estiver fechado, terminar com sucesso.

5. Se o tableau contiver um ramo que não pode ser expandido classicamente, terminar com falha.

6. Se o tableau estiver bloqueado devido à fórmula $T \neg \alpha$, fazer $S \leftarrow S \cup$ átomos $(\alpha)$ e voltar ao passo 3 .

Ao adicionarmos átomos ao conjunto-contexto $S$, o que estamos fazendo é uma mudança da lógica com a qual estamos trabalhando. A cada passo de adição ao conjunto $S$ estamos cada vez mais próximos da lógica clássica. A lógica clássica é atingida quando todos os átomos estão em $S$.

A construção do tableau nos diz quais os próximos átomos a serem adicionados a $S$, dando imediatamente uma heurística que diz qual o próximo átomo a ser incluído no conjunto-contexto $S$.

\footnotetext{
${ }^{3}$ Se o seqüente a ser provado é válido, então o tableau só pode ficar bloqueado devido à impossibilidade de aplicação da regra $(T \neg)$. Em outras palavras, o tableau só pode ficar bloqueado se, para a fórmula $T \neg \alpha$ sobre a qual a regra seria aplicada, tivermos átomos $(\alpha) \not \subset S$.
} 
Exemplo 3.7 Vamos decidir se $\Gamma \vdash A$, onde $\Gamma$ e $A$ são os mesmos do exemplo 3.5. O tableau correspondente a essa prova é o da Figura 3.1. O tableau inicial é composto pelas três primeiras fórmulas, e o conjunto $S$ é inicializado com vazio.

As fórmulas (4) e (5) são obtidas de (3) usando a regra $(F \vee)$. A fórmula (6) é obtida de (4) usando a regra $(F \neg)$. A fórmula (7) é obtida de (1) e (4) usando a regra $\left(T \vee_{1}\right)$. A fórmula (8) é obtida de (2) e (5) usando a regra $\left(T \vee_{2}\right)$. A fórmula (9) é obtida de (8) usando a regra $(T \neg)$ e fazendo $S \leftarrow S \cup\{q\}$.

Pela figura, vemos que o tableau fecha $\operatorname{com} S=\{q\}$.

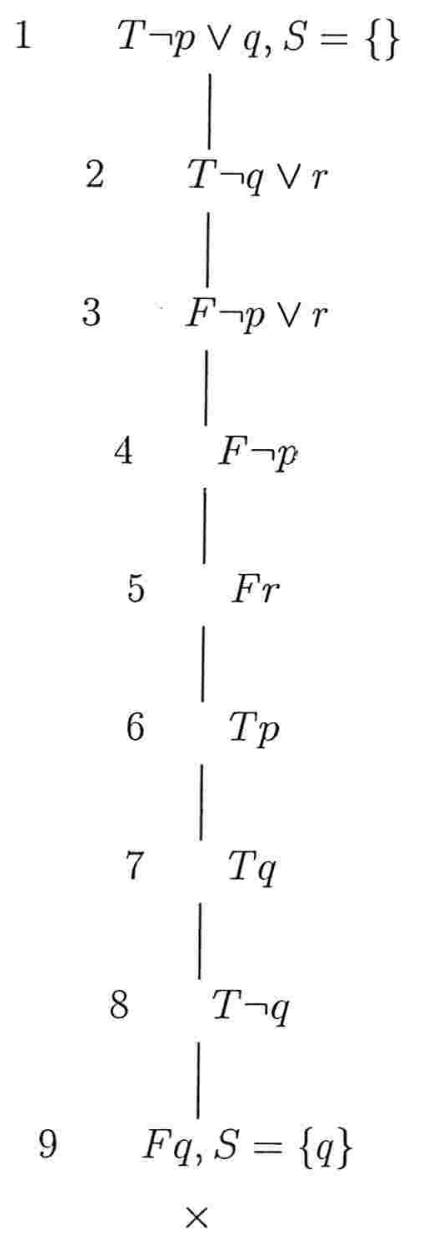

Figura 3.1: Tableau KE- $S_{3}$ para $\neg p \vee q, \neg q \vee r \vdash \neg p \vee r$.

Em [FW01] são provados os teoremas de correção e completude do método de tableaux KE- $S_{3}$ com relação à semântica $S_{3.2}$. 


\section{Capítulo 4}

\section{Implementação}

\subsection{Arcabouços orientados a objetos}

Um arcabouço orientado a objetos (do inglês, object-oriented framework) é o projeto reutilizável de um sistema ou subsistema, implementado através de um conjunto de classes concretas e abstratas e suas colaborações [JF88, BJ94, FHLS98].

Em outras palavras, o arcabouço deve dar uma solução genérica para um conjunto de problemas similares em um determinado domínio de aplicação. Deste modo, ele não deve implementar as especificidades de cada problema, mas apenas as características comuns. Para permitir a implementação das funcionalidades específicas de cada problema, o arcabouço deve fornecer ganchos (do inglês hooks) onde se possa adicionar novos componentes (ou colaborações).

A Figura 4.1 mostra um esquema de um arcabouço. O retângulo $A$ representa o arcabouço. $G 1, G 2, \ldots, G n$ são os ganchos onde os novos componentes com as funcionalidades específicas $F E 1, F E 2, \ldots, F E n$ são adicionados.

Ao ato de adicionarmos funcionalidades específicas ao arcabouço damos o nome de instanciação do arcabouço.

No nível de programação, o esquema de arcabouço orientado a objetos pode ser implementado em uma linguagem de programação orientada a objetos (como $\mathrm{C}++$, Java ou SmallTalk) através do uso de classes abstratas e derivação.

Uma classe abstrata é uma classe cujos métodos podem não ter implementação. Sob esse aspecto, pode-se considerar que a classe abstrata é incompleta.

$\mathrm{O}$ arcabouço pode então ser representado por uma ou mais classes abstratas. Os 


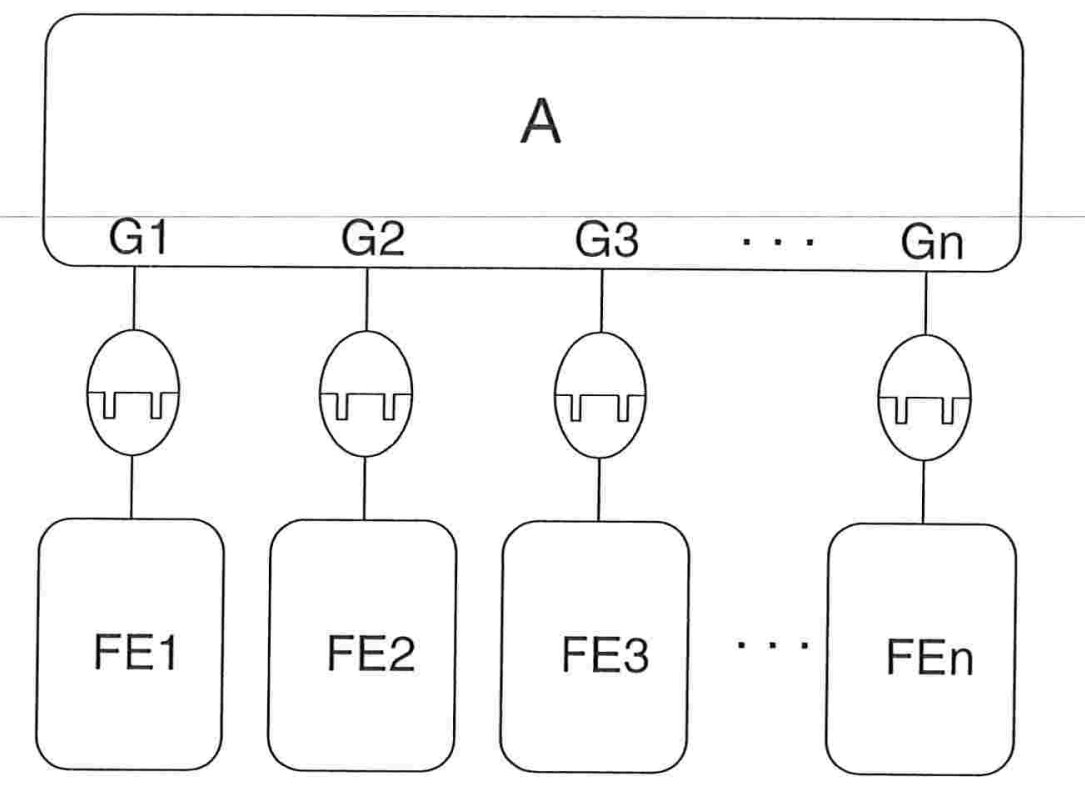

Figura 4.1: Um esquema de um arcabouço.

ganchos do arcabouço são os métodos sem implementação.

Uma classe derivada é uma classe que herda os membros é métodos de uma outra classe (chamada classe primitiva). Uma classe derivada de uma classe abstrata será abstrata se não der implementação para todos os métodos abstratos da classe primitiva, e concreta, caso contrário.

A instanciação do arcabouço, no nível da implementação, consiste em derivar as classes abstratas que constituem o arcabouço, e dar implementação a todos os ganchos de modo a completar todas as funcionalidades e transformar o arcabouço em uma aplicação completa.

A Figura 4.2 mostra um exemplo da implementação de um arcabouço. A classe $A$ representa o arcabouço. Os métodos $F E 1(), F E 2(), \ldots, F E n()$ representam os ganchos do arcabouço. As implementações desses métodos na classe derivada $D$ representam os componentes com novas funcionalidades específicas do arcabouço.

O uso do arcabouço orientado a objetos como modelo de desenvolvimento apresenta vantagens e desvantagens [FHLS98]. 


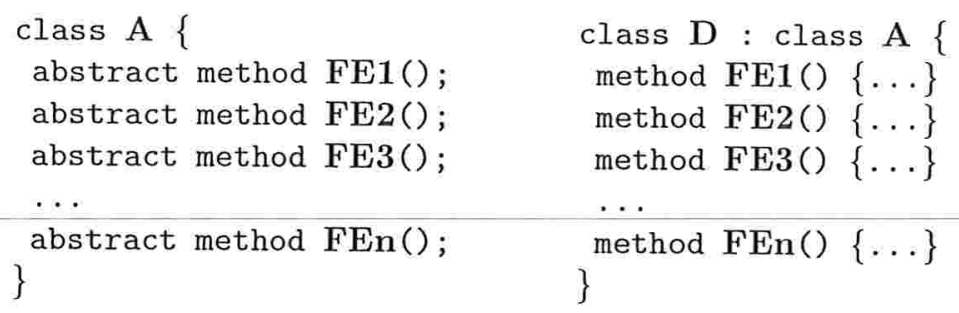

Figura 4.2: Implementação de um arcabouço.

\section{Vantagens}

- Reuso de experiência. Quando usamos um arcabouço previamente construído, estamos reutilizando a experiência dos desenvolvedores do arcabouço, porque estes já analisaram o domínio da aplicação para construir um projeto de qualidade.

- Tempo reduzido de desenvolvimento. Como o domínio de aplicação já foi analizado pelos desenvolvedores do arcabouço e todas as decisões estruturais já foram tomadas no projeto do arcaboiço, os usuários de um arcabouço podem desenvolver aplicações em menos tempo. Além disso, o arcabouço pode oferecer componentes prontos para o uso na aplicação.

- Qualidade melhorada. Se o projeto do arcabouço foi bem pensado e executado com qualidade, então as aplicações derivadas deste arcabouço herdarão essa qualidade de projeto.

- Custo reduzido de manutenção. Se várias aplicações são derivadas de um único arcabouço, então essas aplicações terão um mesmo padrão de projeto e serão mantidas mais facilmente.

\section{Desvantagens}

- Incompatibilidade com o arcabouço. Se os requisitos da aplicação são incompatíveis com o projeto do arcabouço, pode ser difícil implementá-la a partir deste. O mais grave é que a incompatibilidade pode ser encontrada muito tarde, durante o desenvolvimento da aplicação. Uma boa documentação sobre as capacidades do arcabouço pode ajudar a solucionar este problema. Projetos de protótipos também podem ajudar a familiarizar os usuários com as funcionalidades do arcabouço. 
- Tempo de aprendizado. Usar um arcabouço requer um certo aprendizado. Se o arcabouço for muito complexo, pode ser necessário muito tempo para se aprender a utilizá-lo.

- Perda do controle no projeto. Como o arcabouço geralmente tem a priori um projeto especificado e implementado, as aplicações derivadas precisam ser implementadas de acordo com este projeto.

\subsection{O arcabouço para métodos de tableaux}

Neste projeto, foi feita a implementação em linguagem de programação $\mathrm{C}++$ dos três métodos de tableaux descritos nos capítulos anteriores: o método analítico de Smullyan, o método KE de D'Agostino e o método para raciocínio por aproximações $\mathrm{KE}-S_{3}$ de Finger e Wassermann. Para isso, foi criado um arcabouço para métodos de tableau.

O desenvolvimento do arcabouço e das aplicações derivadas deste (ou seja, cada um dos métodos de tableaux) foi feito concorrentemente, o que apresenta algumas vantagens:

- Ao se analisar todas as aplicações, pode-se ter uma melhor idéia dos requisitos do arcabouço, visto que se conhecerá as funcionalidades comuns e as funcionalidades específicas de cada uma delas.

- Como as aplicações já são conhecidas durante o projeto do arcabouço, as incompatibilidades entre o arcabouço e as aplicações são imediatamente detectadas e evitadas.

- Pela mesma razão, o tempo de aprendizado do arcabouço é diminuído, e não há perda de controle no projeto das aplicações.

A Figura 4.3 mostra a estrutura básica do projeto. Temos o arcabouço genérico Tableau, que implementa a funcionalidade genérica de um método de tableau. As aplicações derivadas deste arcabouço são AnalyticTableau e KETableau, que implementam, respectivamente, o método analítico e o método KE.

A aplicação KETableau é especial, porque é também um arcabouço. A aplicação KES3Tableau, que implementa o método $\mathrm{KE}-S_{3}$, instancia o arcabouço KETableau. 
Associado a cada um dos métodos de tableau, temos um módulo de estratégia, que é responsável pela implementação da heurística de resolução do tableau correspondente. Cada um dos módulos Strategy é também um arcabouço. Isto significa que para cada método de tableau, podemos ter várias heurísticas de resolução diferentes.

No Apêndice A, o uso do arcabouço é explicado com detalhes. O intuito do apêndice é fornecer informações para facilitar o uso do arcabouço para o desenvolvimento de novas aplicações.

\subsection{As implementações}

Como pode ser visto no Apêndice A, o método principal do arcabouço para métodos de tableau é o método Tableau : $\operatorname{close}()^{1}$. É neste método que toda a inteligência está embutida, na forma de heurísticas de escolha da próxima regra a ser aplicada no tableau a cada passo. Vamos então discutir as heurísticas que foram utilizadas nos métodos de tableau.

\subsubsection{As heurísticas}

\section{A ordem de aplicação das regras}

Primeiramente, observemos os dois tableaux analíticos abaixo, para verificação da validade do seqüente

$$
a_{1} \vee b_{1}, a_{1} \rightarrow a_{2} \vee b_{2}, b_{1} \rightarrow a_{2} \vee b_{2} \vdash a_{2} \vee b_{2}
$$

\footnotetext{
${ }^{1}$ Algumas práticas já utilizadas na adaptação KE* do sistema KE introduzido por Endriss [End99] são adotadas nas implementações:

- A busca por fórmulas assinaladas complementares para o fechamento do tableau é restrita a fórmulas literais;

- A busca por fórmulas a serem usadas como premissas secundárias de regras com duas premissas é restrita a fórmulas literais, com uma exceção: diretamente após cada aplicação da regra $\mathrm{PB}$, a próxima aplicação (óbvia) de uma regra de duas premissas é feita sem restrição a literais. Por exemplo, se PB é aplicada sobre $A$ subfórmula de $T A \vee B$, então o ramo esquerdo será iniciado com $T A$ e o ramo direito será iniciado com $F A$ e $T B$, seja $A$ literal ou não.

Além disso, uma melhoria é introduzida fazendo com que as fórmulas $\beta$ não sejam analisadas até que todas as fórmulas $\alpha$ sejam analisadas.

$\mathrm{O}$ sistema KE* com as restrições acima é correto e completo. Além disso, é mais eficiente, pois os passos que mais exigem tempo em todo o procedimento de prova são os passos onde se faz busca em uma lista de fórmulas - ou seja, o fechamento do tableau e a aplicação de regras com duas premissas -, e as restriçōes descritas acima reduzem o espaço de busca nessas listas de fórmulas.
} 

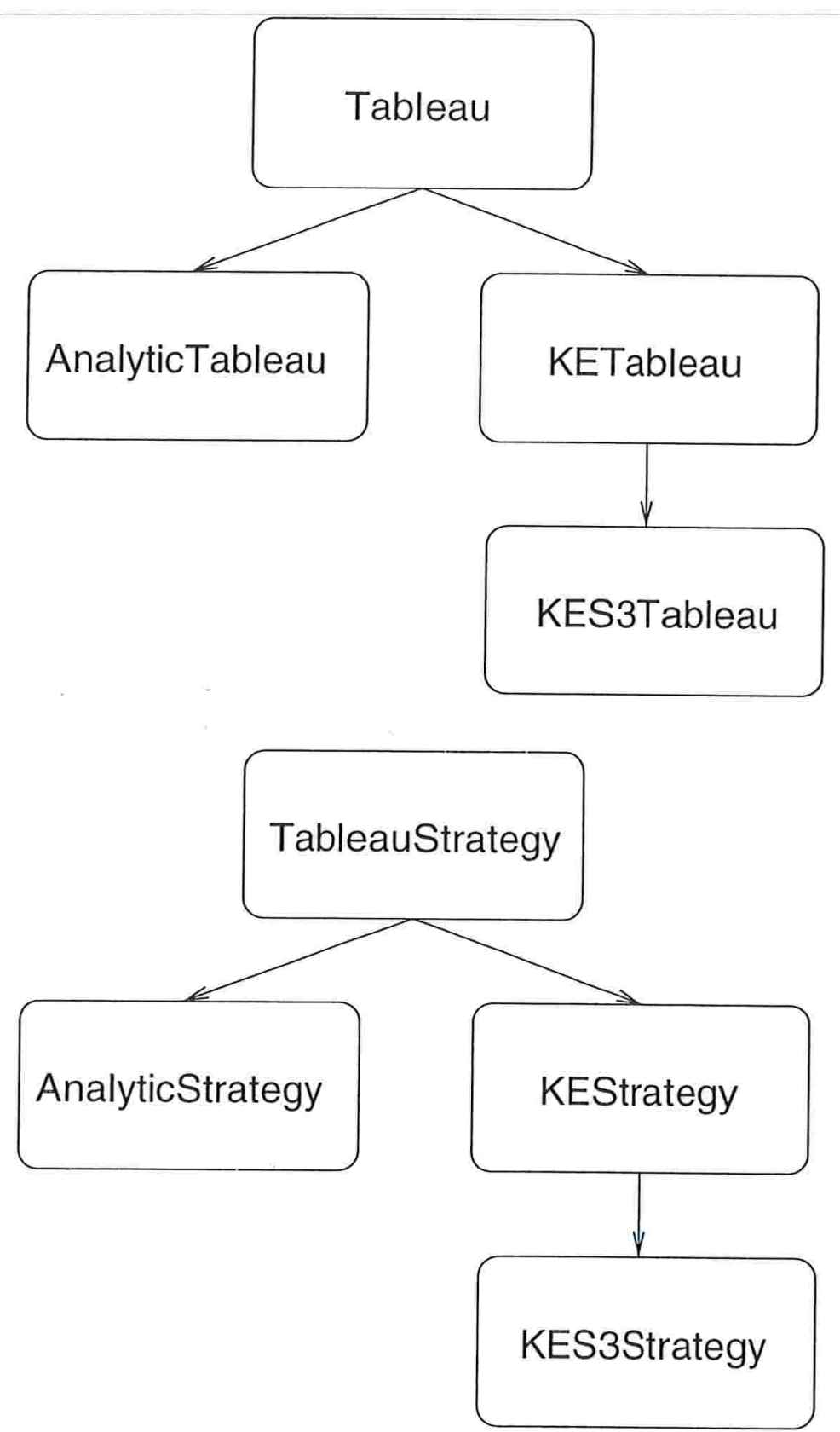

Figura 4.3: A estrutura básica do projeto. 


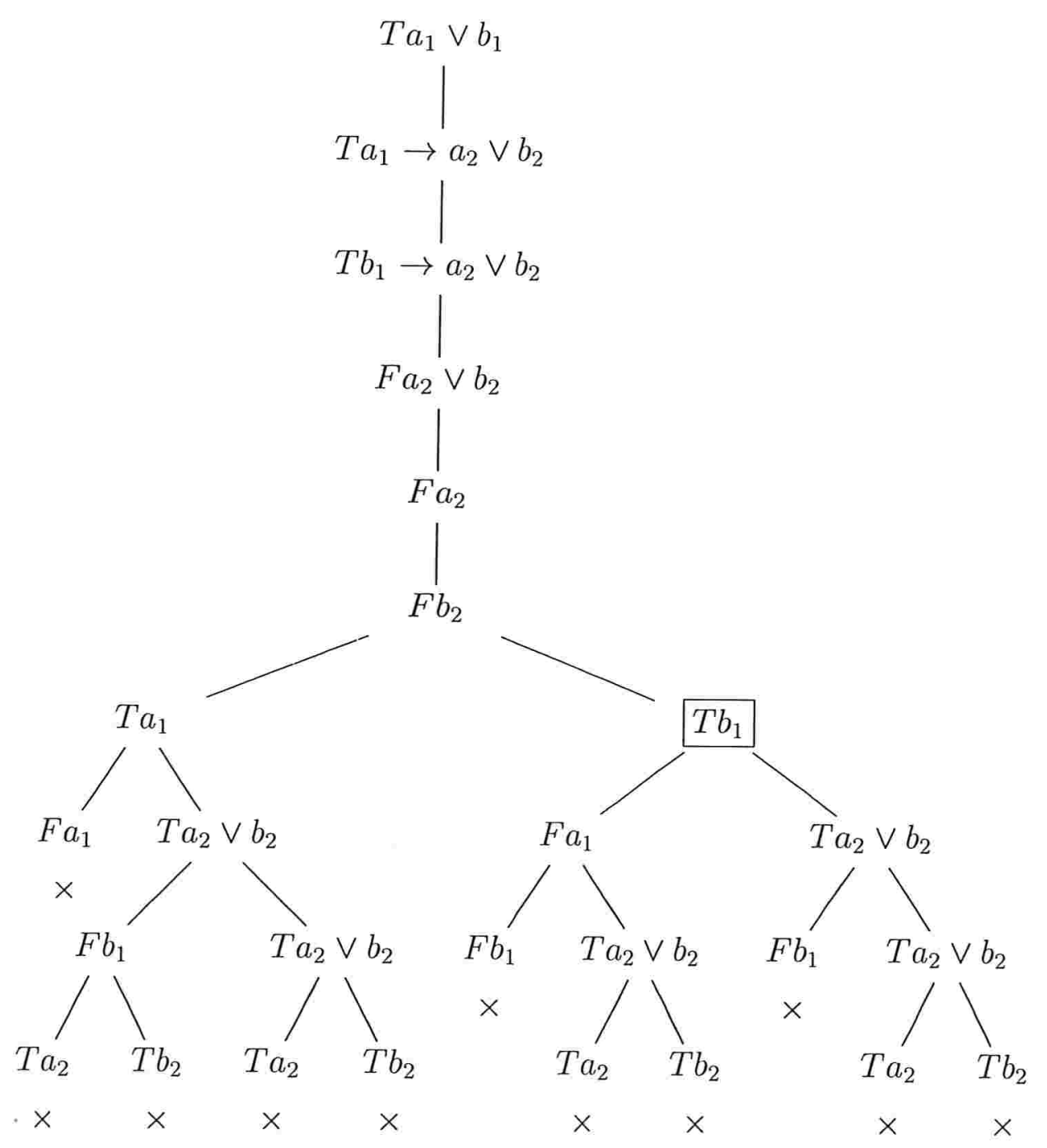

Figura 4.4: Tableau analítico para $a_{1} \vee b_{1}, a_{1} \rightarrow a_{2} \vee b_{2}, b_{1} \rightarrow a_{2} \vee b_{2} \vdash a_{2} \vee b_{2}$ 
No tableau da Figura 4.4, as regras são aplicadas na seguinte ordem de preferência:

$D_{1}$ primeira ocorrência de fórmula do tipo $\alpha$ ainda não aplicada;

$D_{2}$ primeira ocorrência de fórmula do tipo $\beta$ ainda não aplicada.

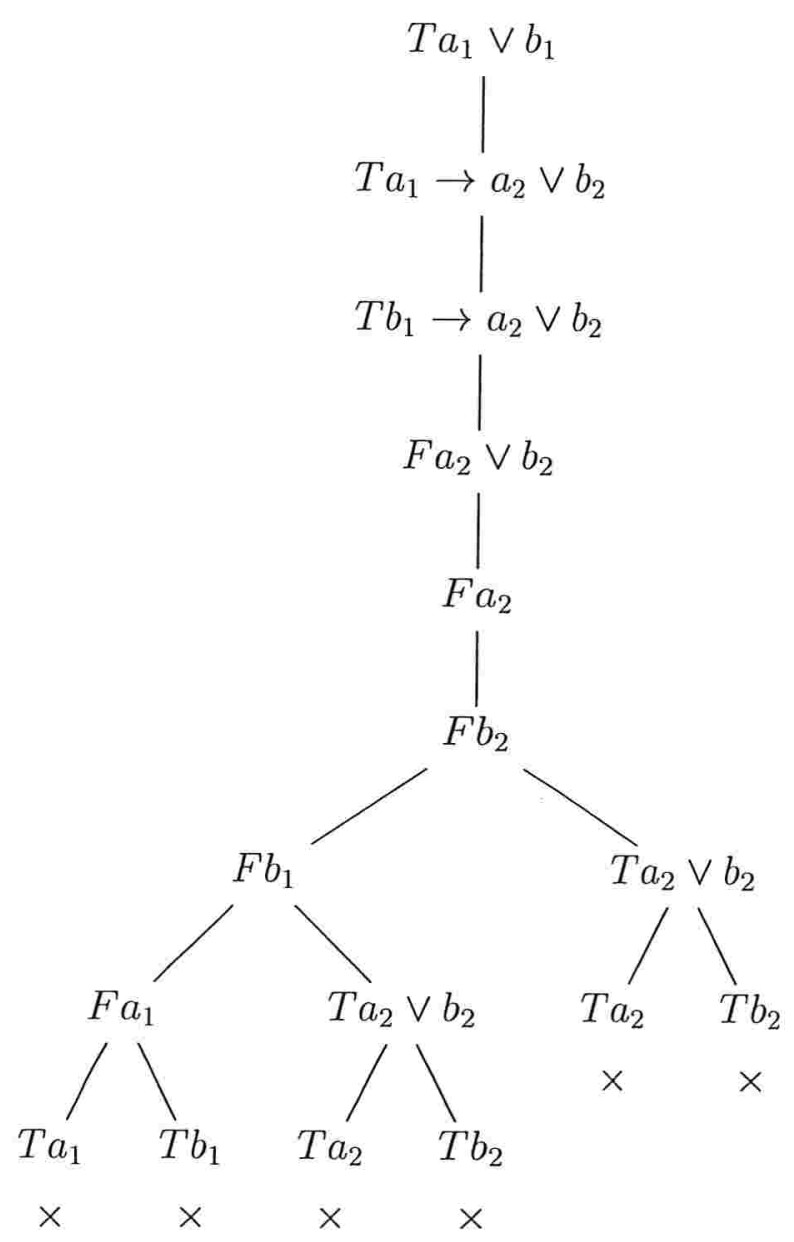

Figura 4.5: Tableau analítico para $a_{1} \vee b_{1}, a_{1} \rightarrow a_{2} \vee b_{2}, b_{1} \rightarrow a_{2} \vee b_{2} \vdash a_{2} \vee b_{2}$.

No tableau da Figura 4.5, as regras são aplicadas na seguinte ordem de preferência:

$U_{1}$ primeira ocorrência de fórmula do tipo $\alpha$ ainda não aplicada;

$U_{2}$ última ocorrência de fórmula do tipo $\beta$ ainda não aplicada.

No tableau da Figura 4.4, note que a aplicação da regra 


$$
\frac{T a_{1} \rightarrow a_{2} \vee b_{2}}{F a_{1} \mid T a_{2} \vee b_{2}}
$$

no ramo enraizado na fórmula destacada é redundante ${ }^{2}$. Neste ponto, a prova poderia ser encurtada se fosse aplicada a regra

$$
\frac{T b_{1} \rightarrow a_{2} \vee b_{2}}{F b_{1} \mid T a_{2} \vee b_{2}}
$$

Agora, seja

$$
\Gamma_{n}=\bigcup_{i=1}^{n}\left\{a_{i} \rightarrow a_{i+1} \vee b_{i+1}, b_{i} \rightarrow a_{i+1} \vee b_{i+1}\right\}
$$

e considere o tableau analítico com as mesmas regras de preferência $D_{i}$ e $U_{i}$ para os seqüentes

$$
a_{1} \vee b_{1}, \Gamma_{n} \vdash a_{n+1} \vee b_{n+1}
$$

Teremos como resultado a Tabela $4.1 .^{3}$

\begin{tabular}{|l|r|r|r|r|}
\hline & \multicolumn{2}{|c|}{$D_{i}$} & \multicolumn{2}{|c|}{$U_{i}$} \\
\hline$n$ & \# nós & \# fórmulas & \# nós & \# fórmulas \\
\hline 1 & 21 & 26 & 11 & 16 \\
2 & 125 & 132 & 19 & 26 \\
3 & 789 & 798 & 27 & 36 \\
4 & 4741 & 4752 & 35 & 46 \\
5 & 27333 & 27346 & 43 & 56 \\
6 & 153221 & 153236 & 51 & 66 \\
\hline
\end{tabular}

Tabela 4.1: Número de nós gerados e número de fórmulas geradas na prova do seqüente $a_{1} \vee b_{1}, \Gamma_{n} \vdash$ $a_{n+1} \vee b_{n+1}$ pelo método de tableau analítico usando as regras de preferência $D_{i}$ e $U_{i}$.

Neste exemplo, as diferenças nos números de nós e fórmulas gerados pelas duas heurísticas sugerem que uma escolha que leve em conta apenas a ordem em que as fórmulas aparecem no tableau não é uma escolha inteligente. Podemos facilmente "enganar" uma heurística deste tipo alterando a ordem das fórmulas do tableau. Portanto, outras propriedades das fórmulas precisam ser exploradas. ${ }^{4}$

\footnotetext{
${ }^{2}$ Em decorrência dessa redundância, ocorrem repetições de subtableaux. Repetições dessa natureza são responsáveis pelo caráter exponencial das provas de tableaux analítico.

${ }^{3}$ Os resultados desta tabela foram obtidos pela execução dos testes na implementação, utilizando as regras de preferência descritas.

${ }^{4}$ As duas heurísticas descritas a seguir, a heurística da valoração e a heurística da polaridade, são formas conhecidas de se atacar o problema de escolha da ordem de aplicação das regras do tableau, e portanto podem ser consideradas de domínio público.
} 
Preferência através de valorações

No caso do método de tableaux KE, a aplicação de regras sobre fórmulas do tipo $\beta$ não-levam à bifurcação do tableau. Assim, as repetições de subtableaux poderão ser evitadas através de uma heurística sobre a regra $\mathrm{PB}$, que é a única que leva à bifurcação do tableau.

No tableau da Figura 4.6, as regras são aplicadas na seguinte ordem de preferência:

$K_{1}$ primeira ocorrência de fórmula do tipo $\alpha$ ainda não aplicada;

$K_{2}$ primeira ocorrência de fórmula do tipo $\beta$ ainda não aplicada, usando uma fórmula literal como secundária;

$K_{3}$ regra $\mathrm{PB}$ sobre subfórmula da primeira ocorrência de fórmula do tipo $\beta$ ainda não aplicada.

Note que os ramos gerados após a segunda aplicação dá regra PB não adicionam nenhuma informação nova ao tableau (ver as fórmulas desťacadas), porque a regra foi aplicada sobre uma fórmula $\left(a_{1}\right)$ sobre a qual a regra já havia sido aplicada neste ramo.

Semanticamente, como temos $F a_{1}$ no ramo $\left(v\left(a_{1}\right)=0\right)$, e $T a_{1} \rightarrow a_{2} \vee b_{2}$, então $v\left(a_{1} \rightarrow a_{2} \vee b_{2}\right)=1$. Como queremos falsificar o tableau, ou seja, achar uma valoração que falsifique as fórmulas do tableau inicial, devemos olhar para as fórmulas $A$ com $v(A) \neq 1$, onde $v$ é a valoração parcial dada pelos literais do ramo corrente. Ou seja, ao fazermos essa restrição na aplicação da regra $\mathrm{PB}$, estamos evitando aplicações redundantes como a do exemplo acima.

Dos comentários acima segue a

Heurística da valoração: aplicar PB sobre uma subfórmula (sobre a qual PB ainda não foi aplicada) de uma fórmula $A$ do tipo $\beta$ não analisada tal que $v(A) \neq 1$ segundo a valoração parcial dada pelas fórmulas literais do ramo corrente $(p \in \mathcal{P})$ :

$$
v(p)= \begin{cases}1 & \text { se } T p \in \text { ramo } \\ 0 & \text { se } F p \in \text { ramo } \\ * & \text { caso contrário }\end{cases}
$$




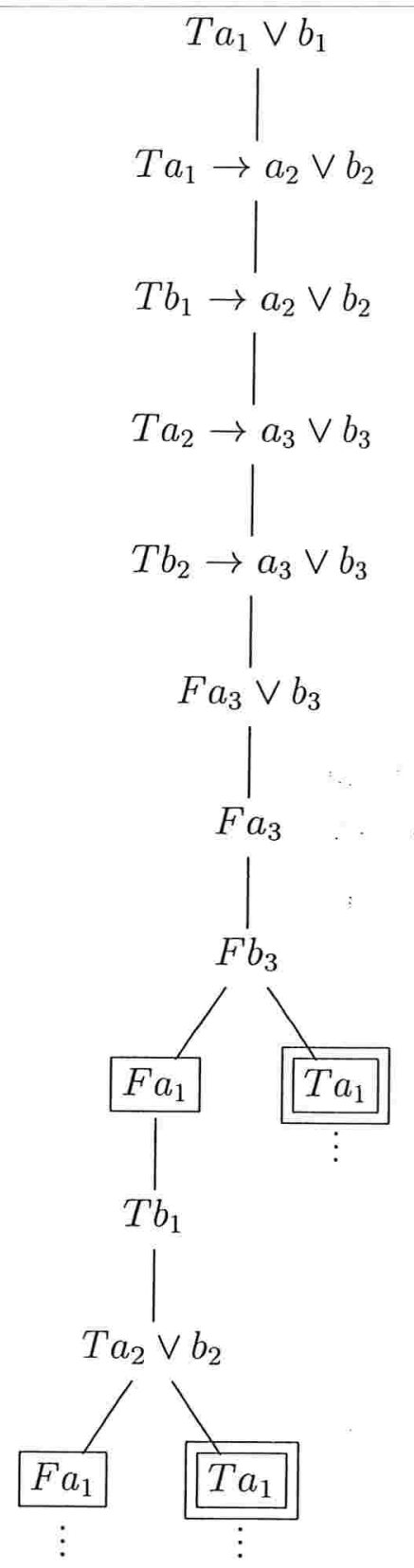

Figura 4.6: Tableau KE (incompleto) para $a_{1} \vee b_{1}, \Gamma_{2} \vdash a_{3} \vee b_{3}$. 
A Figura 4.7 mostra o tableau KE para o seqüente $a_{1} \vee b_{1}, \Gamma_{2} \vdash a_{3} \vee b_{3}$ usando a heurística da valoração.

A regra PB no ramo destacado com caixa simples foi aplicada sobre $a_{1}$, subfórmula de $T a_{1} \vee b_{1}$, que é a primeira fórmula $\beta$ não analisada com valor diferente de 1 segundo a valoração dada pelo ramo $\left(v\left(T a_{1} \vee b_{1}\right)=*^{5}\right)$.

A regra PB no ramo destacado com caixa dupla foi aplicada sobre $b_{1}$, subfórmula de $T b_{1} \rightarrow a_{2} \vee b_{2}$, que é a primeira fórmula $\beta$ não analisada com valor diferente de 1 segundo a valoração dada pelo ramo $\left(v\left(T b_{1} \rightarrow a_{2} \vee b_{2}\right)=*\right)$.

\section{Preferência através da polaridade}

Observe na Tabela 4.2 as regras com duas premissas do tableau KE anotadas com as polaridades.

$$
\begin{array}{|cccc|}
\hline F\left(A^{-} \wedge B^{-}\right) & & F\left(A^{-} \wedge B^{-}\right) & \\
\frac{T A^{+}}{F B^{-}} & \left(F \wedge_{1}\right) & \frac{T B^{+}}{F A^{-}} & \left(F \wedge_{2}\right) \\
T\left(A^{+} \vee B^{+}\right) & & T\left(A^{+} \vee B^{+}\right) & \\
\frac{F A^{-}}{T B^{+}} & \left(T \vee_{1}\right) & \frac{F B^{-}}{T A^{+}} & \left(T \vee_{2}\right) \\
\frac{T\left(A^{-} \rightarrow B^{+}\right)}{} & & \frac{T\left(A^{-} \rightarrow B^{+}\right)}{F B^{-}} & \left(T \rightarrow_{2}\right) \\
\frac{T A^{+}}{T B^{+}} & \left(T \rightarrow_{1}\right) & \frac{F A^{-}}{} & \\
\hline
\end{array}
$$

Tabela 4.2: Regras de expansão de tableaux KE com duas premissas anotadas com polaridades.

Considere, por exemplo, a regra $\left(F \wedge_{1}\right)$ :

$$
\begin{gathered}
F\left(\mathbf{A}^{-} \wedge B^{-}\right) \\
T \mathbf{A}^{+} \\
F B^{-}
\end{gathered}
$$

Note que a fórmula $A$ ocorre na premissa secundária com polaridade positiva, enquanto que na premissa primária, $A$ ocorre com polaridade negativa. Mais genericamente, em todas as regras de expansão com duas premissas, a fórmula da premissa secundária é uma subfórmula da premissa primária, e as duas ocorrências da fórmula têm polaridades opostas.

\footnotetext{
${ }^{5}$ Denotamos $*=$ valor indefinido.
} 


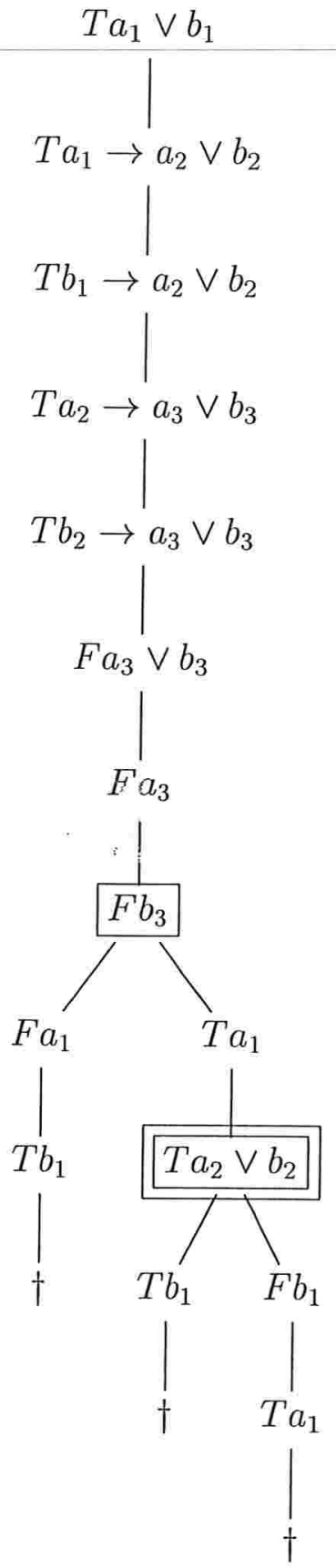

Figura 4.7: Tableau KE para $a_{1} \vee b_{1}, \Gamma_{2} \vdash a_{3} \vee b_{3}$ usando a heurística da valoração. 


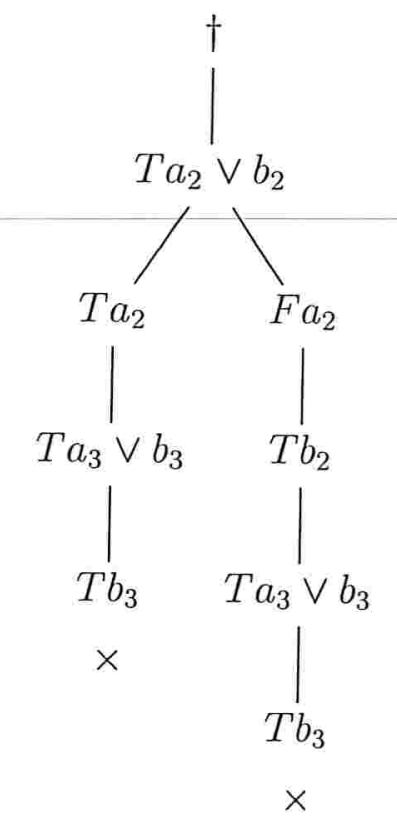

Figura 4.8: Continuação da Figura 4.7.

Deste modo, é vantajoso aplicar em primeiro lugar a regra PB sobre uma subfórmula de uma fórmula $\beta$ ainda não analisada, que tenha uma fórmula literal existente no ramo como subfórmula de polaridade oposta, ou seja,

Heurística da polaridade: aplicar PB sobre uma subfórmula $B$ de uma fórmula do tipo $\beta A$ não analisada tal que, para alguma fórmula literal $S p$ do ramo $(S \in\{T, F\}$, $p \in \mathcal{P}), A$ contém uma ocorrência de $p$ e as ocorrências de $p$ em $A$ e em $S p$ têm polaridades opostas.

O tableau para o seqüente $a_{1} \vee b_{1}, \Gamma_{2} \vdash a_{3} \vee b_{3}$ usando a heurística da polaridade é exibido na Figura 4.9.

A regra $\mathrm{PB}$ no ramo destacado com caixa simples foi aplicada sobre $a_{2}$, subfórmula da fórmula $T a_{2} \rightarrow \mathrm{a}_{3}^{+} \vee b_{3}$, que é a primeira fórmula $\beta$ não analisada que contém um literal do ramo $\left(F \mathbf{a}_{\mathbf{3}}^{-}\right)$com polaridade oposta.

A regra PB no ramo destacado com caixa dupla foi aplicada sobre $a_{1}$, subfórmula da fórmula $T a_{1} \rightarrow \mathrm{a}_{2}^{+} \vee b_{2}$, que é a primeira fórmula $\beta$ não analisada que contém um literal do ramo $\left(\mathrm{Fa}_{2}^{-}\right)$com polaridade oposta.

Note que este tableau é bem menor que o tableau da Figura 4.7, por que a ordem de escolha da heurística da polaridade é mais natural que a ordem de escolha da 


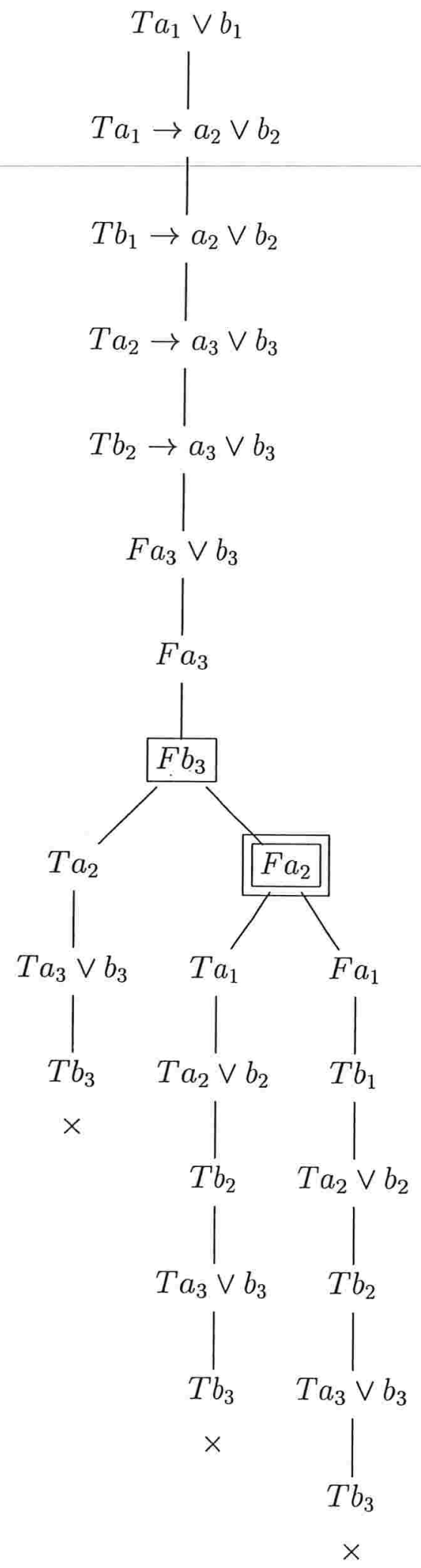

Figura 4.9: Tableau KE para $a_{1} \vee b_{1}, \Gamma_{2} \vdash a_{3} \vee b_{3}$ usando a heurística da polaridade. 
heurística da valoração.

\subsubsection{O método $\mathrm{KE}-S_{3}$}

$\mathrm{O}$ método $\mathrm{KE}-S_{3}$ difere do método $\mathrm{KE}$ apenas na manutenção do conjunto-contexto $S$. O conjunto contexto é inicializado no método virtual preClose(), é atualizado na aplicação da regra de uma premissa $(T \neg)$, e é retornado para o nó-pai no método virtual postClose().

Duas heurísticas foram implementadas para o método $\mathrm{KE}-S_{3}$. Ambas utilizam o critério da distância ${ }^{6}$ descrito a seguir para definir a ordem de seleção das fórmulas a serem analisadas.

O Critério da distância. Toda fórmula pode ser representada por uma árvore onde os nós internos são os conectivos lógicos e as folhas são os átomos. Mais genericamente, um seqüente

$$
A_{1}, A_{2}, \ldots, A_{n} \vdash B_{1}, B_{2}, \ldots, B_{m}
$$

Pode ser representado pela árvore da Figura 4.10.

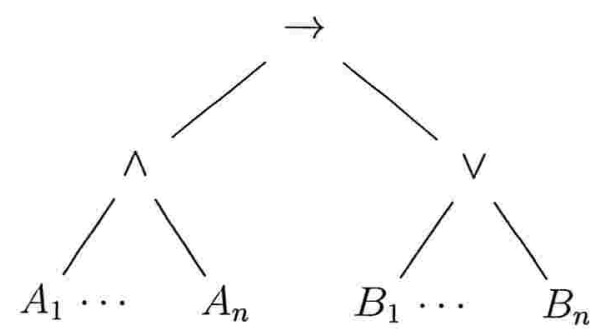

Figura 4.10: Árvore para o seqüente $A_{1}, A_{2}, \ldots, A_{n} \vdash B_{1}, B_{2}, \ldots, B_{m}$.

Nessa árvore, uma medida de interesse é a distância entre os átomos da fórmula.

Definimos a distância entre dois átomos $a$ e $b$ como a menor das distâncias entre ocorrências de $a$ e ocorrências de $b$. Denotamos $d(a, b) .^{7}$

\footnotetext{
${ }^{6} \mathrm{O}$ critério da distância é original, mas guarda algumas semelhanças com o grafo de dependências de Kowalski [Kow79], no sentido em que busca a solução do problema a partir das conclusões (abordagem top-down).

${ }^{7}$ na prática, essa distância é computada montando-se a árvore do seqüente como descrito anteriormente, e calculando-se a distância entre os nós internos da árvore. Depois, calcula-se a distância entre os átomos $p_{1}$ e $p_{2}$ segundo a fórmula:

$$
d\left(p_{1}, p_{2}\right)=\min \left\{d\left(p_{1}, n_{k}\right)+d\left(n_{k}, n_{l}\right)+d\left(n_{l}, p_{2}\right)\right\}
$$

onde $n_{k}$ é um nó interno com pelo menos um filho igual a $p_{1}\left(d\left(p_{1}, n_{k}\right)=1\right)$ e $n_{l}$ é um nó interno com pelo menos um filho igual a $p_{2}\left(d\left(p_{2}, n_{l}\right)=1\right)$.
} 
Heuristicamente, podemos supor que um átomo estará próximo do local onde ele é necessário na prova. Em outras palavras, assumimos uma premissa de relevância local, uma vez que usaremos a noção de distância para determinar a relevância de um átomo para a prova.

Suponhamos que as arestas $\left(\wedge, A_{i}\right), 1 \leq i \leq n$, e $\left(\vee, B_{j}\right), 1 \leq j \leq m$ sejam assinaladas com peso $\infty$, e as demais arestas com peso 1 . Seja $b$ um átomo com ocorrência em alguma fórmula $B_{j}$ e $a$ um átomo com ocorrência em alguma fórmula $A_{i}$. Então o único modo de a distância entre $b$ e $a$ ser finita é existir um caminho que começa em $b$ e termina em $a$ que não passa pelas arestas de peso infinito. Ou seja, algum átomo $p$ do caminho tem ocorrência tanto em uma fórmula $A_{i}$ quanto em uma fórmula $B_{j}$.

A partir do parágrafo anterior, podemos fazer a seguinte observação: se fizermos uma busca a partir das conclusões (fórmulas $B_{j}$ ), através de caminhos de comprimento finito, então as fórmulas totalmente irrelevantes para a prova (fórmulas $A_{i}$ cujos átomos não ocorrem em nenhum $B_{j}$ ) não serão atingidas pela busca.

Mais uma definição é necessária para que possamos aplicar o critério da distância às heuristicas do método $\mathrm{KE}-S_{3}$.

Definimos a distância entre uma fórmula $A$ e um conjunto de átomos $\mathrm{B}$ como

$$
d(A, B)=\min \{d(a, b)\}
$$

onde $a$ é átomo de $A$ e $b \in B$.

A primeira heurística implementada para o método $\mathrm{KE}-S_{3}$ é similar à heurística da polaridade para o método KE. Sua ordem de preferência é a seguinte:

$S P_{1}$ primeira ocorrência de fórmula do tipo $\alpha$ ainda não aplicada;

$S P_{2}$ primeira ocorrência de fórmula do tipo $\beta$ ainda não aplicada, usando uma fórmula literal como secundária;

$S P_{3}$ dentre as fórmulas do tipo $\beta$ ainda não aplicadas que satisfazem a Heurística da Polaridade, regra PB sobre subfórmula da ocorrência com o menor número de átomos não ocorrentes em $S$ e com menor distância do conjunto de literais do ramo. 
A escolha da fórmula com o menor número de átomos não ocorrentes em $S$ procura conservar o conjunto contexto $S$ com o menor tamanho possível.

A segunda heurística tem a seguinte ordem de preferência:

$P B_{1}$ primeira ocorrência de fórmula do tipo $\alpha$ ainda não aplicada exceto fórmula na forma $T \neg A$;

$P B_{2}$ primeira ocorrência de fórmula do tipo $\beta$ ainda não aplicada, usando uma fórmula literal como secundária;

$P B_{3}$ dentre as fórmulas do tipo $\beta$ ainda não aplicadas que satisfazem a Heurística da Polaridade, regra PB sobre subfórmula da ocorrência com o menor número de átomos não ocorrentes em $S$ e com menor distância do conjunto de literais do ramo;

$P B_{4}$ primeira ocorrência de fórmula do tipo $\alpha$ na forma $T \neg A$.

Ou seja, a primeira heurística dá preferência a fórmulas do tipo $\alpha$, sem distinção da regra $(T \neg)$, que adiciona elementos a conjunto-contexto $S$. Jà a segunda heurística adia as aplicações dessa regra até que nenhuma outra regra possa ser aplicada.

Exemplo 4.1 Vamos provar a validade do seqüente $a \vee c, e \rightarrow f, a \rightarrow b, c \rightarrow d \vdash b \vee d$ usando a primeira heurística $S P_{i}$.

A Figura 4.11 mostra a representação em árvore do seqüente.

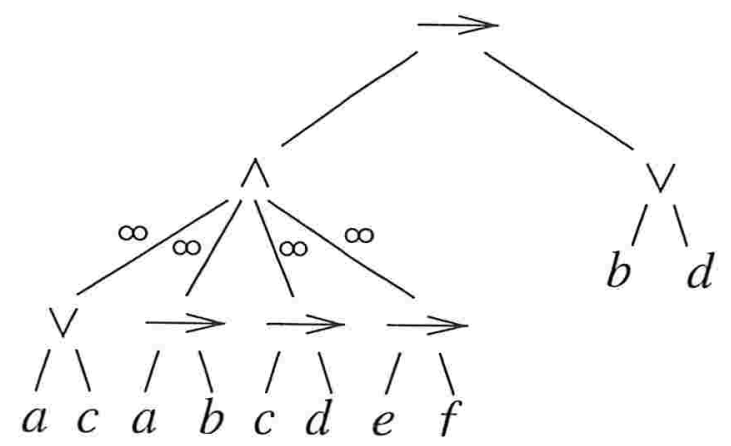

Figura 4.11: Representação em árvore do seqüente $a \vee c, e \rightarrow f, a \rightarrow b, c \rightarrow d \vdash b \vee d$.

A partir da árvore, calculamos as distâncias entre os átomos, que são exibidas na Tabela 4.3. 


\begin{tabular}{|c|cccccc|}
\hline$d(\cdot, \cdot)$ & $\mathrm{a}$ & $\mathrm{b}$ & $\mathrm{c}$ & $\mathrm{d}$ & $\mathrm{e}$ & $\mathrm{f}$ \\
\hline $\mathrm{a}$ & 0 & 2 & 2 & 4 & $\infty$ & $\infty$ \\
$\mathrm{b}$ & & 0 & 4 & 2 & $\infty$ & $\infty$ \\
$\mathrm{c}$ & & & 0 & 2 & $\infty$ & $\infty$ \\
$\mathrm{d}$ & & & & 0 & $\infty$ & $\infty$ \\
$\mathrm{e}$ & & & & & 0 & 2 \\
$\mathrm{f}$ & & & & & & 0 \\
\hline
\end{tabular}

Tabela 4.3: Tabela de distâncias entre os átomos do seqüente $a \vee c, e \rightarrow f, a \rightarrow b, c \rightarrow d \vdash b \vee d$.

O tableau para o seqüente é exibido na Figura 4.12.

As fórmulas 6 e 7 foram obtidas a partir da aplicação da regra $(F \vee)$ sobre a fórmula 5. Neste momento, não é possível aplicar nenhuma regra do tipo $\alpha$ e nenhuma regra do tipo $\beta$. É necessário aplicar a regra $(P B)$ sobre alguma fórmula do tipo $\beta$ ainda não analisada (as fórmulas candidatas são 1, 2, 3 e 4). A fórmula escolhida é a 3, porque dentre as que têm o menor número de átomos fora do conjunto-contexto $S=\emptyset, 2$, é a primeira cuja distância do conjunto de literais do ramo $\{F b, F d\}$ é mínima, 0 . A fórmula 9 foi obtida a partir da aplicação da regra $\left(T \rightarrow_{1}\right)$ sobre 3 e 8 , o que fecha o ramo esquerdo do tableau. A fórmula 11 foi obtida a partir da aplicação da regra $\left(T \vee_{1}\right)$ sobre 1 e 10 . A fórmula 12 foi obtida a partir da aplicação da regra $\left(T \rightarrow_{1}\right)$ sobre 4 e 11 , o que fecha o ramo direito do tableau. $\square$

Exemplo 4.2 Vamos provar a validade do mesmo seqüente do exemplo anterior, mas com as fórmulas em forma clausal, $a \vee c, \neg e \vee f, \neg a \vee b, \neg c \vee d \vdash b \vee d$ usando a primeira heurística $S P_{i}$.

A Figura 4.13 mostra a representação em árvore do seqüente.

A partir da árvore, calculamos as distâncias entre os átomos, que são exibidas na Tabela 4.4.

\begin{tabular}{|c|cccccc|}
\hline$d(\cdot, \cdot)$ & $\mathrm{a}$ & $\mathrm{b}$ & $\mathrm{c}$ & $\mathrm{d}$ & $\mathrm{e}$ & $\mathrm{f}$ \\
\hline $\mathrm{a}$ & 0 & 3 & 2 & 5 & $\infty$ & $\infty$ \\
$\mathrm{b}$ & & 0 & 5 & 2 & $\infty$ & $\infty$ \\
$\mathrm{c}$ & & & 0 & 3 & $\infty$ & $\infty$ \\
$\mathrm{d}$ & & & & 0 & $\infty$ & $\infty$ \\
$\mathrm{e}$ & & & & & 0 & 3 \\
$\mathrm{f}$ & & & & & & 0 \\
\hline
\end{tabular}

Tabela 4.4: Tabela de distâncias entre os átomos do seqüente $a \vee c, \neg e \vee f, \neg a \vee b, \neg c \vee d \vdash b \vee d$.

O tableau para o seqüente é exibido na Figura 4.14. 


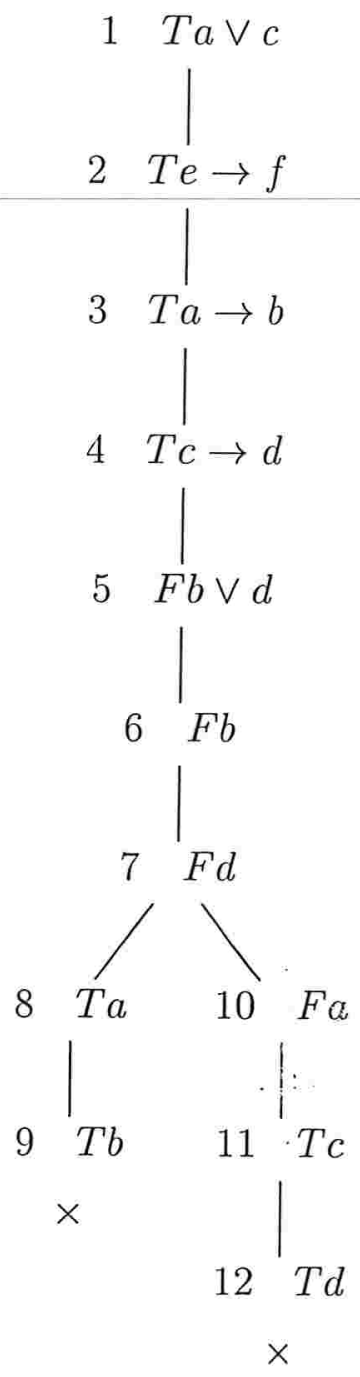

Figura 4.12: Tableau para o seqüente $a \vee c, e \rightarrow f, a \rightarrow b, c \rightarrow d \vdash b \vee d$ usando a heurística $S P_{i}$.

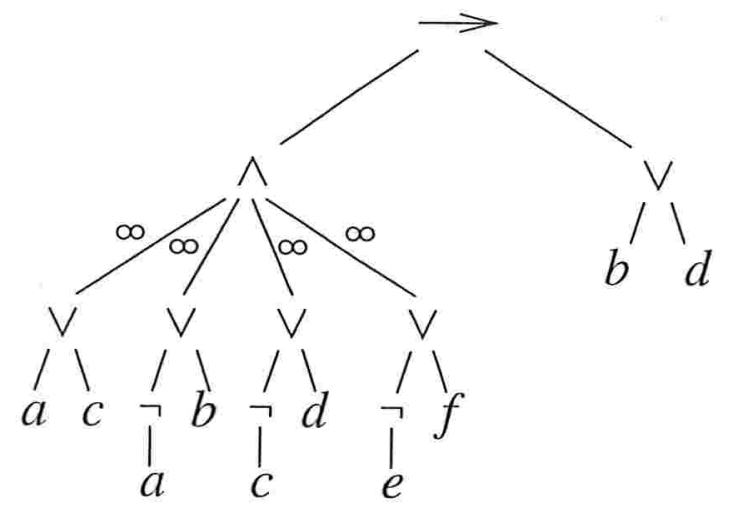

Figura 4.13: Representação em árvore do seqüente $a \vee c, \neg e \vee f, \neg a \vee b, \neg c \vee d \vdash b \vee d$. 


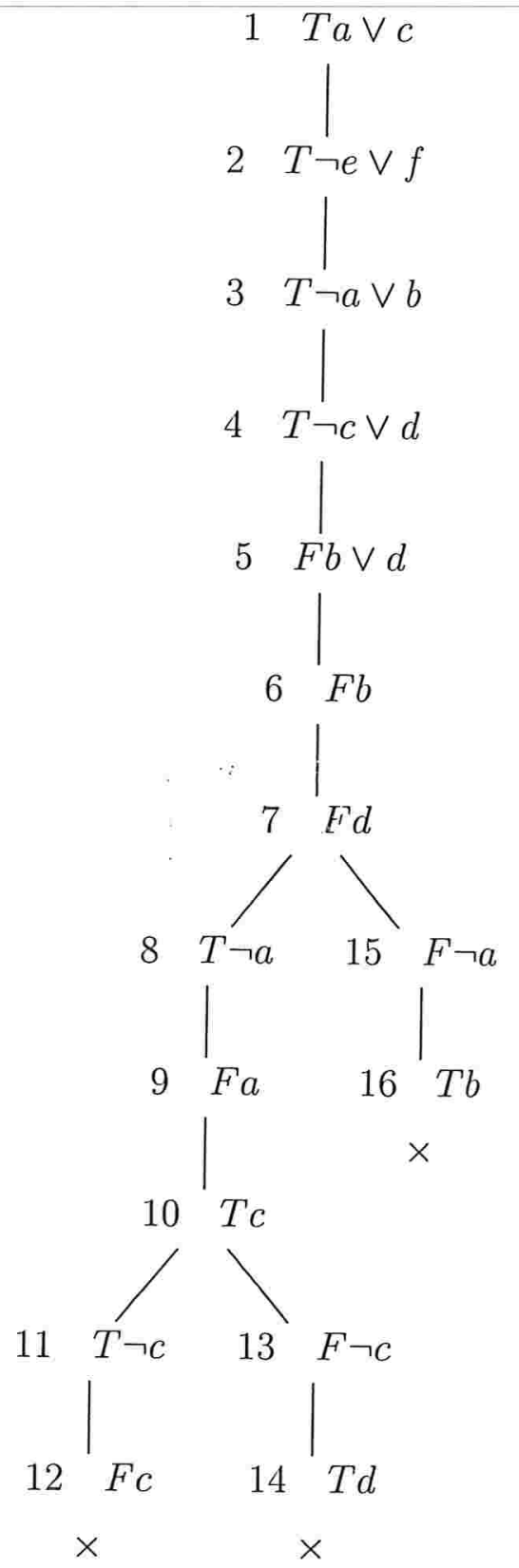

Figura 4.14: Tableau para o seqüente $a \vee c, \neg e \vee f, \neg a \vee b, \neg c \vee d \vdash b \vee d$ usando a heurística $S P_{i}$. 
As fórmulas 6 e 7 foram obtidas a partir da aplicação da regra $(F \vee)$ sobre a fórmula 5. Neste momento, não é possível aplicar nenhuma regra do tipo $\alpha$ e nenhuma regra do tipo $\beta$. É necessário aplicar a regra $(P B)$ sobre alguma fórmula do tipo $\beta$-ainda não analisada (as fórmulas candidatas são 1, 2, 3 e 4). A fórmula escolhida é a 3 , porque dentre as que têm o menor número de átomos fora do conjunto-contexto $S=\emptyset, 2$, é a primeira cuja distância do conjunto de literais do ramo $\{F b, F d\}$ é mínima, 0. A fórmula 9 foi obtida a partir da aplicação da regra $(T \neg)$ sobre 8 , o que obriga $S=\{a\}$. A fórmula 10 foi obtida a partir da aplicação da regra $\left(T \vee_{1}\right)$ sobre 1 e 9 . Neste momento, não é possível aplicar nenhuma regra do tipo $\alpha$ e nenhuma regra do tipo $\beta$. É necessário aplicar a regra $(P B)$ sobre alguma fórmula do tipo $\beta$ ainda não analisada (as fórmulas candidatas são 2 e 4). A fórmula escolhida é a 4 , porque dentre as que têm o menor número de átomos fora do conjunto-contexto $S=\emptyset, 2$, é a fórmula cuja distância do conjunto de literais do ramo $\{F b, F d, F a, T c\}$ é mínima, 0. A fórmula 12 foi obtida a partir da aplicação da regra $(T \neg)$ sobre 11 , o que obriga $S=\{a, c\}$ e fecha o ramo terminado em 12 . A fórmula 14 foi obtida a partir da aplicação da regra $\left(T \vee_{1}\right)$ sobre 4 e 13 , o que fecha o ramo terminado em 14. A fórmula 16 foi obtida a partir da aplicação da regra $\left(T \vee_{1}\right)$ sobre 3 e 15 , o que fecha o ramo terminado em 16.

Note que os átomos e e $f$ não entraram em $S$ porque a fórmula 2, que é irrelevante para a prova, não foi analisada.

Finalmente, apresentamos na figura 4.15 o mesmo exemplo utilizando a heurística $P B_{i}$.

No capítulo 5 , os resultados obtidos pelas duas heurísticas são comparados. 


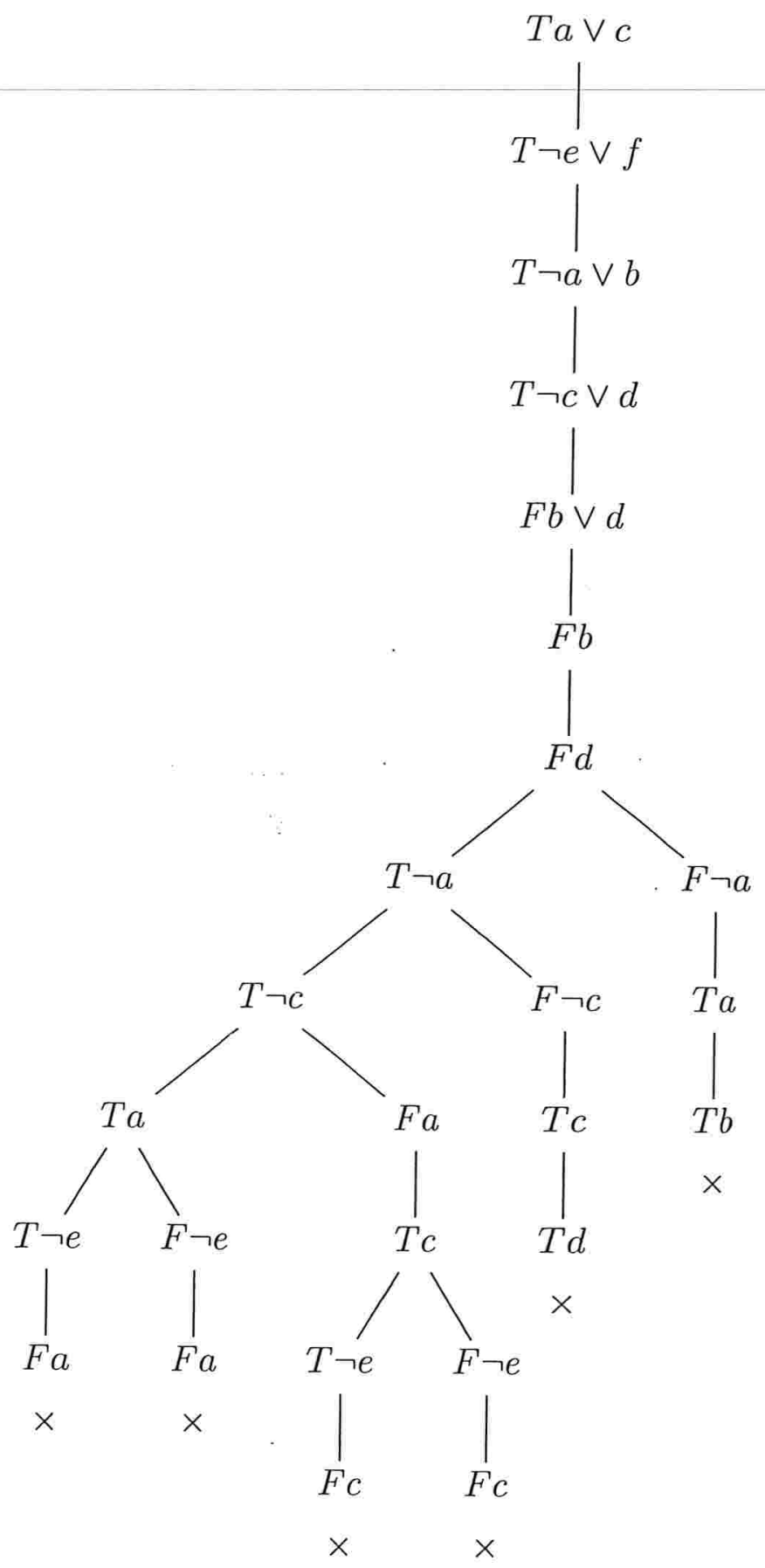

Figura 4.15: Tableau para o seqüente $a \vee c, \neg e \vee f, \neg a \vee b, \neg c \vee d \vdash b \vee d$ usando a heurística $P B_{i}$. O tableau fecha com $S=\{a, c\}$. 


\section{Capítulo 5}

\section{Resultados}

\subsection{Os casos de teste}

Para fazer o teste comparativo dos métodos de tableaux implementados, consideramos os principais conjuntos de fórmulas que são conhecidamente difíceis. Os casos de teste são os seguintes:

1. Gamma: exemplo extraído de [CS00], p. 22.

$$
a_{1} \vee b_{1}, \Gamma_{n} \vdash a_{n+1} \vee b_{n+1}
$$

onde

$$
\Gamma_{n}=\bigcup_{i=1}^{n}\left\{a_{i} \rightarrow a_{i+1} \vee b_{i+1}, b_{i} \rightarrow a_{i+1} \vee b_{i+1}\right\}
$$

2. H: exemplo extraído de [D'A92].

$$
\vdash H_{n}
$$

onde $H_{n}$ é dado por

$$
\begin{aligned}
& H_{1}=p_{1} \vee \neg p_{1} \\
& H_{2}=\left(p_{1} \wedge p_{2}\right) \vee\left(p_{1} \wedge \neg p_{2}\right) \vee\left(\neg p_{1} \wedge p_{2}\right) \vee\left(\neg p_{1} \wedge \neg p_{2}\right)
\end{aligned}
$$

3. PHP - Pigeon Hole Principle ou Princípio do Escaninho: exemplo extraído de [CS00], p. 29.

$$
A_{n} \vdash B_{n}
$$


onde

$$
\begin{aligned}
A_{n} & =\bigwedge_{i=0}^{n} \bigvee_{j=0}^{n-1} p_{i j} \\
B_{n} & =\bigvee_{j=0}^{n-1} \bigvee_{i=0}^{n-1} \bigvee_{k=i+1}^{n}\left(p_{i j} \wedge p_{k j}\right)
\end{aligned}
$$

4. Statman: exemplo extraído de [Sta78]. ${ }^{1}$

$$
\bigwedge_{i=1}^{n}\left(A_{i} \vee B_{i}\right) \vdash c_{n} \vee d_{n}
$$

onde

$$
\begin{array}{ll}
A_{1}=c_{1} & A_{i+1}=F_{i} \rightarrow c_{i+1} \\
B_{1}=d_{1} & B_{i+1}=F_{i} \rightarrow d_{i+1} \\
& \\
F_{k}=\bigwedge_{j=1}^{k}\left(c_{j} \vee d_{j}\right) &
\end{array}
$$

\subsection{Resultado dos casos de teste}

Todos os métodos de tableau foram testados com cada caso de teste. Para cada teste, foram medidos:

- o número de nós do tableau fechado;

- o número de fórmulas do tableau fechado;

- o tempo gasto em segundos para o fechamento do tableau.

\footnotetext{
${ }^{1}$ Statman [Sta78] mostrou que esta família de fórmulas tem provas polinomiais com corte, mas sem corte as provas são exponenciais (ver [CSO0], p. 24).
} 


\subsubsection{Tableau analítico}

A Tabela 5.1 mostra o resultado dos testes para o tableau analítico com as heurísticas $D_{i}{ }^{2}$ e $U_{i}{ }^{3}$.

\begin{tabular}{|l|l||r|r|r||r|r|r|}
\hline & \multicolumn{1}{|c||}{} & \multicolumn{3}{c||}{ analytic } & \multicolumn{3}{|c|}{ analytic+BU } \\
\hline Caso & $n$ & \# nós & \# fórmulas & Tempo (s) & \# nós & \# fórmulas & Tempo (s) \\
\hline \hline Gamma & 1 & 21 & 27 & 0.002793 & 11 & 17 & 0.001436 \\
& 2 & 125 & 133 & 0.020373 & 19 & 27 & 0.003645 \\
& 3 & 789 & 799 & 0.155993 & 27 & 37 & 0.004496 \\
& 4 & 4741 & 4753 & 1.109542 & 35 & 47 & 0.006930 \\
& 5 & 27333 & 27347 & 7.483438 & 43 & 57 & 0.009229 \\
& 6 & 153221 & 153237 & 48.384375 & 51 & 67 & 0.012195 \\
\hline \hline H & 1 & 1 & 5 & 0.000152 & 1 & 5 & 0.000152 \\
& 2 & 17 & 29 & 0.002124 & 17 & 31 & 0.002201 \\
& 3 & 511 & 712 & 0.086488 & 511 & 838 & 0.091186 \\
\hline \hline PHP & 1 & 3 & 8 & 0.000439 & 3 & 8 & 0.000437 \\
& 2 & 107 & 119 & 0.017646 & 107 & 119 & 0.017904 \\
& 3 & 67051 & 67076 & 25.846443 & 65047 & 65072 & 24.697791 \\
\hline \hline Statman & 1 & 3 & 7 & 0.000408 & 3 & 7 & 0.000408 \\
& 2 & 15 & 28 & 0.002118 & 11 & 20 & 0.001512 \\
& 3 & 63 & 117 & 0.010052 & 59 & 89 & 0.009678 \\
& 4 & 239 & 438 & 0.043034 & 441 & 636 & 0.089275 \\
& 5 & 927 & 1703 & 0.179719 & 4103 & 5919 & 0.970773 \\
& 6 & 3647 & 6728 & 0.879744 & 45325 & 65802 & 12.873804 \\
\hline
\end{tabular}

Tabela 5.1: Teste do método de tableaux analíticos.

Observando os dados da tabela, vemos que nos casos H e Statman, a heurística $D_{i}$ tem um melhor desempenho, enquanto que nos casos Gamma e PHP a heurística $U_{i}$ é a melhor.

Era de se esperar que nenhuma das duas heurísticas fosse melhor que a outra no caso geral, porque nenhuma delas usa um critério inteligente para a escolha da ordem de análise das fórmulas, apenas a ordem em que ocorrem no tableau.

No Apêndice B são exibidos os gráficos dos resultados dos testes.

\footnotetext{
${ }^{2}$ coluna "analytic"

${ }^{3}$ coluna "analytic + BU"
} 


\subsubsection{Tableau KE}

A Tabela 5.2 mostra o resultado dos testes para o tableau analítico com a heurística $K_{i}{ }^{4}$, a heurística da valoração ${ }^{5}$ e a heurística da polaridade ${ }^{6}$.

\begin{tabular}{|l|l||r|r|r||r|r|r||r|r|r|}
\hline & & \multicolumn{3}{c||}{ KE } & \multicolumn{3}{|c||}{ KE+V } & \multicolumn{3}{|c|}{ KE+P } \\
\hline Caso & $n$ & \#nós & \#fmls & T (s) & \#nós & \#fmls & T (s) & \#nós & \#fmls & T (s) \\
\hline \hline Gamma & 1 & 3 & 13 & 0.001299 & 3 & 13 & 0.001737 & 3 & 13 & 0.001403 \\
& 2 & 13 & 42 & 0.010141 & 7 & 23 & 0.006142 & 7 & 23 & 0.006337 \\
& 3 & 37 & 117 & 0.046355 & 11 & 33 & 0.015440 & 11 & 33 & 0.015199 \\
& 7 & 109 & 338 & 0.200616 & 15 & 43 & 0.030519 & 15 & 43 & 0.030138 \\
& 5 & 325 & 997 & 0.820640 & 19 & 53 & 0.052747 & 19 & 53 & 0.052012 \\
& 6 & 973 & 2970 & 3.564614 & 23 & 63 & 0.083877 & 23 & 63 & 0.082882 \\
& 7 & 2917 & 8885 & 13.231674 & 27 & 73 & 0.124285 & 27 & 73 & 0.151914 \\
& 8 & 8749 & 26626 & 49.277312 & 31 & 83 & 0.176152 & 31 & 83 & 0.175679 \\
\hline \hline H & 1 & 1 & 4 & 0.000111 & 1 & 4 & 0.000109 & 1 & 4 & 0.000108 \\
& 2 & 3 & 17 & 0.001450 & 5 & 17 & 0.001599 & 5 & 17 & 0.001490 \\
& 3 & 21 & 103 & 0.019906 & 13 & 55 & 0.009115 & 13 & 55 & 0.008841 \\
& 4 & 105 & 677 & 0.492401 & 29 & 179 & 0.047016 & 29 & 179 & 0.045761 \\
& 5 & 465 & 4777 & 10.325982 & 61 & 619 & 0.290332 & 61 & 619 & 0.227181 \\
\hline \hline PHP & 1 & 1 & 6 & 0.000199 & 1 & 6 & 0.000198 & 1 & 6 & 0.000197 \\
& 2 & 3 & 29 & 0.002681 & 3 & 28 & 0.002447 & 3 & 28 & 0.002449 \\
& 3 & 61 & 261 & 0.254678 & 11 & 110 & 0.053459 & 11 & 110 & 0.053243 \\
& 4 & 483 & 2219 & 8.619986 & 47 & 511 & 1.268295 & 47 & 511 & 1.378396 \\
\hline \hline Statman & 1 & 1 & 5 & 0.000165 & 1 & 5 & 0.000163 & 1 & 5 & 0.000162 \\
& 2 & 7 & 30 & 0.003533 & 3 & 18 & 0.001745 & 3 & 18 & 0.009173 \\
& 3 & 31 & 124 & 0.060553 & 13 & 58 & 0.019585 & 13 & 58 & 0.018665 \\
& 4 & 207 & 711 & 0.407214 & 47 & 178 & 0.134915 & 47 & 178 & 0.157982 \\
& 5 & 1079 & 3696 & 4.181898 & 145 & 508 & 0.763058 & 145 & 508 & 0.665001 \\
& 6 & 5391 & 19539 & 36.835890 & 403 & 1358 & 3.136678 & 403 & 1358 & 3.010920 \\
\hline
\end{tabular}

Tabela 5.2: Teste do método de tableaux KE.

Observando os dados da tabela, vemos que a heurística da polaridade apresenta um desempenho melhor que o das outras duas heurísticas. Isto se deve ao fato de a regra de preferência usando a polaridade das fórmulas estar intimamente ligada à estrutura das regras de expansão do tableau KE.

A Tabela 5.3 mostra os resultados dos mesmos testes utilizando a heurística da distância em conjunção com as heurísticas da valoração e da polaridade. ${ }^{7}$

Podemos observar que a heurística da distância nada ajuda nestes casos de teste.

\footnotetext{
${ }^{4}$ coluna "KE"

${ }^{5}$ coluna "KE+V"

${ }^{6}$ coluna "KE+P"

${ }^{7}$ As heurísticas são modificadas da seguinte maneira: aplicar PB sobre uma subfórmula de uma fórmula $A$ que satisfaça as condições da heurística da valoração/polaridade e que tenha distância mínima do conjunto de literais do ramo.
} 


\begin{tabular}{|l|l||r|r|r||r|r|r|}
\hline & & \multicolumn{3}{c||}{ KE+V } & \multicolumn{3}{|c|}{ KE+P } \\
\hline Caso & $n$ & \#nós & \#fmls & $\mathrm{T}(\mathrm{s})$ & \#nós & \#fmls & $\mathrm{T}(\mathrm{s})$ \\
\hline \hline Gamma & 1 & 3 & 13 & 0.001737 & 3 & 13 & 0.001761 \\
& 2 & 5 & 23 & 0.006490 & 5 & 23 & 0.029050 \\
& 3 & 7 & 35 & 0.016886 & 7 & 35 & 0.020094 \\
& 4 & 9 & 49 & 0.035752 & 9 & 49 & 0.047569 \\
& 5 & 11 & 65 & 0.096447 & 11 & 65 & 0.068034 \\
& 6 & 13 & 83 & 0.115460 & 13 & 83 & 0.133260 \\
& 7 & 15 & 103 & 0.188568 & 15 & 103 & 0.230932 \\
& 8 & 17 & 125 & 0.359210 & 17 & 125 & 0.351875 \\
\hline \hline H & 1 & 1 & 4 & 0.000114 & 1 & 4 & 0.000113 \\
& 2 & 3 & 17 & 0.001323 & 3 & 17 & 0.001324 \\
& 3 & 21 & 103 & 0.025815 & 7 & 55 & 0.009094 \\
& 4 & 105 & 677 & 0.616623 & 15 & 185 & 0.073449 \\
& 5 & 465 & 4777 & 10.661724 & 31 & 661 & 0.531249 \\
\hline \hline PHP & 1 & 1 & 6 & 0.000197 & 1 & 6 & 0.000196 \\
& 2 & 3 & 29 & 0.002991 & 3 & 29 & 0.003104 \\
& 3 & 61 & 261 & 0.358510 & 21 & 173 & 0.144977 \\
& 4 & 483 & 2219 & 11.360033 & 143 & 1289 & 5.716319 \\
\hline \hline Statman & 1 & 1 & 5 & 0.000158 & 1 & 5 & 0.000161 \\
& 2 & 3 & 18 & 0.001990 & 3 & 18 & 0.001936 \\
& 3 & 31 & 110 & 0.040688 & 31 & 105 & 0.041894 \\
& 4 & 183 & 620 & 0.521748 & 135 & 483 & 0.463096 \\
& 5 & 783 & 2688 & 4.190906 & 509 & 1860 & 3.561454 \\
& 6 & 3015 & 10948 & 27.988467 & 1779 & 6750 & 22.077161 \\
\hline
\end{tabular}

Tabela 5.3: Teste do método de tableaux KE com heurística da distância. 
No Apêndice B são exibidos os gráficos dos resultados dos testes.

\subsubsection{Tableau KE- $S_{3}$}

Para os testes do método de tableaux $\mathrm{KE}-S_{3}$, vamos eliminar as conjunções e as implicações das fórmulas. Deste modo, forçamos o aparecimento de mais algumas negações nas fórmulas, tentando induzir o uso da regra $(T \neg){ }^{8}$

Os casos de teste ficam sendo, então, os seguintes:

1. Gamma

$$
a_{1} \vee b_{1}, \Gamma_{n} \vdash a_{n+1} \vee b_{n+1}
$$

onde

$$
\Gamma_{n}=\bigcup_{i=1}^{n}\left\{\neg a_{i} \vee\left(a_{i+1} \vee b_{i+1}\right), \neg b_{i} \vee\left(a_{i+1} \vee b_{i+1}\right)\right\}
$$

2. $\mathrm{H}$

$$
\vdash H_{n}
$$

onde $H_{n}$ é dado por

$$
\begin{aligned}
& H_{1}=p_{1} \vee \neg p_{1} \\
& H_{2}=\neg\left(p_{1} \vee p_{2}\right) \vee \neg\left(p_{1} \vee \neg p_{2}\right) \vee \neg\left(\neg p_{1} \vee p_{2}\right) \vee \neg\left(\neg p_{1} \vee \neg p_{2}\right)
\end{aligned}
$$

3. PHP

$$
\vdash A_{n} \vee B_{n}
$$

onde

$$
\begin{aligned}
A_{n} & =\neg \bigvee_{i=0}^{n} \neg \bigvee_{j=0}^{n-1} p_{i j} \\
B_{n} & =\bigvee_{j=0}^{n-1} \bigvee_{i=0}^{n-1} \bigvee_{k=i+1}^{n} \neg\left(\neg p_{i j} \vee \neg p_{k j}\right)
\end{aligned}
$$

${ }^{8}$ Note que esta transformação não é válida nas lógicas $S_{3}$, ou seja, estes casos de teste não necessariamente são logicamente equivalentes aos casos de teste da seção anterior na semântica'de $S_{3}$. 


\section{Statman}

$$
\bigcup_{i=1}^{n}\left(A_{i} \vee B_{i}\right) \vdash c_{n} \vee d_{n}
$$

onde

$$
\begin{array}{ll}
A_{1}=c_{1} & A_{i+1}=\neg F_{i} \vee c_{i+1} \\
B_{1}=d_{1} & B_{i+1}=\neg F_{i} \vee d_{i+1} \\
& \\
F_{k}=\neg \bigvee_{j=1}^{k} \neg\left(c_{j} \vee d_{j}\right) &
\end{array}
$$

A Tabela 5.4 mostra o resultado dos testes para o tableau KE- $S_{3}$ com a heurística $S P_{i}{ }^{9}$ e a heurística $P B_{i}{ }^{10}$, mas inicialmente sem a heurística da distância.

\begin{tabular}{|l|l||r|r|r|r||r|r|r|r|}
\hline & & \multicolumn{9}{c||}{$\mathrm{KE}_{3} S_{3}$} & \multicolumn{3}{|c|}{ KE- $S_{3}+\mathrm{PB}$} \\
\hline Caso & $n$ & \#nós & \#fmls & $\mathrm{T}(\mathrm{s})$ & $|S|$ & \#nós & \#fmls & $\mathrm{T}(\mathrm{s})$ & $|S|$ \\
\hline \hline Gamma & 1 & 9 & 28 & 0.005383 & 2 & 11 & 31 & 0.007239 & 2 \\
& 2 & 19 & 60 & 0.022599 & 4 & 19 & 62 & 0.022715 & 4 \\
& 3 & 45 & 134 & 0.105748 & 6 & 53 & 160 & 0.109554 & 6 \\
& 4 & 109 & 300 & 0.261566 & 8 & 105 & 306 & 0.249372 & 8 \\
& 5 & 173 & 482 & 0.596367 & 10 & 189 & 550 & 0.670404 & 10 \\
& 6 & 429 & 1140 & 1.826961 & 12 & 363 & 1022 & 1.575956 & 12 \\
& 7 & 685 & 1862 & 3.722508 & 14 & 633 & 1790 & 3.489517 & 14 \\
\hline \hline H & 1 & 1 & 6 & 0.000191 & 1 & 1 & 6 & 0.000219 & 1 \\
& 2 & 3 & 19 & 0.001278 & 2 & 11 & 37 & 0.004655 & 2 \\
& 3 & 7 & 57 & 0.007294 & 3 & 41 & 171 & 0.047230 & 3 \\
\hline \hline PHP & 1 & 3 & 16 & 0.001061 & 2 & 3 & 20 & 0.001228 & 2 \\
& 2 & 51 & 192 & 0.066302 & 6 & 37 & 227 & 0.054892 & 6 \\
& 3 & 935 & 4228 & 5.839093 & 12 & 841 & 3995 & 6.882294 & 12 \\
& 4 & 22667 & 126694 & 530.427588 & 20 & 22177 & 97848 & 693.912202 & 20 \\
\hline \hline Statman & 1 & 1 & 5 & 0.000173 & 0 & 1 & 5 & 0.000174 & 0 \\
& 2 & 7 & 48 & 0.006805 & 2 & 7 & 44 & 0.009174 & 2 \\
& 3 & 37 & 219 & 0.075732 & 4 & 55 & 299 & 0.192884 & 4 \\
& 4 & 125 & 686 & 0.432528 & 6 & 407 & 2003 & 2.317840 & 6 \\
\hline
\end{tabular}

Tabela 5.4: Teste do método de tableaux $\mathrm{KE}-S_{3}$ sem a heurística da distância.

Observando os dados da tabela, vemos que para nenhum dos casos de teste existe diferença no tamanho do conjunto-contexto $S$ no tableau final. Ou seja, o uso da heurística $P B_{i}$ não melhora a eficácia do método. Além disso, para todos os casos, o uso da heurística $S P_{i}$ torna o método mais eficiente.

Vejamos agora os resultados com a heurística da distância (Tabela 5.5).

\footnotetext{
${ }^{9}$ coluna "KE- $S_{3}$ "

${ }^{10}$ coluna "KE- $S_{3}+\mathrm{PB}$ "
} 


\begin{tabular}{|l|l||r|r|r|r||r|r|r|r|}
\hline & \multicolumn{1}{|c||}{} & \multicolumn{9}{c||}{ KE- $_{3}$} & \multicolumn{4}{|c|}{ KE- $S_{3}+\mathrm{PB}$} \\
\hline Caso & $n$ & \#nós & \#fmls & $\mathrm{T}(\mathrm{s})$ & $|S|$ & \#nós & \#fmls & $\mathrm{T}(\mathrm{s})$ & $|S|$ \\
\hline \hline Gamma & 1 & 9 & 26 & 0.006016 & 2 & 11 & 30 & 0.008323 & 2 \\
& 2 & 23 & 72 & 0.035984 & 4 & 25 & 82 & 0.041576 & 4 \\
& 3 & 63 & 198 & 0.222385 & 6 & 67 & 218 & 0.180890 & 6 \\
& 4 & 169 & 529 & 0.857960 & 8 & 187 & 598 & 0.897771 & 8 \\
& 5 & 455 & 1427 & 3.404131 & 10 & 491 & 1561 & 3.643146 & 10 \\
& 6 & 1277 & 4016 & 14.220320 & 12 & 1323 & 4184 & 14.347676 & 12 \\
& 7 & 3703 & 11666 & 56.962195 & 14 & 3695 & 11671 & 56.162057 & 14 \\
\hline \hline H & 1 & 1 & 6 & 0.000196 & 1 & 1 & 6 & 0.000246 & 1 \\
& 2 & 5 & 21 & 0.001990 & 2 & 11 & 34 & 0.004747 & 2 \\
& 3 & 13 & 63 & 0.010944 & 3 & 43 & 157 & 0.036399 & 3 \\
\hline \hline PHP & 1 & 3 & 16 & 0.001093 & 2 & 3 & 20 & 0.001307 & 2 \\
& 2 & 13 & 75 & 0.020335 & 6 & 41 & 237 & 0.068699 & 6 \\
& 3 & 69 & 411 & 0.595718 & 12 & 907 & 4193 & 8.174117 & 12 \\
& 4 & 577 & 3644 & 20.874021 & 20 & 22993 & 100704 & 786.988453 & 20 \\
\hline \hline Statman & 1 & 1 & 5 & 0.000173 & 0 & 1 & 5 & 0.000173 & 0 \\
& 2 & 7 & 48 & 0.007948 & 2 & 7 & 49 & 0.012063 & 2 \\
& 3 & 39 & 231 & 0.095406 & 4 & 67 & 437 & 0.303217 & 4 \\
& 4 & 157 & 890 & 0.819562 & 6 & 777 & 5130 & 7.793823 & 6 \\
\hline
\end{tabular}

Tabela 5.5: Teste do método de tableaux KE- $S_{3}$ com a heurística da distância.

Novamente, a heurística da distância não melhora em nenhum dos casos o desempenho do algoritmo.

A Tabela 5.6 mostra o resultado dos testes Gamma com fórmulas irrelevantes para o tableau $\mathrm{KE}-S_{3}$ com a heurística $S P_{i}$ e a heurística $P B_{i}$, e a Tabela 5.7 mostra os resultados das heurísticas em conjunção com a heurística da distância.

A família de testes é a seguinte:

$$
c_{1} \vee d_{1}, \Delta_{n}, a_{1} \vee b_{1}, \Gamma_{n} \vdash a_{n+1} \vee b_{n+1}
$$

onde

$$
\begin{aligned}
& \Delta_{n}=\bigcup_{i=1}^{n}\left\{\neg c_{i} \vee\left(c_{i+1} \vee d_{i+1}\right), \neg d_{i} \vee\left(c_{i+1} \vee d_{i+1}\right)\right\} \\
& \Gamma_{n}=\bigcup_{i=1}^{n}\left\{\neg a_{i} \vee\left(a_{i+1} \vee b_{i+1}\right), \neg b_{i} \vee\left(a_{i+1} \vee b_{i+1}\right)\right\}
\end{aligned}
$$

Note que as fórmulas irrelevantes atrapalham a prova (comparar os tempos de execução com os tempos da Tabela 5.4), e quando usamos $P B_{i}$ sem a heurística da 


\begin{tabular}{|r||r|r|r|r||r|r|r|r|}
\hline \multicolumn{1}{|c||}{} & \multicolumn{4}{c||}{ KE- $_{3}$} & \multicolumn{4}{|c|}{ KE- $S_{3}+\mathrm{PB}$} \\
\hline$n$ & \#nós & \#fmls & $\mathrm{T}(\mathrm{s})$ & $|S|$ & \#nós & \#fmls & $\mathrm{T}(\mathrm{s})$ & $|S|$ \\
\hline \hline 1 & 19 & 56 & 0.028246 & 2 & 39 & 102 & 0.048521 & 4 \\
2 & 45 & 132 & 0.131016 & 4 & 145 & 403 & 0.373984 & 8 \\
3 & 73 & 214 & 0.292364 & 6 & 429 & 1184 & 1.923869 & 12 \\
4 & 209 & 576 & 1.228155 & 8 & 1965 & 5310 & 14.347284 & 16 \\
5 & 293 & 820 & 2.234904 & 10 & 5395 & 14539 & 50.660406 & 20 \\
6 & 841 & 2268 & 8.295132 & 12 & 29309 & 78401 & 361.697747 & 24 \\
\hline
\end{tabular}

Tabela 5.6: Teste do método de tableaux $\mathrm{KE}-S_{3}$ com fórmulas irrelevantes, sem a heurística da distância.

\begin{tabular}{|r||r|r|r|r||r|r|r|r|}
\hline \multicolumn{1}{|c||}{} & \multicolumn{4}{c||}{${\mathrm{KE}-S_{3}}$} & \multicolumn{4}{|c|}{ KE- $S_{3}+\mathrm{PB}$} \\
\hline$n$ & \#nós & \#fmls & $\mathrm{T}(\mathrm{s})$ & $|S|$ & \#nós & \#fmls & $\mathrm{T}(\mathrm{s})$ & $|S|$ \\
\hline \hline 1 & 9 & 31 & 0.022876 & 2 & 15 & 48 & 0.062565 & 2 \\
2 & 23 & 77 & 0.163566 & 4 & 55 & 152 & 0.332533 & 4 \\
3 & 63 & 205 & 1.069044 & 6 & 137 & 372 & 1.650295 & 6 \\
4 & 169 & 538 & 5.502665 & 8 & 313 & 868 & 7.334279 & 8 \\
5 & 455 & 1438 & 27.214882 & 10 & 689 & 1979 & 30.051540 & 10 \\
6 & 1277 & 4029 & 125.476909 & 12 & 1609 & 4782 & 124.422070 & 12 \\
\hline
\end{tabular}

Tabela 5.7: Teste do método de tableaux $\mathrm{KE}-S_{3}$ com fórmulas irrelevantes e com a heurística da distância.

distância, o método adiciona átomos irrelevantes ao conjunto-contexto $S$, enquanto que com o uso da distância, nenhuma das duas heurísticas adiciona átomos irrelevantes ao conjunto-contexto $S$. Além disso, em nenhum dos testes executados, a heurística $P B_{i}$, que adia as aplicações da regra $(T \neg)$, é melhor. Isso se deve ao fato de o adiamento dessas aplicações obrigar o adiamento da análise de outras fórmulas, o que pode gerar bifurcações do tableau que com a outra heurística não ocorreriam.

No Apêndice B são exibidos os gráficos dos resultados dos testes. 


\section{Capítulo 6}

\section{Conclusão}

Vimos que a escolha da heurística que define a ordem de aplicação das regras de um método de tableaux é um passo crucial no desenvolvimento de um tal método. Observamos na prática o fato provado por D'Agostino [D'A90] que os tableaux KE são mais eficientes que os tableaux analíticos. Além disso, a heurística da polaridade para a escolha da fórmula sobre a qual se aplica a regra PB é a melhor heurística dentre as implementadas, pois aproveita a estrutura das regras de expansão. Finạlmente, descobrimos uma heurística baseada na noção de relevância local que impede a análise de fórmulas totalmente irrelevantes para a prova. No entanto, essa heurística não apresenta nenhuma vantagem quando todos os átomos ocorrentes nas fórmulas são relevantes. Vale lembrar que a heurística pode ser enganada por outros testes. Por exemplo, pode-se forjar um teste com pelo menos uma fórmula que contenha um átomo relevante para a prova e um átomo irrelevante. Na prática o que se pode fazer é adaptar uma heurística de acordo com o conhecimento da aplicação onde o método é aplicado.

Pela análise dos resultados, observamos que o uso da heurística $P B_{i}$, que adia o aumento do conjunto-contexto $S$ leva à pior performance, enquanto que o uso da heurística $S P_{i}$ torna as provas do Tableau KE- $S_{3}$ iguais às provas do Tableau KE, a menos da informação adicional do conjunto-contexto $S$ nos passos intermediários da resolução do tableau. Em outras palavras, o Tableau KE- $S_{3}$ não exibe um ganho de performance se comparado ao Tableau KE.

Em [FW02a], Finger e Wassermann analisam as perdas e ganhos do sistema KE$S_{3}$ com relação ao sistema original $S_{3}$ de Cadoli e Schaerf, e concluíram que, apesar de o sistema $\mathrm{KE}-S_{3}$ ser mais expressivo (admite mais teoremas que o sistema original 
com um mesmo conjunto-contexto $S$ ), exibe menos controle. Então, eles propõem uma generalização $\mathrm{KE}-S_{e}$ de $\mathrm{KE}-S_{3}$ que apresenta vários conjuntos-contexto, um para cada regra de expansão. Cada regra pode ter um custo diferente, e resta determinar esses custos para cada aplicação específica.

Existem trabalhos sendo feitos [FW02b] sobre a viabilidade de desenvolvimento de um sistema de tableaux para a lógica $S_{1}$, o que permitiria desenvolver um sistema de raciocínio por aproximações próximo ao de Cadoli e Schaerf totalmente baseado em sistemas de tableaux. 


\section{Apêndice A}

\section{Manual do Usuário do Arcabouço para Métodos de Tableau}

A Figura A.1 mostra um esquema detalhado do arcabouço para méto-dos de tableau. As classes principais do arcabouço estão representadas na figura.

Nas seções a seguir será explicado o funcionamento de cada uma das classes apresentadas na figura.

\section{A.1 Classe Formula}

A classe Formula encapsula a fórmula da lógica proposicional. A declaração da classe Formula é mostrada na Figura A.2.

\section{A.1.1 enum opType}

A enumeração opType tem como elementos os tipos de operadores que podem ocorrer em uma fórmula.

O valor AND representa o operador binário de conjunção $\wedge$. O valor ANDN representa o operador $n$-ário de conjunção $\wedge$. O valor OR re-presenta o operador binário de disjunção $\vee$. O valor ORN representa o operador $n$-ário de disjunção $\vee$. O valor IMPLIES representa o ope-rador de implicação $\rightarrow$. O valor NOT representa o operador unário de negação $\neg$. O valor ATOM é um valor especial, indicando que a fórmula onde ele ocorre é atômica. 


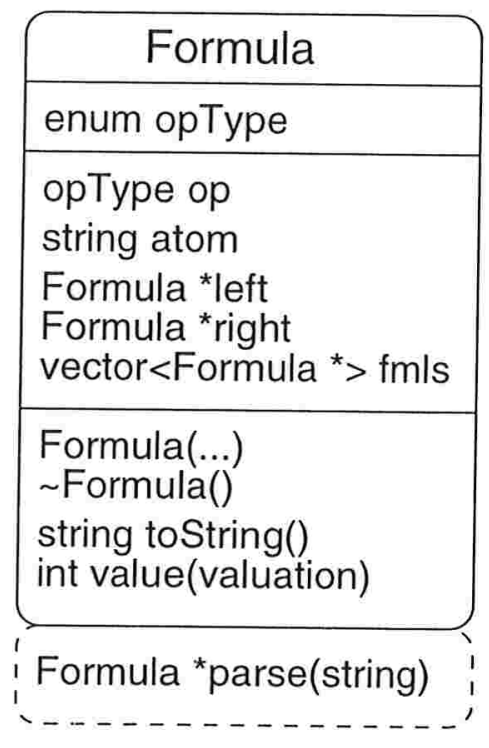

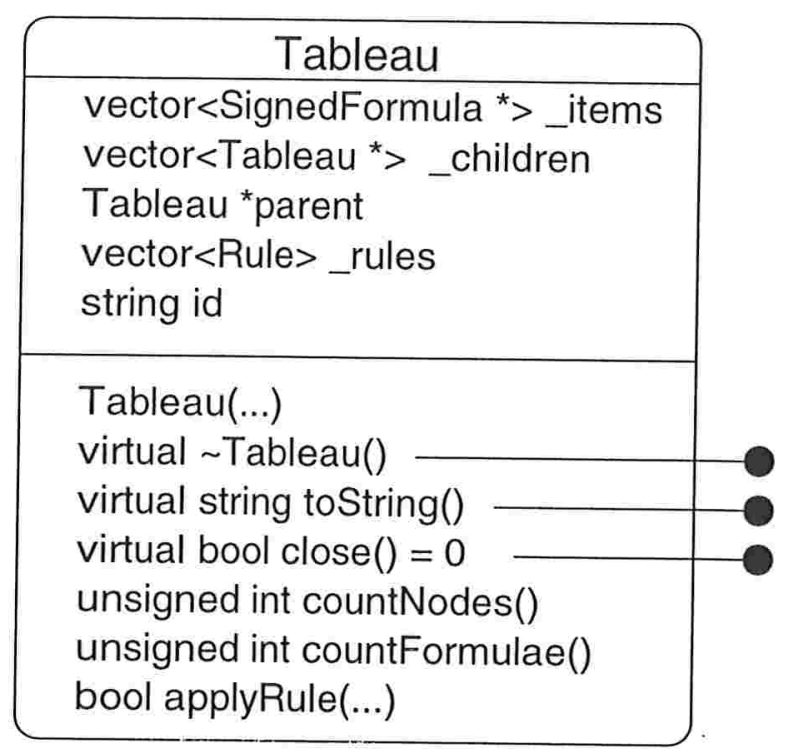

\begin{tabular}{|l|}
\hline \multicolumn{1}{|c|}{ SignedFormula } \\
\hline $\begin{array}{l}\text { enum Sign } \\
\text { enum fmlType }\end{array}$ \\
\hline $\begin{array}{l}\text { Sign sign } \\
\text { Formula *fml } \\
\text { fmlType ty }\end{array}$ \\
\hline $\begin{array}{l}\text { SignedFormula(...) } \\
\text { fmlType type() } \\
\text { string toString() } \\
\text { int value(valuation) }\end{array}$ \\
\hline
\end{tabular}

\begin{tabular}{|c|}
\hline TableauStrategy \\
\hline $\begin{array}{l}\text { string id } \\
\text { vector }<\text { SignedFormula * }>\text { _items } \\
\text { vector }<\text { SignedFormula * }>\text { _alphas } \\
\text { vector }<\text { SignedFormula * }>\text { _betas } \\
\text { vector }<\text { SignedFormula * }>\text { _lits } \\
\text { map }<\text { string, int }>\text { _mlits }\end{array}$ \\
\hline $\begin{array}{l}\text { TableauStrategy(...) } \\
\text { bool init(id, items, alphas, betas, lits) } \\
\text { bool classify(index) } \\
\text { virtual unsigned int chooseAlpha() }\end{array}$ \\
\hline $\begin{array}{l}\text { virtual unsigned int chooseBeta() } \\
\text { virtual int nextRule() }=0\end{array}$ \\
\hline
\end{tabular}

Figura A.1: Classes componentes do arcabouço para métodos de tableau. 


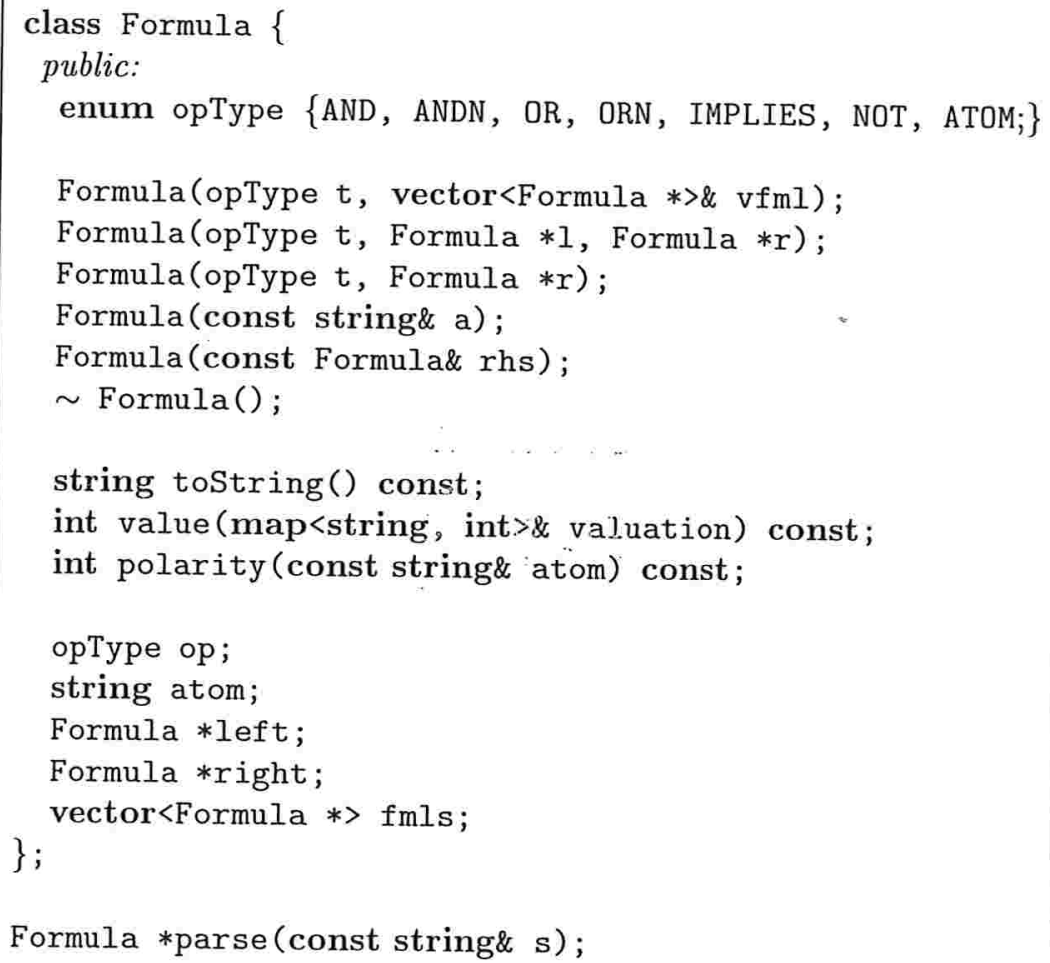

Figura A.2: Declaração da classe Formula. 


\section{A.1.2 Construtores e destrutor}

O construtor

Formula (opType $t$, vector $<$ Formula $*>\&$ vfml)

é o construtor para fórmulas de conjunção e disjunção $n$-ária (portanto, apenas para $t=A N D N$ ou $t=O R N)$. Armazena os operandos no vetor membro fmls. Para uma fórmula construída a partir deste construtor, os membros atom, left e right não têm significado e podem ser ignorados.

O construtor

Formula(opType t, Formula $* 1$, Formula $* r$ )

é o construtor para fórmulas de conjunção, disjunção e implicação binárias (portanto, apenas para $t=A N D, t=O R$ ou $t=I M P L I E S)$. Armazena os operandos nos ponteiros membro left e right. Para uma fórmula construída a partir deste construtor, os membros atom e fmls não têm significado e podem ser ignorados.

O construtor

Formula (opType t, Formula $*$ is)

é o construtor para fórmulas de negação (portanto, apenas para $t=N O T$ ). Armazena o operando no ponteiro membro right. Para uma fórmula construída a partir deste construtor, os membros atom, left e fmls não têm significado e podem ser ignorados.

O construtor

Formula (const string\& a)

é o construtor para fórmulas atômicas (portanto, apenas para $t=A T O M$ ). Armazena o átomo na string membro atom. Para uma fórmula construída a partir deste construtor, os membros left, right e fmls não têm significado e podem ser ignorados.

O destrutor da classe é responsável pela destrução (liberação de memória) dos objetos Formula correspondentes às subfórmulas. 


\section{A.1.3 string toString() const}

O método toString () retorna a representação em caracteres da fórmula, com todos os parênteses para evitar ambigüidades.

\section{A.1.4 int value (map<string, int $>\&$ valuation) const}

Dada uma valoração para os átomos valuation, o método value() retorna:

- -1 , se o valor da fórmula é indefinido segundo a valoração valuation;

- 0, se o valor da fórmula é falso segundo a valoração;

- 1 , se o valor da fórmula é verdadeiro segundo a valoração.

\section{A.1.5 int polarity(const string\& atom) const}

Dado um átomo atom, o método polarity () retorna a polaridade da(s) ocorrência(s) de atom dentro da fórmula. Retorna:

- -1 , se não houver nenhuma ocorrência de atom na fórmula;

- 0 , se há apenas ocorrências de polaridade negativa de atom na fórmula;

- 1, se há apenas ocorrências de polaridade positiva de atom na fórmula;

- 2, se há ocorrências de polaridade positiva e negativa.

\section{A.1.6 Formula *parse (const string\& s)}

Esta função auxiliar faz o parsing de uma string que representa uma fórmula. A fórmula, e todas as suas subfórmulas exceto os átomos, devem estar entre parênteses. A função retorna um apontador para uma área recém-alocada onde está o objeto Formula representado pela string, ou um apontador nulo se a string não for uma fórmula válida. 


\section{A.2 Classe SignedFormula}

A classe SignedFormula encapsula a fórmula assinalada, usada em todos os métodos de tableau do projeto. A declaração da classe SignedFormula é mostrada na Figura A.3.

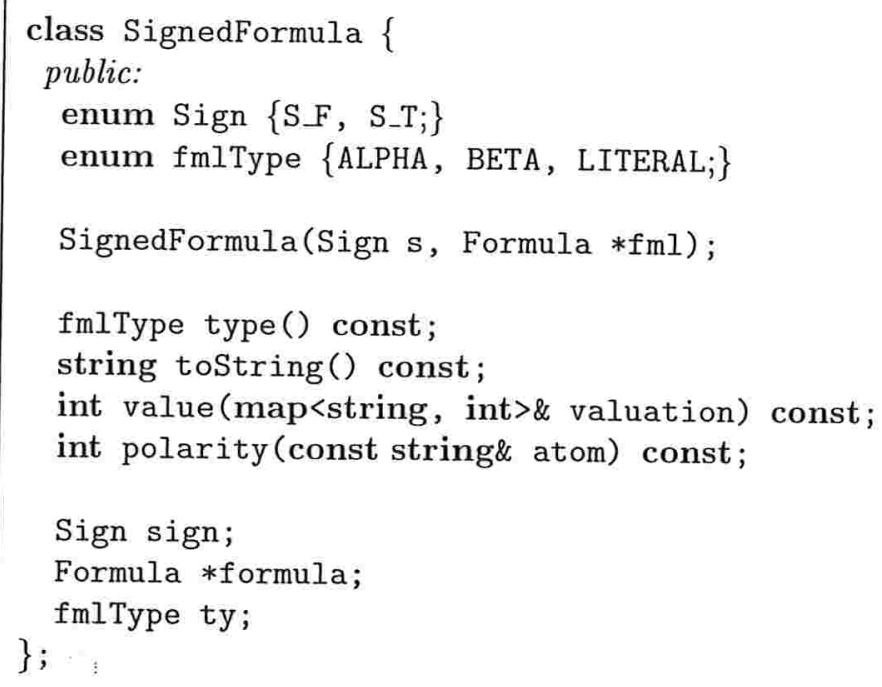

Figura A.3: Declaração da classe SignedFormula.

\section{A.2.1 enum Sign}

A enumeração Sign tem como elementos os dois rótulos possíveis para uma fórmula assinalada: $F$ (valor S_F) e $T$ (valor S_T).

\section{A.2.2 enum fmlType}

A enumeração fmlType tem como elementos os tipos de fórmulas assinaladas: fórmulas $\alpha$ (valor ALPHA), $\beta$ (valor BETA) e fórmulas literais (valor LITERAL).

\section{A.2.3 Construtor}

O construtor

SignedFormula(Sign s, Formula *fml); 
constrói uma fórmula assinalada com rótulo s (armazenado no campo sign). A fórmula proposicional é armazenada no campo formula.

\section{A.2.4 fmlType type() const}

Este método retorna o tipo da fórmula assinalada ( $\alpha, \beta$ ou literal).

\section{A.2.5 string toString() const}

Este método retorna a representação em caracteres da fórmula assinalada.

\section{A.2.6 int value (map<string, int $>\&$ valuation) const}

Este método é similar ao método Formula: : value(), e incorpora a semântica do rótulo da fórmula já discutida anteriormente.

\section{A.2.7 int polarity(const string\& atom) const}

Este método é similar ao método Formula: : polarity(), e incorpora a semântica de rótulo da fórmula já discutida anteriormente.

\section{A.3 Classe Tableau}

A classe Tableau encapsula um método de tableau. A declaração da classe Tableau é mostrada na Figura A.4.

\section{A.3.1 Construtores e destrutor}

O construtor

Tableau(const string\& id, SignedFormula $* \mathrm{fml}$, Tableau $*$ parent $=$ NULL)

constrói um objeto tableau a partir de uma única fórmula fml. É necessário fornecer um identificador para o tableau (id), e se o tableau não for raiz (se for um subtableau de um outro tableau), deve-se fornecer um apontador para o tableau- 


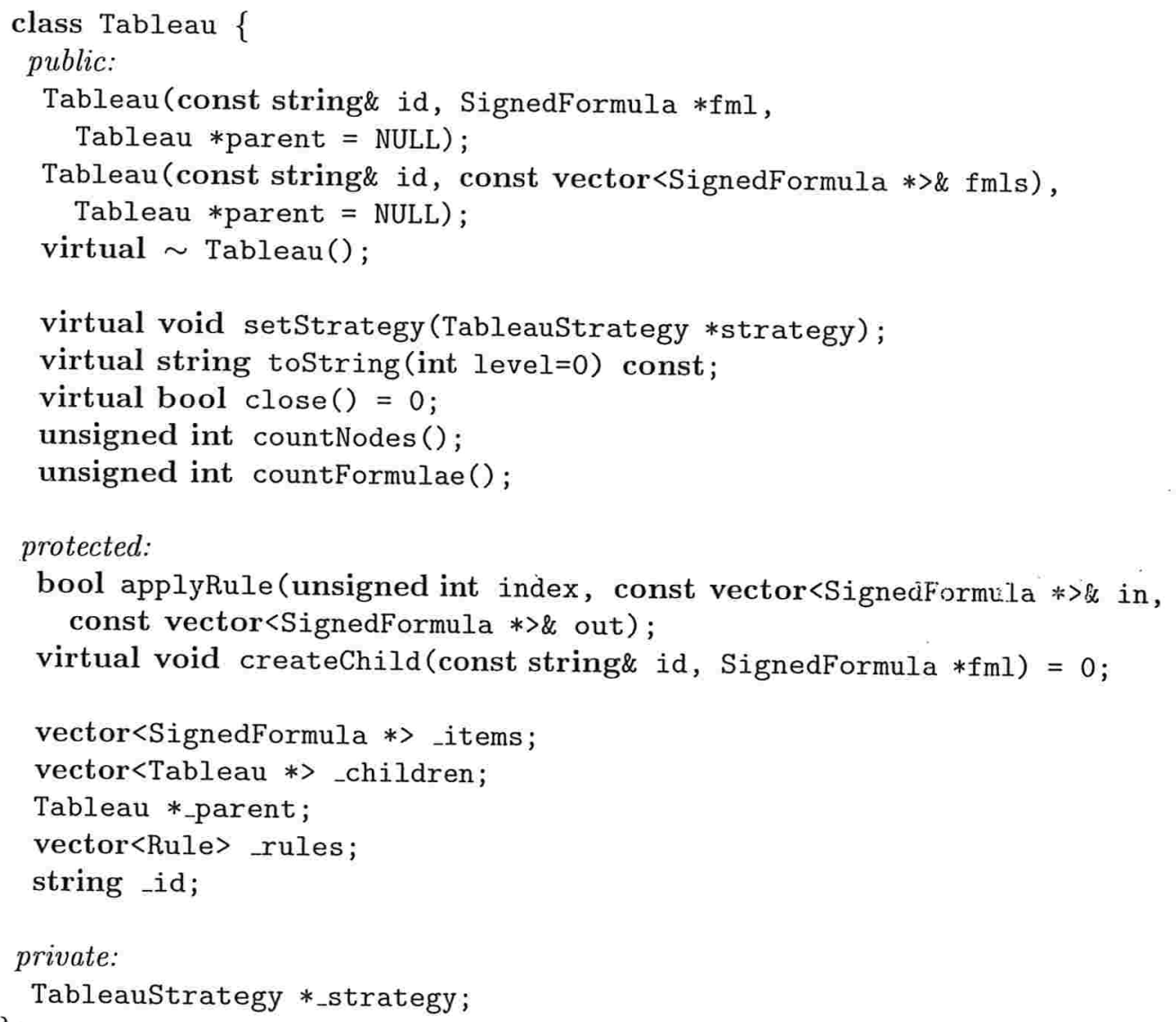

Figura A.4: Declaração da classe Tableau. 
pai (parent). Este construtor é normalmente utilizado para a construção de subtableaux. Vide a subseção A.3.8.

O construtor

Tableau (const string\& id, const vector $<$ SignedFormula $*>$ \& fmls),

Tableau $*$ parent $=$ NULL)

constrói um objeto tableau a partir de um vetor de fórmulas (fmls). Este construtor é normalmente utilizado para a construção do tableau-raiz.

O destrutor deve ser responsável pela dealocação dos objetos alocados dinamicamente pela classe.

\section{A.3.2 virtual void setStrategy(TableauStrategy *strategy)}

Este método inicializa o membro _strategy, que é um apontador para o objeto que contém a estratégia do método de tableau. A classe TableauStrategy é discutida em detalhes na seção A.4.

\section{A.3.3 virtual string toString(int level=0) const}

Este método retorna a representação em caracteres do tableau. Como padrão, essa representação é a concatenação da representação de todas as fórmulas do tableau (armazenadas no vetor_items). Este método é virtual porque cada implementação de tableau pode dar uma representação em caracteres diferente (como é o caso da classe KES3Tableau, que inclui os conjuntos-contexto $S$ na representação).

\section{A.3.4 virtual bool $\operatorname{close}()=0$}

Este é um método virtual puro, ou seja, não tem implementação na classe Tableau. Cada implementação de tableau deve dar a implementação mais conveniente.

A regra geral para a implementação deste método é:

- no construtor, chamar o método setStrategy (), e depois o método_strategy-> init() para inicializar o objeto;

- no método close(): 
- chamar o método _strategy->classify() para classificar as fórmulas ainda não classificadas do tableau;

- chamar o método_strategy->nextRule() para descobrir a próxima fórmula a ser analisada;

- tratar o valor de retorno de _strategy->nextRule() apropriadamente, com os métodos_strategy->chooseAlpha() e _strategy->chooseBeta().

- repetir o processo até que se feche o tableau, ou que não haja mais fórmulas a serem analisadas.

\section{A.3.5 unsigned int countNodes()}

Retorna o número total de nós gerados a partir deste tableau. Este método é normalmente chamado a partir do tableau-raiz.

\section{A.3.6 unsigned int countFormulae()}

Retorna o número total de fórmulas geradas a partir deste tableau. Este método é normalmente chamado a partir do tableau-raiz.

\section{A.3.7 bool applyRule(unsigned int index, const vector $<$ SignedFormula $*>\&$ in, const vector $<$ SignedFormula $*>$ \& out)}

As regras de tableau são armazenadas no vetor _rules, que é um vetor de apontadores para função do seguinte tipo:

typedef bool ( $*$ Rule) (const vector $<$ SignedFormula $*>\&$, vector $<$ SignedFormula $*>$ \&)

ou seja, uma regra é uma função que recebe dois vetores de fórmulas assinaladas e retorna um bool. O primeiro parâmetro é o vetor com as premissas da regra. As premissas devem ser fornecidas em ordem: o primeiro elemento deve ser a premissa primária, e o segundo, a premissa secundária (se houver). O segundo parâmetro é o vetor com as conclusões da regra. A função retorna true se a aplicação da regra é bem-sucedida, e false, caso contrário.

O vetor de regras _rules deve ser inicializado na construção do tableau. 
O método applyRule() recebe o índice da regra a ser aplicada no vetor _rules, e as premissas e conclusões da regra, e procede à aplicação desta regra.

\section{A.3.8 virtual void createChild(const string\& id, SignedFormula $* \mathrm{fml})=0$}

Este método é responsável pela criação de subtableaux. Recebe o identificador do novo tableau, e a nova fórmula a ser incluída nele. É geralmente utilizado na bifurcação do tableau.

Note que este é um método virtual puro, sendo cada classe derivada responsável pela sua implementação.

\section{A.4 Classe TableauStrategy}

A classe TableauStrategy encapsula uma estratégia para um método de tableau. A declaração da classe TableauStrategy é mostrada na Figura A.5.

\section{A.4.1 bool init(const string\& cab!eau_id, vector $\langle$ SignedFormula $*>$. *items, vector $\langle$ SignedFormula $*>* a l$ phas, vector $\langle$ SignedFormula $*>$ *betas, vector $<$ SignedFormula $*>*$ lits)}

Este método faz a inicialização dos membros _items, _alphas, _betas e _lits. É geralmente chamado no construtor do tableau, e recebe como parâmetros os membros correspondentes do tableau.

Além disso, inicializa o membro mlits, que faz a manutenção dos literais do tableau. Para um átomo $\mathrm{x}$,

- se o tableau tem uma fórmula assinalada $F x$, então $\operatorname{mlits}[\mathrm{x}]=1$;

- se o tableau tem uma fórmula assinalada $T x$, então $\operatorname{mlits}[\mathrm{x}]=2$;

- se o tableau tem $F x$ e $T x$, então $\operatorname{mlits}[\mathrm{x}]=3$.

Retorna true se o tableau está fechado, ou seja, se para algum átomo x, .mlits [x] $=3$. 


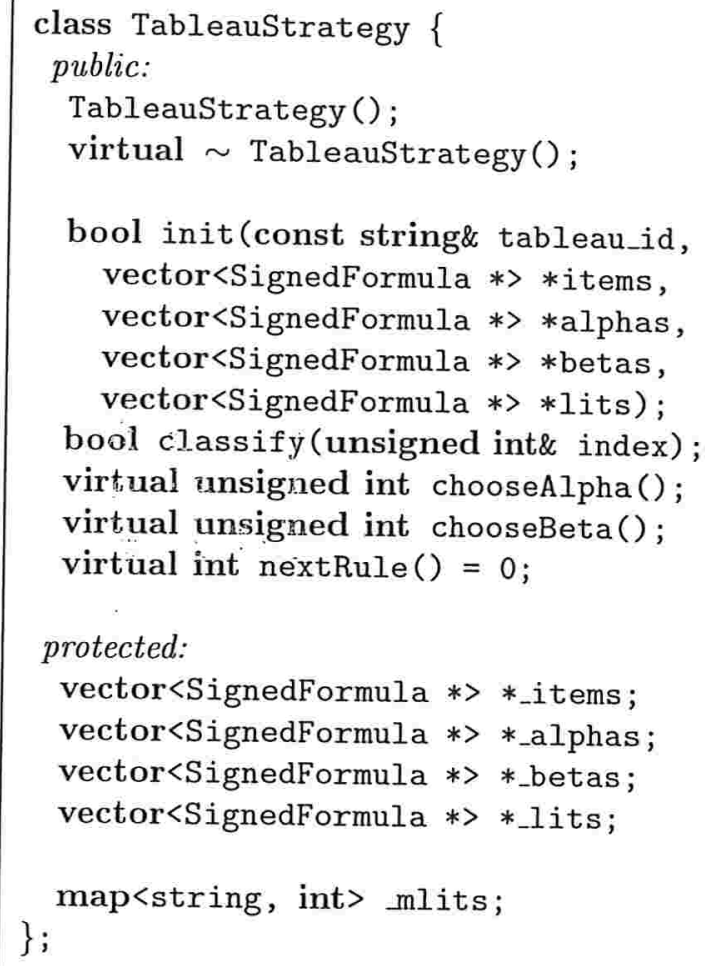

Figura A.5: Declaração da classe TableauStrategy. 


\section{A.4.2 bool classify(unsigned int\& index)}

Este método faz a classificação das fórmulas no vetor _items. Coloca as fórmulas do tipo $\alpha$ no vetor_alphas, as fórmulas do tipo $\beta$ no vetor _betas, e os literais no vetor _lits. Retorna true se o tableau estiver fechado.

O parâmetro index indica a partir de que posição do vetor _items a classificação será feita. Isto evita que chamadas consecutivas deste método reclassifiquem fórmulas que já foram classificadas.

\section{A.4.3 virtual unsigned int chooseAlpha()}

Retorna o índice no vetor _alphas da próxima fórmula $\alpha$ a ser escolhida. Este método é virtual porque cada estratégia pode ter uma maneira diferente de escolher a próxima fórmula.

\section{A.4.4 virtual unsigned int chooseBeta()}

Retorna o índice no vetor betas da próxima fórmula $\beta$ a ser escolhida. Este método é virtual porque cada estratégia pode ter uma maneira diferente de escolher a próxima fórmula. ${ }^{1}$

\section{A.4.5 virtual int nextRule ()$=0$}

Este método indica qual a próxima regra a ser aplicada. O padrão para o valor de retorno é:

- -1 , se não houver nenhuma regra a ser aplicada;

- 0, se for uma regra com uma premissa (aplicável sobre fórmula $\alpha$ );

- 1, se for uma regra com duas premissas (aplicável sobre fórmula $\beta$ ).

Valores de retorno maiores que 1 podem ser usados nas classes derivadas (como, por exemplo, na classe KEStrategy, que utiliza o valor 2 para aplicação do Princípio da Bivalência). ${ }^{2}$

\footnotetext{
${ }^{1} \mathrm{Na}$ classe KEStrategy e derivadas, além do método chooseBeta(), existe o método chooseLit(), que retorna o índice no vetor lits do literal que será usado como premissa secundária da regra.

${ }^{2} \mathrm{Na}$ classe KEStrategy, existe o método choosePB(), que retorna uma fórmula sobre a qual será aplicado o Princípio da Bivalência.
} 
É um método virtual puro. Cada classe derivada deve dar a sua implementação. 


\section{Apêndice B}

\section{Gráficos}

Neste apêndice são exibidos os gráficos correspondentes a cada um dos testes realizados.

Para cada um dos testes temos dois gráficos: o primeiro mostra o número de nós gerados e o segundo mostra o número de fórmulas geradas.

Os gráficos são:

1. Gamma (nodes): na abscissa, o número do caso de teste Gamma; na ordenada, o número de nós gerados para o teste;

2. Gamma (formulae): na abscissa, o número do caso de teste Gamma; na ordenada, o número de fórmulas geradas para o teste;

3. H (nodes): na abscissa, o número do caso de teste $\mathrm{H}$; na ordenada, o número de nós gerados para o teste;

4. H (formulae): na abscissa, o número do caso de teste $\mathrm{H}$; na ordenada, o número de fórmulas geradas para o teste;

5. PHP (nodes): na abscissa, o número do caso de teste PHP; na ordenada, o número de nós gerados para o teste;

6. PHP (formulae): na abscissa, o número do caso de teste PHP; na ordenada, o número de fórmulas geradas para o teste;

7. Statman (nodes): na abscissa, o número do caso de teste Statman; na ordenada, o número de nós gerados para o teste; 
8. Statman (formulae): na abscissa, o número do caso de teste Statman; na ordenada, o número de fórmulas geradas para o teste;

9. Gamma clausal (nodes): na abscissa, o número do caso de teste Gamma na forma clausal; na ordenada, o número de nós gerados para o teste;

10. Gamma clausal (formulae): na abscissa, o número do caso de teste Gamma na forma clausal; na ordenada, o número de fórmulas geradas para o teste;

11. H clausal (nodes): na abscissa, o número do caso de teste $\mathrm{H}$ na forma clausal; na ordenada, o número de nós gerados para o teste;

12. H clausal (formulae): na abscissa, o número do caso de teste $\mathrm{H}$ na forma clausal; na ordenada, o número de fórmulas geradas para o teste;

13. PHP clausal (nodes): na abscissa, o número do caso de teste PHP na forma clausal; na ordenada, o número de nós gerados para o teste;

14. PHP clausal (formulae): na abscissa, o número do caso de teste PHP na forma clausal; na ordenada, o número de fórmulas geradas para o teste;

15. Statman clausal (nodes): na abscissa, o número do caso de teste Statman na forma clausal; na ordenada, o número de nós gerados para o teste;

16. Statman clausal (formulae): na abscissa, o número do caso de teste Statman na forma clausal; na ordenada, o número de fórmulas geradas para o teste;

17. Gamma clausal w/ irrelevant formulae (nodes): na abscissa, o número do caso de teste Gamma na forma clausal com fórmulas irrelevantes; na ordenada, o número de nós gerados para o teste;

18. Gamma clausal w/ irrelevant formulae (formulae): na abscissa, o número do caso de teste Gamma na forma clausal com fórmulas irrelevantes; na ordenada, o número de fórmulas geradas para o teste.

19. Gamma clausal w/ irrelevant formulae w/ distance (nodes): na abscissa, o número do caso de teste Gamma na forma clausal com fórmulas irrelevantes; na ordenada, o número de nós gerados para o teste com a heurística da distância;

20. Gamma clausal w/ irrelevant formulae w/ distance (formulae): na abscissa, o número do caso de teste Gamma na forma clausal com fórmulas irrelevantes; 
na ordenada, o número de fórmulas geradas para o teste com a heurística da distância. 

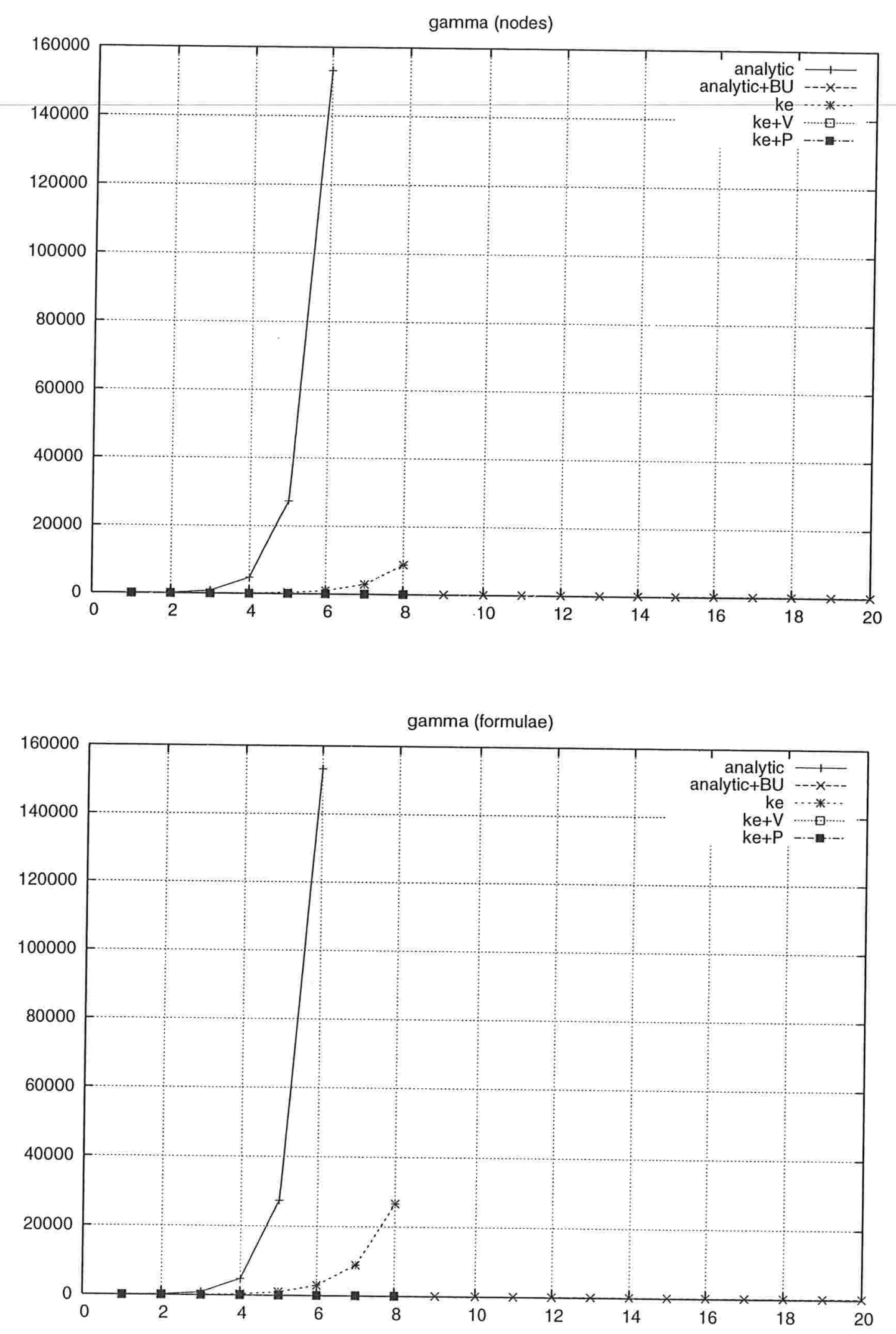

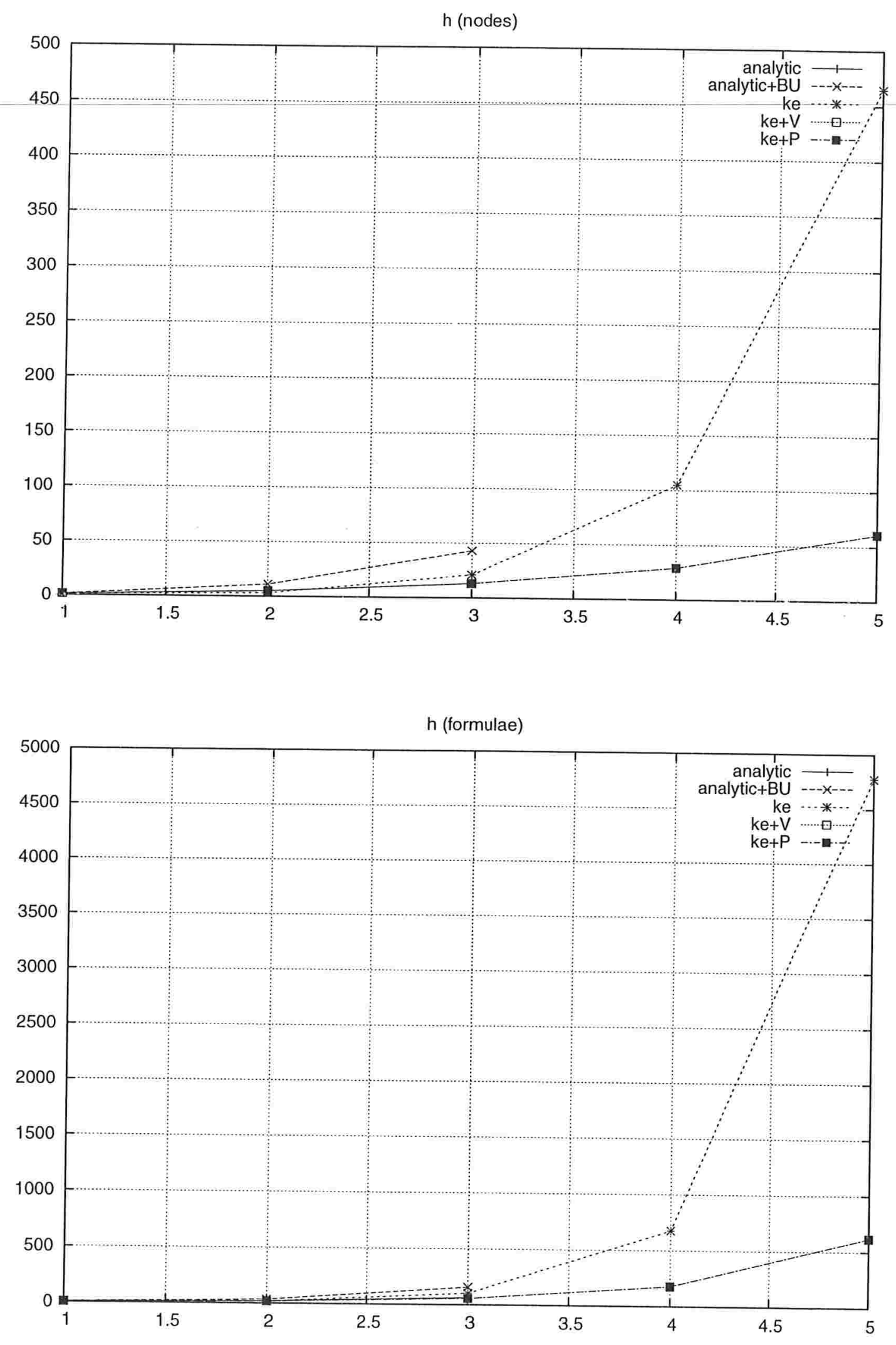

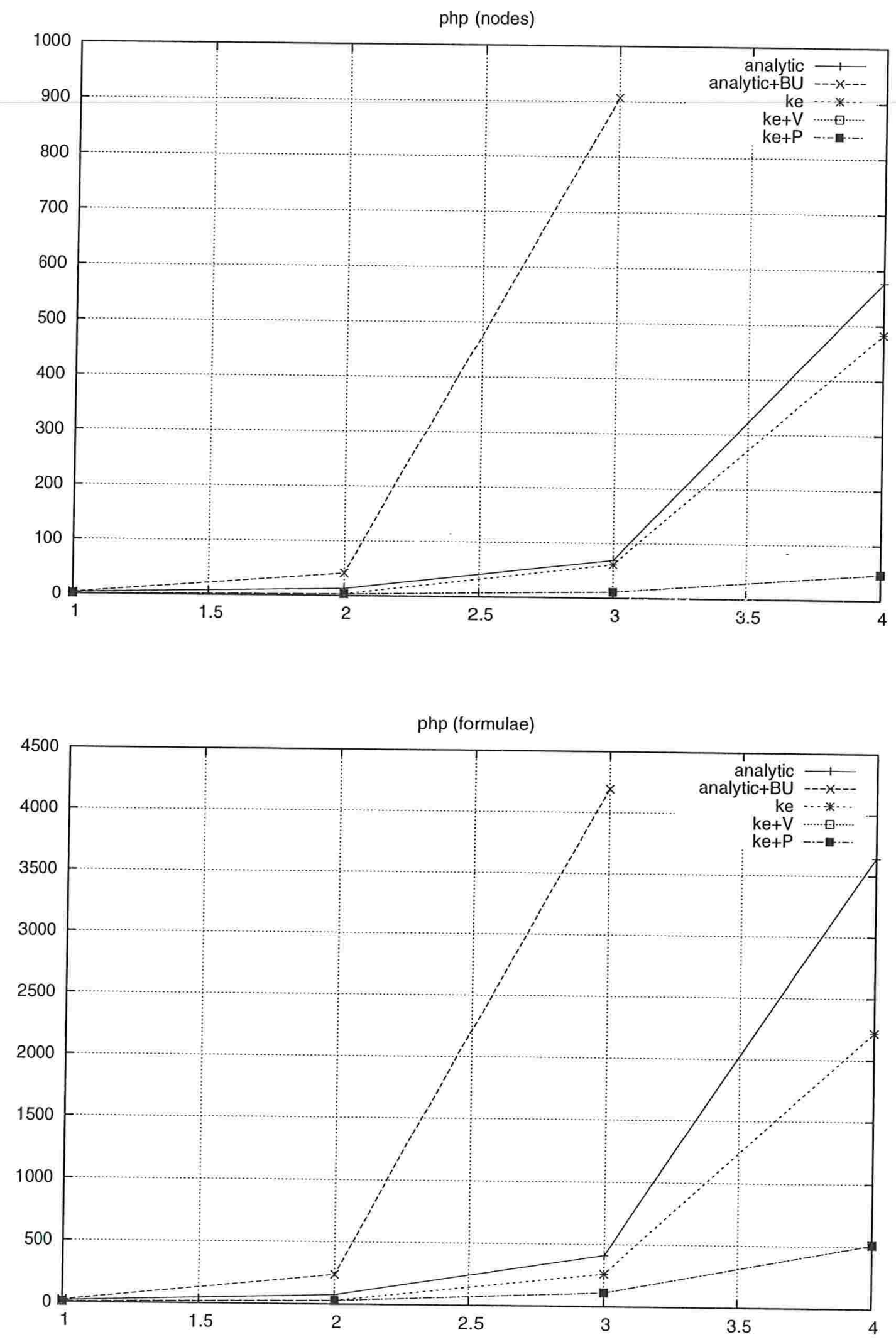


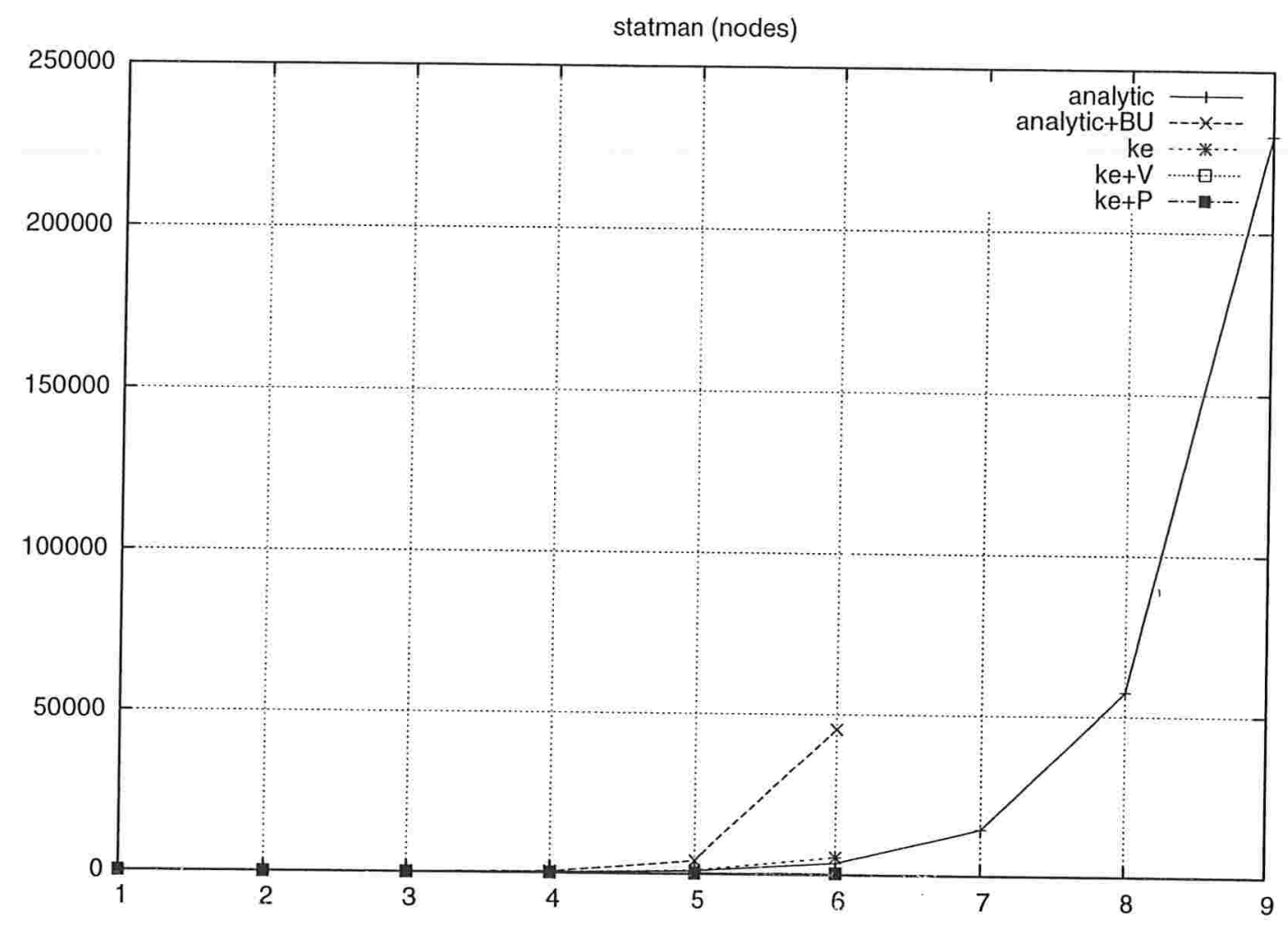

statman (formulae)

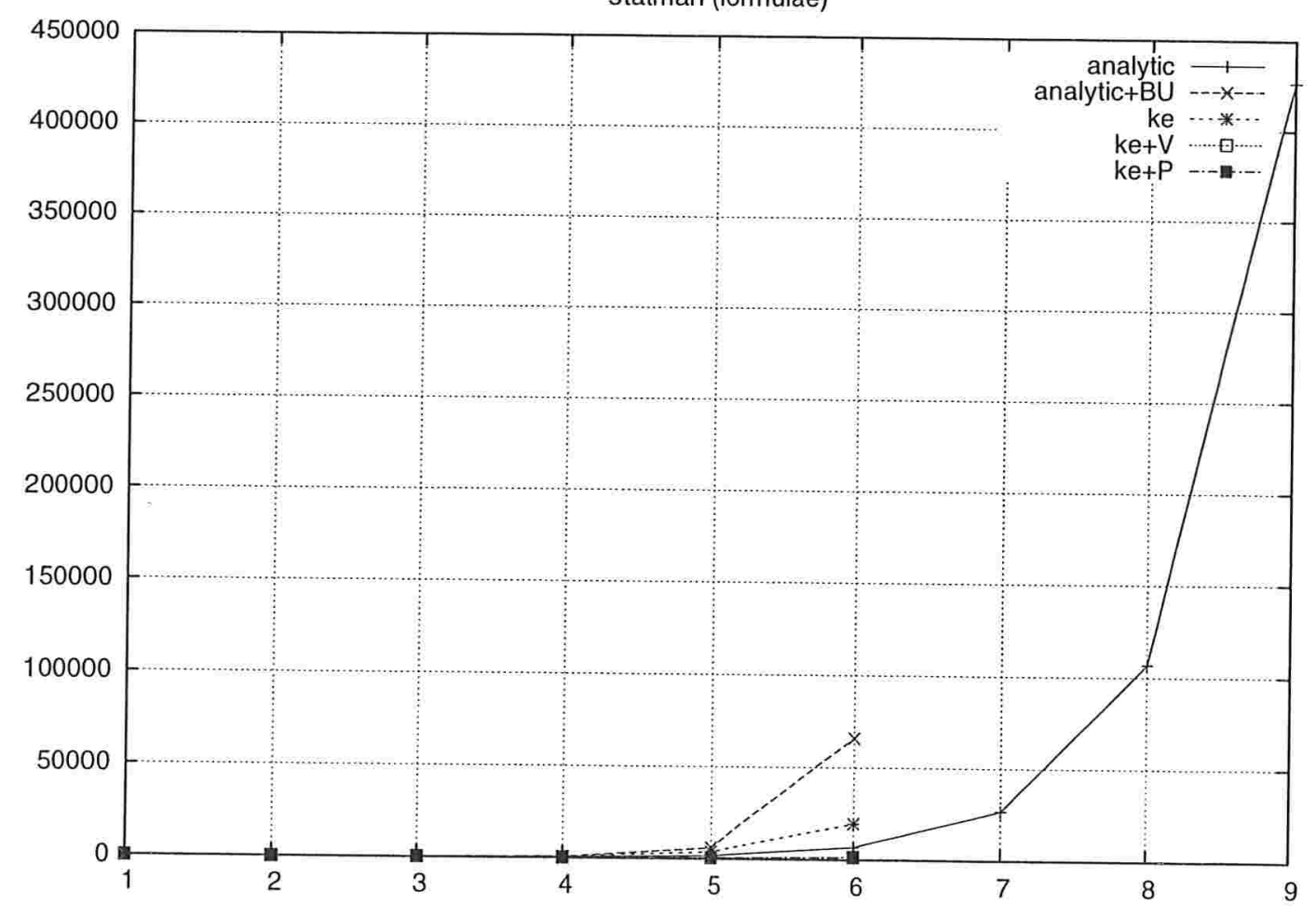



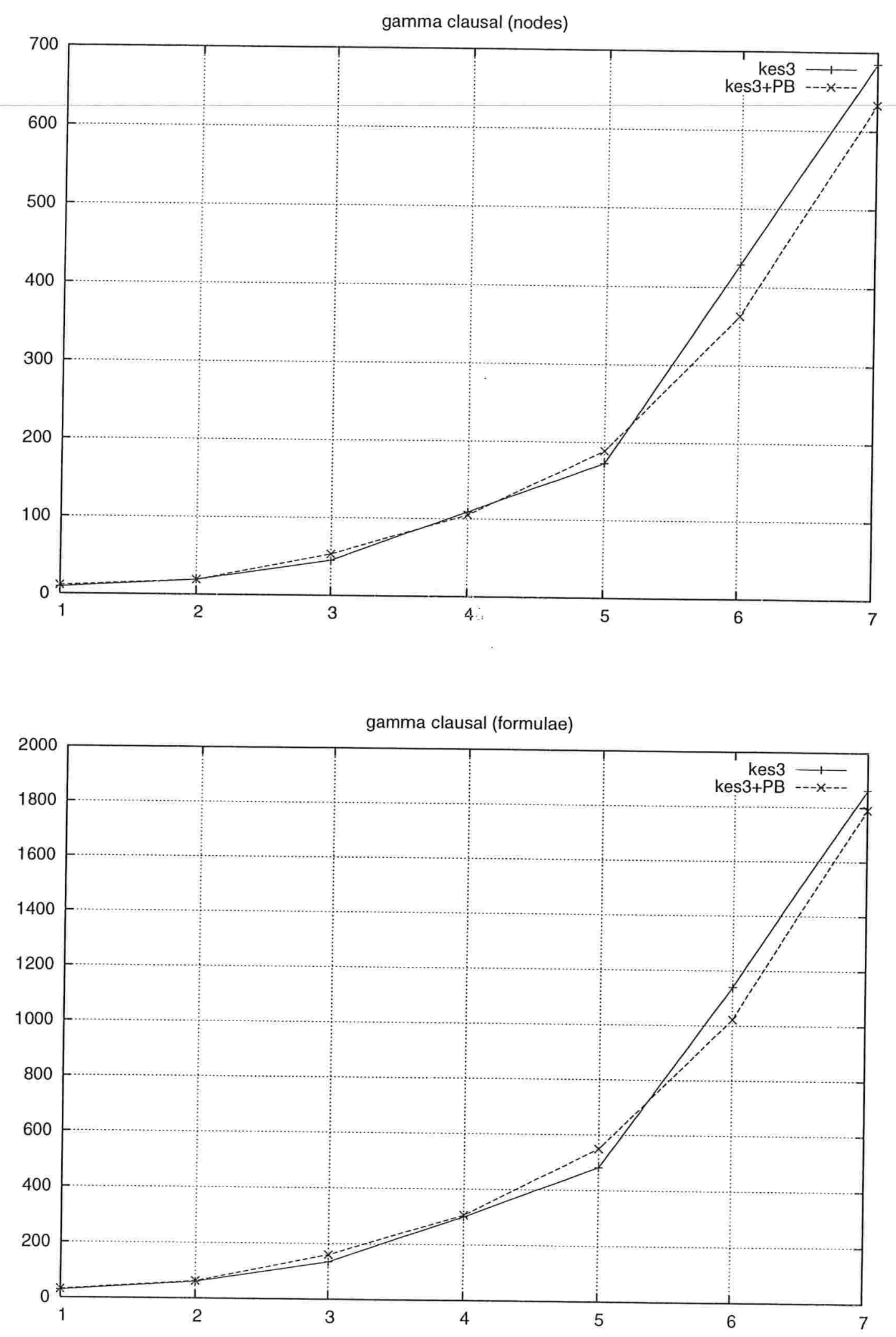

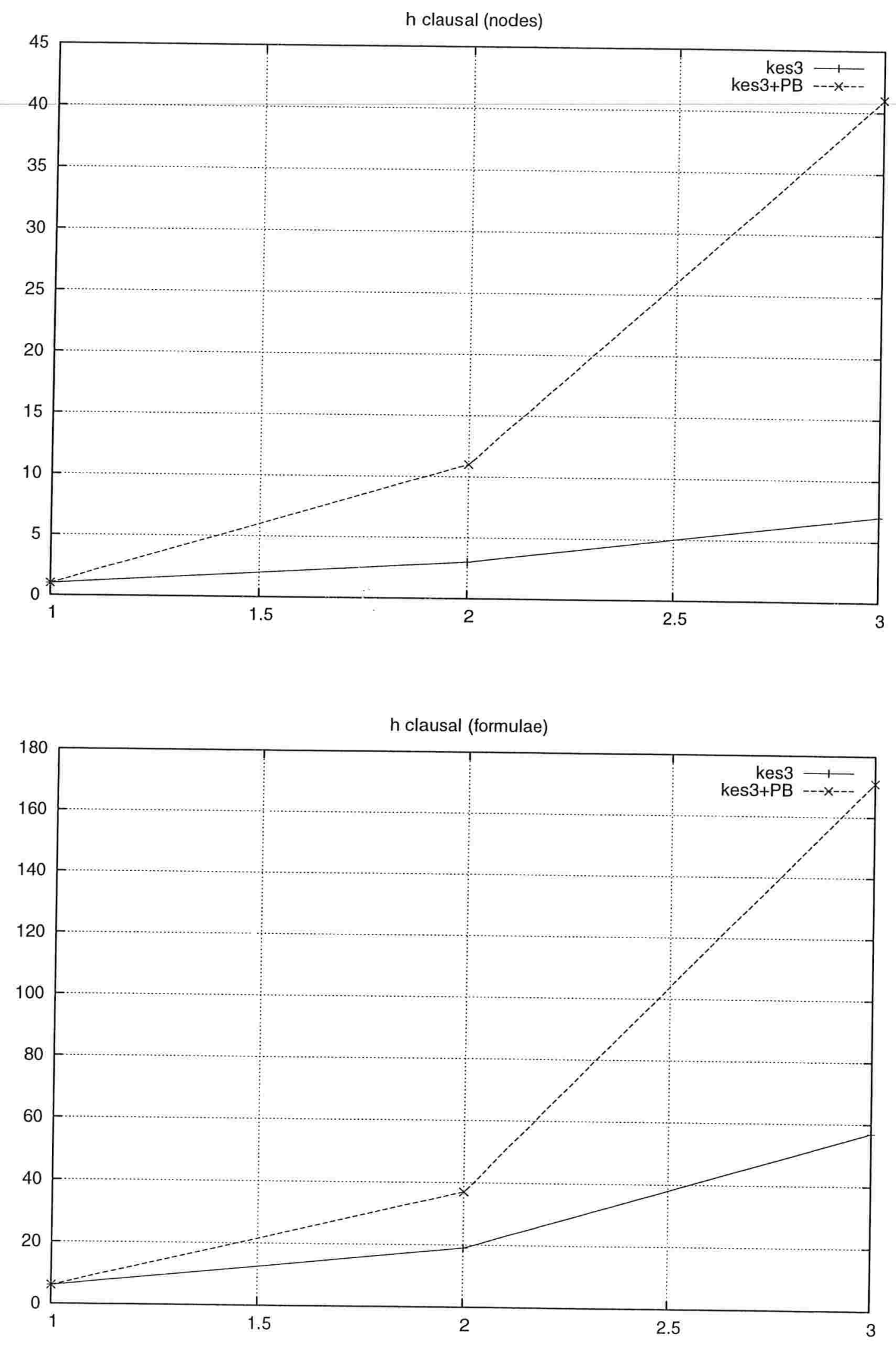

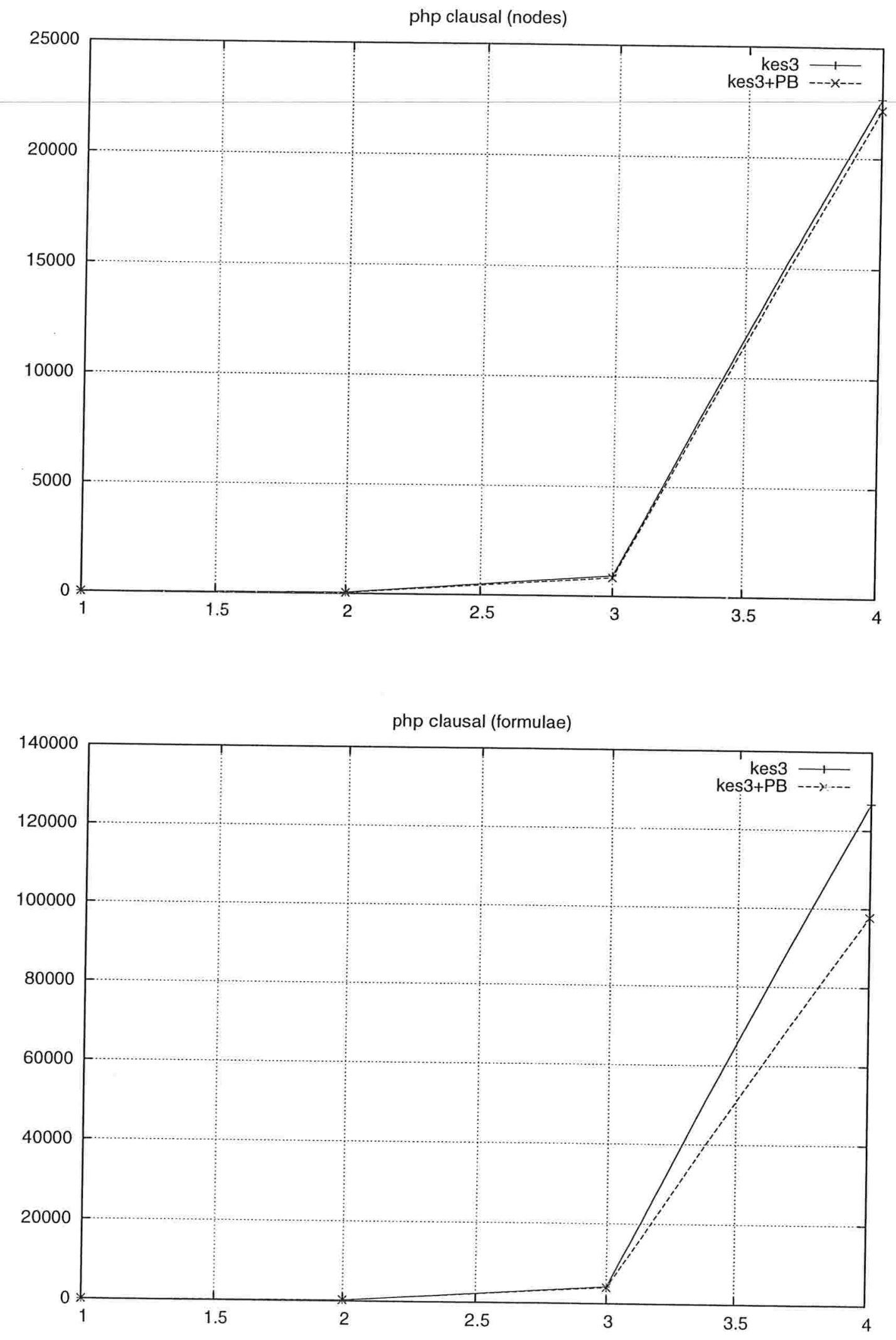

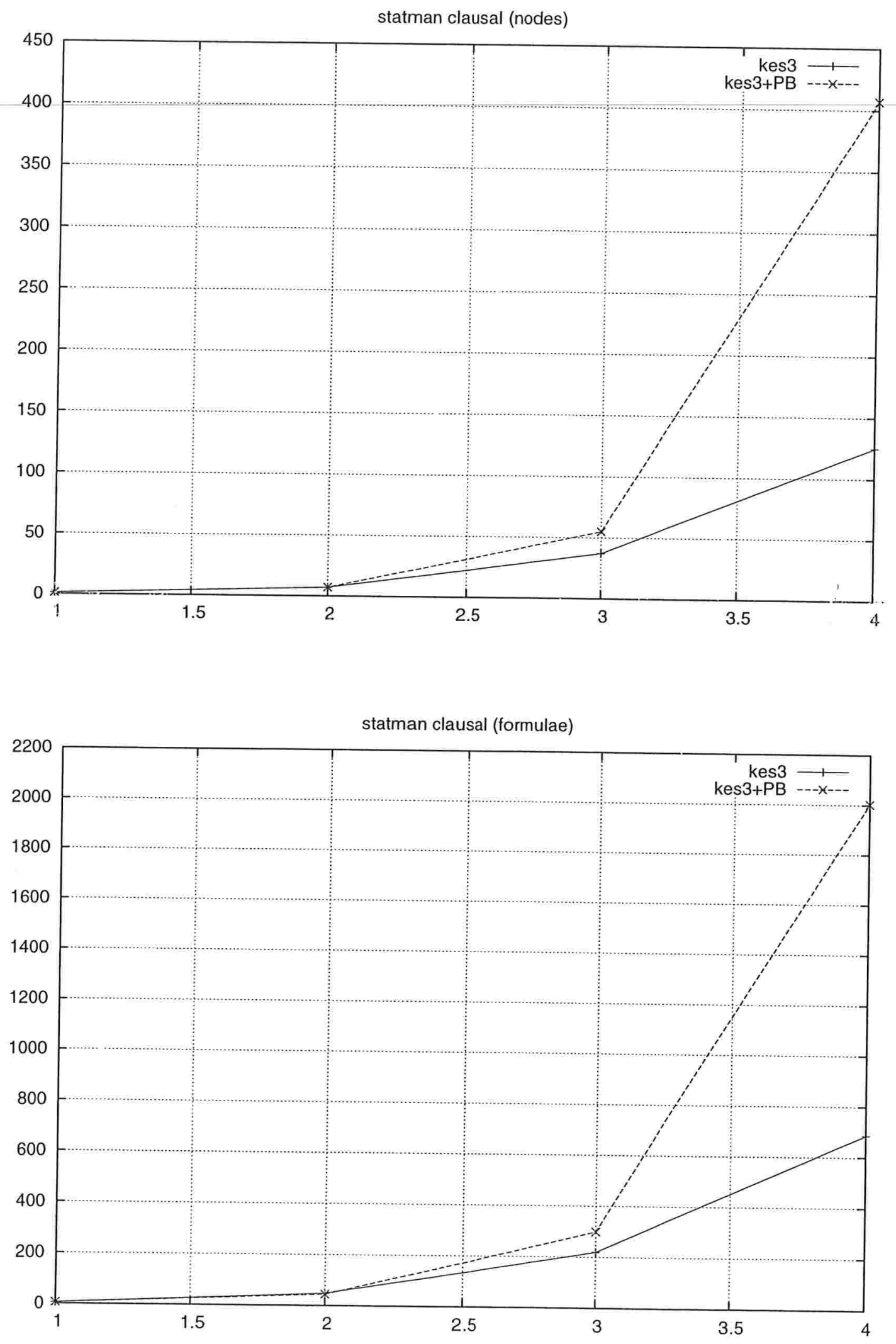

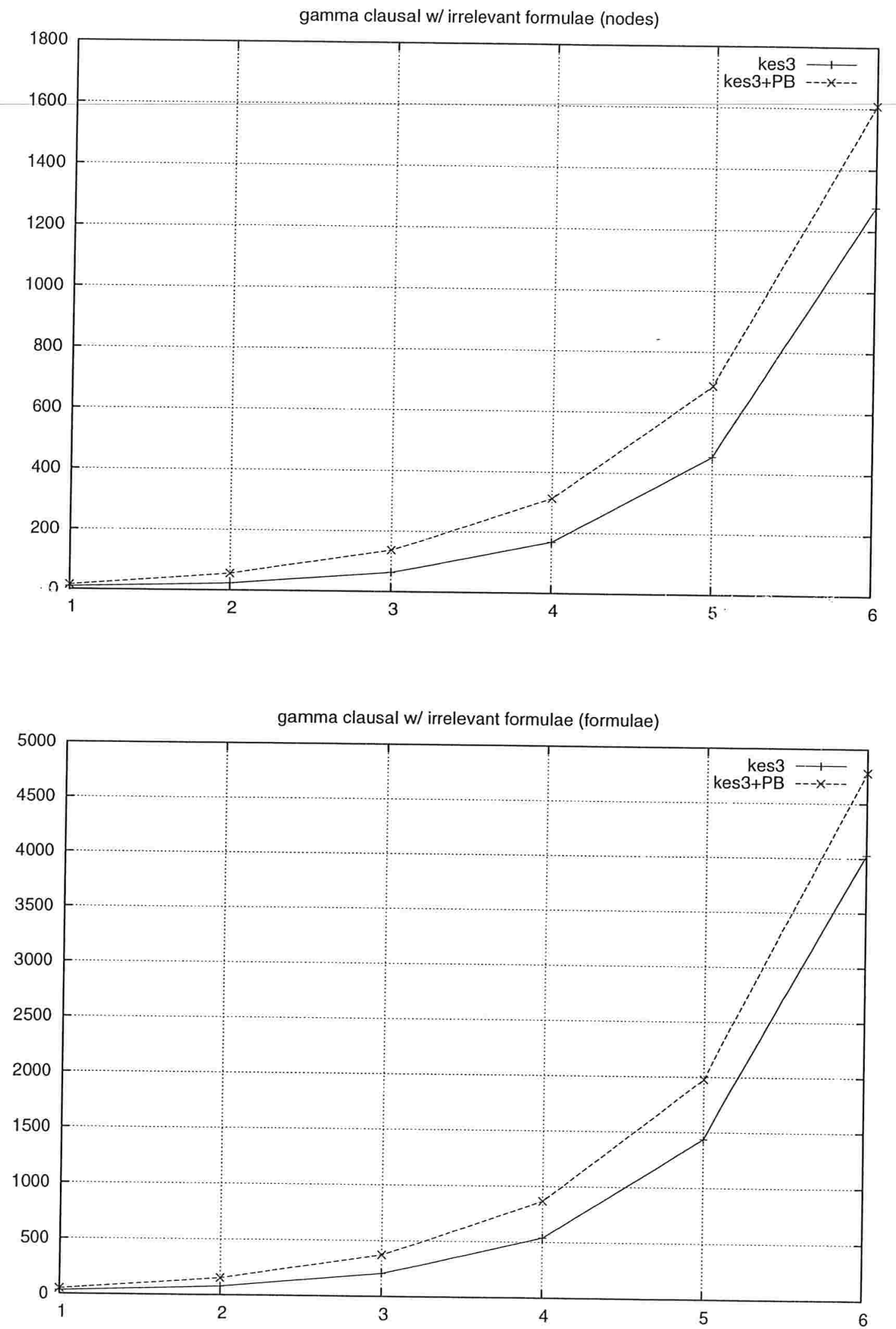

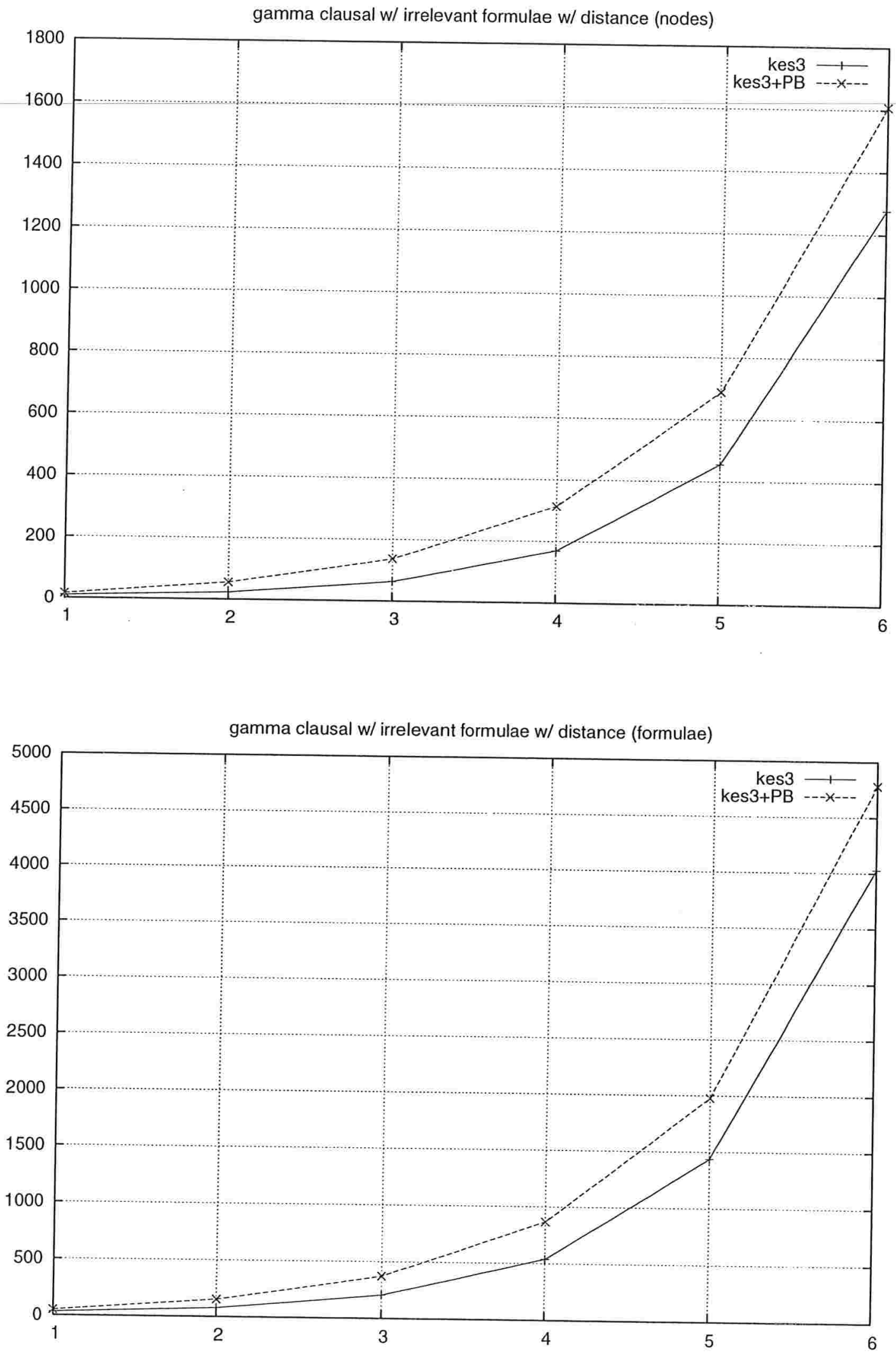


\section{Referências Bibliográficas}

[BJ94] K. Beck and R. Johnson. Patterns generate architectures. In Proceedings of ECOOP 94, pages 139-149, 1994.

[CLR90] T. H. Cormen, C. E. Leiserson, and R. L. Rivest. Introduction to Algorithms. The MIT Press, McGraw-Hill Book Company, 1990.

[Coo71] Stephen A. Cook. The complexity of theorem-proving procedures. In Conference Record of Third Annual ACM Symposium on Theory of Computing, pages 151-158, Șhaker Heights, Ohio, 1971.

[CS00] Alessandra Carbone and Stephen Semmes. A Graphic Apology for Symmetry and Implicitness. Oxford Mathematical Monographs. Oxford Science Publications, 2000.

[D'A90] Marcello D'Agostino. Investigations into the complexity of some propositioal calculi. Master's thesis, Oxford University Computing Laboratory, Programming Research Group, 1990.

[D'A92] Marcello D'Agostino. Are tableaux an improvement on truth-tables? cut-free proofs and bivalence. Journal of Logic, Language and Information, 1:235-252, 1992.

[End99] Ulrich Endriss. A time efficient ke based theorem prover. In N. V. Murray, editor, Automated Reasoning with Analytic Tableaux and Related Methods, International Conference, Tableaux'99, Proceedings, volume 1617 of LNAI, pages 313-318. Springer-Verlag, June 1999.

[FHLS98] Garry Froehlich, H. James Hoover, Ling Liu, and Paul Sorenson. Using object-oriented frameworks. In CRC Handbook of Object Technology. CRC Press, 1998. 
[FW01] Marcelo Finger and Renata Wassermann. Tableaux for approximate reasoning. In Proceedings of the IJCAI Workshop on Inconsistency in Data and Knowledge, Seattle, Washington, USA, August 2001.

[FW02a] Marcelo Finger and Renata Wassermann. Expressivity and control in limited reasoning. In Proceedings of ECAI 2002, 2002.

[FW02b] Marcelo Finger and Renata Wassermann. Logics for approximate reasoning: Approximating classical logic "from above". In Proceedings of SBIA 2002, 2002.

[JF88] R. Johnson and B. Foote. Designing reusable classes. Journal of ObjectOriented Programming, 1(2):22-35, 1988.

[Kow79] Robert Kowalski. Logic for Problem Solving. North-Holland, 1979.

[SC95] Marco Schaerf and Marco Cadoli. Tractable reasoning via approximation. Artificial Intelligence, 74(2):249-310, 1995.

[Smu68] Raymond M. Smullyan. First-Order Logic. Springer-Verlag, 1968.

[Sta78] Richard Statman. Bounds for proof-search and speed-up in predicate calculus. Annals of Mathematical Logic, 15:225-287, 1978. 